Aus der chirurgischen Universitätsklinik zu Leipzig (Geheimrat Tre n d e le n b u r g).

\title{
Experimentelle Untersuchungen über die Wirkung von künstlicher Atmung, Herzmassage, Strophantin und Adrenalin auf den Herzstillstand nach tempo- rärem Verschluß der Aorta und Arteria pulmonalis, unter Bezugnahme auf die Lungenembolieoperation nach Trendelenburg.
}

Von Privatdozent Dr. A. Läwen und Dr. R. Sievers, Assistenten der Klinik.

(Mit Tafel I-III.)

In einer früheren Arbeit ${ }^{1}$ ) haben wir mit Rücksicht auf die Lungenembolie-Operation nach $\mathrm{Tr}$ endele $\mathrm{nburg}$ die Wirkung untersucht, die bei Kaninchen die zeitweilige Abklemmung der Aorta, Pulmonalarterie und der Hohlvenen auf das Herz und den Blutdruck im Aortensystem ausübt. Bei diesen Versuchen wurde der Einfluß der so gesetzten Kreislaufsunterbrechung auf die Atmung und auf die Lebensfähigkeit der Tiere nur wenig berücksichtigt. Wir haben diese Lücke durch neue Versuche ergänzt und uns weiter der Frage zugewendet, ob es durch geeignete Maßnahmen gelingt, die Abklemmung der großen Gefäße in der Nähe des Herzens auf längere Zeit ohne Schaden für die Tiere auszudehnen. Die hierzu benutzten Mittel suchten ihren Angriffspunkt im Gehirn und im Herzen. Es wurde geprüft, ob sich die Funktionen des Gehirns durch Zufuhr von Sauerstoff auf verschiedenem Wege vor, während oder nach der Gefäßabklemmung erhalten oder wiederherstellen ließen. Zur

I) Läwen und Sievers, Experimentelle Untersuchungen über die chirurgisch wichtigen Ablklemmungen der großen Gefäße in der Nähe des Herzens unter besonderer Berücksichtigung der Verhältnisse bei der Lungenembolieoperation nach Trendelenburg. Deutsche Zeitschr. f. Chir., Bd. 94, I 903 , S. 580 . 
Hebung der geschädigten $\mathrm{H}$ e $\mathrm{r} z$ tätigkeit diente die unmittelbare Beeinflussung des Herzmuskels durch Herzmassage oder Injektion geeigneter Pharmaka. Die Wirksamkeit dieser Maßregeln glaubten wir am besten in der Weise demonstrieren zu können, daß wir die Maximalwerte der von den Tieren ohne Schaden vertragenen Gefäßabklemmungen unter Einschaltung der angedeuteten Maßnahmen bestimmten und sie den ohne Kunsthilfe gefundenen Werten gegenüberstellten. Die Resultate dieser Untersuchungen sind im folgenden niedergelegt.

Herrn Geheimrat Trendelenburg erlauben wir uns für sein Interesse an den Versuchen unseren ergebensten Dank abzustatten.

I. Abklemmung von Aorta und Arteria pulmonalis ohne nachfolgende Kunsthilfe.

Die erste Gruppe von Versuchen beschäftigte sich zunächst wieder mit der Frage, wie lange von den Versuchstieren (Kaninchen) die Abschnürung von Aorta und Arteria pulmonalis ohne künstliche Nachhilfe vertragen wird. Auf Grund unserer früheren Versuche waren wir zu dem Schlusse gekommen, daß eine I Minute währende Kompression beider Arterien den Tieren keinen dauernden Schaden zufügt. Eine scharfe obere Grenze für die von den Kaninchen vertragene Kompressionsdauer vermochten wir nicht anzugeben. Die damaligen im wesentlichen der Feststellung der Blutdruckänderungen dienenden Versuche waren fast alle nach Wegnahme der ganzen vorderen Thoraxwand, also bei doppeltem Pneumothorax unter künstlicher Atmung vorgenommen worden. Bei dieser Versuchsanordnung konnten die Tiere nicht am Leben erhalten werden. Auch waren genaue Beobachtungen über das Verhalten der Spontanatmung der Tiere nicht möglich. Wir haben daher diese Experimente durch neue ergänzt, bei denen die Versuchstechnik so gewählt wurde, daß die Tiere bei entsprechender Kompressionsdauer lebensfähig bleiben konnten und eine exakte Prüfung des Verhaltens der Atmung möglich wurde. Wenn die Tiere nach der Gefäßkompression am Leben blieben, so war hierdurch der beste Beweis gegeben, daß das nervöse Zentralorgan durch die zeitweilige Aufhebung seiner Zirkulation nicht dauernd geschädigt war. Der beabsichtigte $Z$ weck wurde 
durch folgende Operationsmethode erreicht: Auf der linken Thoraxseite, von einem T-förmigen Schnitte aus, wurde die 2., manchmal auch die 3. Rippe etwa in der Mammillarlinie durchschnitten und nach innen umgeschlagen. Hierbei wurde die Pleura eröffnet. Von dieser Thoraxwunde aus war es leicht, die Abgangsstelle von Aorta und Pulmonalis durch eine kleine Incision des Perikards freizulegen und mit einer kleinen stumpfen Deschampschen Nadel einen in Ol getauchten Wollfaden um die beiden Gefäße herumzuführen. Der einseitige Pneumothorax hat, wie wir uns oft überzeugt haben, beim Kaninchen auf die Atmung nur einen geringen, auf den Blutdruck gar keinen Einfluß. Auf das Unter- oder Überdruckverfahren oder künstliche Respiration wurde bei diesen Versuchen verzichtet.

Die Resultate finden sich in Tabelle I kurz zusammengestellt. Aus der Tabelle geht zunächst hervor, daß es uns bei einer $2^{1 / 2}$ Minuten dauernden Abklemmung von Aorta und Pulmonalarterie gelang, von 7 Versuchstieren 6 am Leben zu erhalten. Dehnten wir dagegen die Kompressionsdauer auf 3 Minuten aus, so gingen von 7 Tieren 6 zugrunde. Wir können also die Zeit von $2 \frac{1}{2} \mathrm{M} \mathrm{i}$ $\mathrm{n}$ u t e $\mathrm{n}$ als das $\mathrm{M}$ a $\mathrm{x}$ i $\mathrm{m} \mathrm{u}$ m der von den Kaninchen vertragenen Abklemmung von Aorta und Arteria pulmonalis ansehen. Wir haben im folgenden diesen Wert als die Normals chwelle angesehen, die im allgemeinen ohne Schaden für die Tiere nicht überschritten werden darf. $\mathrm{DaB}$ dieser Wert kein absoluter ist, lehren die Versuche 80,78 und 72 , bei denen die Kaninchen eine Abklemmung von $3,3 \frac{1}{2}$ bzw. 4 Minuten vertrugen. In diesen Versuchen zeigten aber, wie weiter unten noch ausgeführt werden wird, die Tiere von vornherein ein Verhalten, das auf eine besondere Resistenz gegen die Abklemmung der Aorta und Pulmonalarterie schließen ließ.

Nach Herstellung der Zirkulationsunterbrechung in Aorta

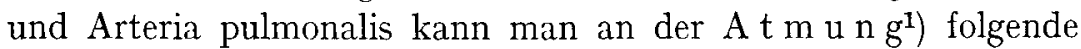
durchaus gesetzmäßig auftretenden Veränderungen beobachten:

I. Die Atemzüge bleiben ruhig, werden aber etwas tiefer.

2. Die Tiere verfallen in heftige klonisch-tonische Krämpfe, die mit einem allgemeinen Streckkrampf der Skelettmuskulatur

I) Cf. Kurve I. (Versuche Nr. I84). 
Experiment. Untersuchungen üb. d. Wirkung von künstl. Atmung usw. I77

$$
\text { T a b e } 11 \text { e } \mathrm{I} \text {. }
$$

Abklemmung von Aorta und Pulmonalis.

\begin{tabular}{|c|c|c|c|c|c|c|c|}
\hline 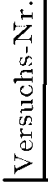 & $\begin{array}{l}\text { Datum der } \\
\text { Operation }\end{array}$ & 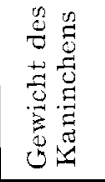 & $\begin{array}{l}\text { Dauer der } \\
\text { Abklem- } \\
\text { mung }\end{array}$ & Ausgang & $\begin{array}{c}\text { Wie- } \\
\text { lange } \\
\text { fehlt die } \\
\text { Atmung? }\end{array}$ & $\begin{array}{l}\text { Wielange } \\
\text { fehlen die } \\
\text { Korneal- } \\
\text { reflexe? }\end{array}$ & Bemerkungen \\
\hline I & 9. X. 08 & $2200 \mathrm{~g}$ & I Min, & lebt & & $21 / 4$ Min. & \\
\hline 2 & I0. $\mathrm{X} .08$ & $2100 \mathrm{~g}$ & $1 / 2$ Min. & iebt & & $2 \frac{1}{2}$ Min. & \\
\hline 3 & 12. X. 08 & 2 I $50 \mathrm{~g}$ & 2 Min. & lebt & & 21/2 Min. & \\
\hline 4 & 14. X. 08 & $3070 \mathrm{~g}$ & $2 \frac{1 / 2}{}$ Min. & $\begin{array}{c}\text { lebt } \\
(\dagger \quad 22 . \\
\mathrm{X} .08)\end{array}$ & & $7 \frac{1}{2}$ Min. & $\begin{array}{l}\dagger \text { Perikarditis- } \\
\text { Pyopneumo- } \\
\text { thorax. }\end{array}$ \\
\hline 7 & I9. $\mathrm{X} .08$ & $2300 \mathrm{~g}$ & $21 / 2$ Min. & $\dagger$ & & & \\
\hline 8 & $2 \mathrm{I} . \mathrm{X} .08$ & $2250 \mathrm{~g}$ & $2 \frac{1}{2}$ Min. & lebt & & $\begin{array}{l}4 \text { Min. } \\
40 \text { Sek. }\end{array}$ & \\
\hline 9 & 22. X. 08 & $1950 \mathrm{~g}$ & $2 \frac{1}{2}$ Min. & $\begin{array}{l}\text { lebt } \\
(\dagger \quad 25 . \\
\text { X. } 08)\end{array}$ & & 41/2 Min. & $\begin{array}{l}\text { Perikarditis, } \\
\text { Pleuritis. } \\
\text { Myokarditis. }\end{array}$ \\
\hline IO & 23. X. 08 & $2350 \mathrm{~g}$ & 21/2 Min. & $\begin{array}{l}\text { lebt } \\
(\dagger 2 \\
\text { XII.08) }\end{array}$ & & & $\begin{array}{l}\text { Unbekannte } \\
\text { Todesursache. }\end{array}$ \\
\hline 87 & 29. IX. 09 & - & $21 / 2$ Min. & lebt & 20 Sek. & - & \\
\hline 89 & 2. X. 09 & $1250 \mathrm{~g}$ & $2 / 2$ Min. & lebt & 8 Sek. & $5 \mathrm{M} .2 \mathrm{I} \mathrm{S}$. & \\
\hline$\frac{5}{6}$ & I 5. X. O8 & $3450 \mathrm{~g}$ & 3 Min. & $\dagger$ & & & \\
\hline 80 & $\begin{array}{ccc}17 . & \text { X. } & 08 \\
27 . & \text { IX. } & 09\end{array}$ & $\begin{array}{l}2500 \mathrm{~g} \\
\mathrm{I} 600 \mathrm{~g}\end{array}$ & $\begin{array}{l}3 \text { Min. } \\
3 \text { Min. }\end{array}$ & lebt & $\begin{array}{l}\text { I Min. } \\
\text { I } 5 \text { Sek. }\end{array}$ & 9 Min. & \\
\hline 83 & 28. IX. 09 & $1400 \mathrm{~g}$ & 3 Min. & $\dagger$ & & & \\
\hline 84 & 28. IX. 09 & $1850 \mathrm{~g}$ & 3 Min. & $\dagger$ & & & \\
\hline 85 & 28. IX. O9 & $2000 \mathrm{~g}$ & 3 Min. & t & & & \\
\hline $\begin{array}{r}86 \\
-8\end{array}$ & 28. IX. 09 & $2250 \mathrm{~g}$ & 3 Min. & $t$ & & & \\
\hline $7^{8}$ & I. VII. 99 & & $3 \frac{1}{2}$ Min. & lebt & $\begin{array}{l}\text { etwa } \\
6 \mathrm{Min} .\end{array}$ & $\begin{array}{c}\text { etwa } \\
\text { I4 Min. }\end{array}$ & \\
\hline $7^{2}$ & 22. VI. O9 & $1700 \mathrm{~g}$ & 4 Min. & lebt & $\begin{array}{ll}\text { I } & \text { Min. } \\
40 & \text { Sek. }\end{array}$ & $\begin{array}{l}\text { I } 3 \text { Min. } \\
25 \text { Sek. }\end{array}$ & \\
\hline 45 & 27. III. 09 & 1650 & $4^{1 / 2}$ Min. & $\dagger$ & & & \\
\hline
\end{tabular}

und einem Exspirationstonus der Atemmuskeln und des Zwerchfells endigen.

3. Die Atmung hört für kurze Zeit ganz auf.

4. Es treten eigentümlich krampfhafte tiefe Inspirationen auf.

Diese Erscheinungen zeigen eine große Ubereinstimmung mit den Atmungsstörungen, wie sie als Folge der Erstickung durch Sauerstoffmangel beobachtet wurden, und die besonders kritisch M a res ${ }^{\mathbf{1}}$ ) geschildert hat. Auf ein kurzes ,Reizstadium" folgt

I) Mares, Über Dyspnoe und Asphyxie. Pflügers Arch. f. Physiol., Bd. 91 , 1902 , S. 529 . 
die ,präterminale Atmungspause“ und hieran schließen sich die „terminalen Atemzüge". Am wenigsten ausgesprochen ist bei unseren Versuchen das Reizstadium. Die beiden anderen Phasen kommen dagegen sehr deutlich und regelmäßig zur Beobachtung. Die als Folge der völligen Abschnürung von Aorta und Pulmonalarterie beobachteten schweren Störungen charakterisieren sich demnach als Erstickungserscheinungen, hervorgerufen durch Sauerstoffmangel. Doch bestehen einige Unterschiede, die in unserer Versuchsanordnung begründet sind. Bei der Asphyxie durch Sauerstoffmangel wird als typisches Verhalten während des Reizstadiums eine erhebliche Steigerung des Blutdrucks beobachtet, die nach $\mathrm{K}$ on ow und $\mathrm{Stenbeck}$ ) durch Erregung des bulbären vasokonstriktorischen Zentrums bedingt wird. Diese Blutdrucksteigerung kann sich, wie wir in unserer früheren Arbeit durch Kurven belegt haben, beim Verschluß von Aorta und Arteria pulmonalis zunächst nicht ausbilden. Hier sinkt der Druck sofort bis fast zur Abszisse ab. Doch läßt sich der Einfluß dieses Vasokonstriktorenreizes noch nachträglich ganz regelmäßig an einer leichten Hebung der Blutdruckkurve erkennen. Auch in der Zahl und Form der terminalen Atemzüge macht sich ein gewisser Unterschied geltend. Bei den Erstickungsversuchen treten nach den Angaben von $\mathrm{M}$ a res in den meisten Fällen diese tiefen krampfhaften Inspirationen vereinzelt oder gruppenweise, manchmal auch verdoppelt auf. Die $Z$ ahl ist augenscheinlich nur gering, nach $\mathrm{R} \mathrm{i} \mathrm{che} \mathrm{t}^{2}$ ) etwa drei oder vier. Bei unseren Abschnürungsversuchen an Kaninchen waren diese Atemzüge immer vereinzelt. Ihre Zahl war in den allermeisten Fällen größer als sie $\mathrm{R}$ i c h e $\mathrm{t}$ bei der Erstickung angibt. Die ersten dieser Atemzüge gehen mit Beteiligung der gesamten Atmungshilfsmuskulatur vor sich, die Inspiration eigentümlich ruckweise, während die Exspiration scheinbar in allmählicher Lösung des Inspirationskrampfes besteht, dann werden sie schwächer und seltener; die letzten bestehen nur noch in leichten Hebungen des Kehlkopfes. Richet sah in den terminalen Atemzügen ein Anzeichen für das Absterben des Atmungszentrums und hat selten ein Tier überleben sehen, das

I) K o n o w und Ste n beck. Skandin. Arch. f. Physiol,, Bd. I.

2) Richet. Arch. de physiologie I 894, S. 653. 
Experiment. Untersuchungen üb. d. Wirkung von künstl. Atmung usw. I 79

diese agonische Atmung zeigte. Demgegenüber stellte aber $\mathrm{M}$ a res fest, daß Kaninchen und Hunde fast stets $z u$ beleben waren, auch wenn sie die terminale Atmung zeigten. Als bessere Bezeichnung schlägt er daher den Namen as phykt is che A t mung vor. Aus den Versuchen, bei denen sich die Tiere wieder erholten, geht ebenfalls mit Sicherheit hervor, daß die asphyktische Atmung nicht auf irreparablen Veränderungen im Zentralnervensystem beruht. In der Mehrzahl unserer Versuche wurde der letzte agonische Atemzug 2 bis $2 \frac{1}{2}$ Minuten nach Umschnürung von Aorta und Pulmonalarterie beobachtet, also zu einer Zeit, die unserem oben festgelegten Normalschwellenwert nahe kam. Der letzte terminale Atemzug erfolgte, wie bei 3 I Versuchen genau festgestellt wurde

$$
\begin{aligned}
& 6 \text { mal I Min. } 23 \text { Sek. bis I Min. } 59 \text { Sek. } \\
& \text { I8 , } 2 \text {, , } 2 \text {, } 30 \text {, } \\
& 6,2,3 \mathrm{I},, 3 \text {, }
\end{aligned}
$$

nach der Konstriktion beider Arterien. In einem von diesen Fällen fehlten die agonalen Atemzüge $\left.{ }^{1}\right)$. Aus diesen Versuchen geht hervor, daß, wenn die Abschnürung von Aorta und Arteria pulmonalis unmittelbar nach dem letzten agonischen Atemzug gelöst wird, mit einiger Sicherheit auf eine Wiederherstellung der Spontanatmung und damit auf eine Erholung der Tiere gerechnet werden kann. Irgendeine Kunsthilfe ist dann nicht notwendig. Läßt man nach dem letzten Atemzug die Umschnürung noch liegen, so tritt vollkommener Atmungsstillstand ein, der auch dann noch eine Zeitlang bestehen bleibt, wenn die Konstriktion von Aorta und Lungenarterie wieder beseitigt worden ist. Erholen sich die Tiere, so treten nach einiger Zeit wieder spontane Atemzüge auf: man bemerkt zunächst schwache Kehlkopfhebungen und synchron mit ihnen zunehmende Kontraktionen des Diaphragmas, denen dann immer ergiebiger und frequenter die Beteiligung der gesamten Atmungsmuskulatur folgt. So gleicht die wiederkehrende Atmung in ihrer Form dem agonalen Typus, nur daß die einzelnen Phasen in umgekehrter Reihenfolge auftreten. Die Dauer des völligen Atmungsstillstandes ist ab-

I) Im ganzen haben wir bei ca. I80 Versuchstieren die asphyktische Atmung nur vicrmal vermißt (s. auch Versuche 105, I06, I I auf Tab. II). 
hängig von der Umschnürungszeit. Bei einer Konstriktion von $2 \frac{1}{2}$ Minuten fehlt die Atmung nur einige Sekunden bis etwa $1 / 4$ oder $1 / 3$ Minute. Wird ausnahmsweise eine längere Abschnürung vertragen, so haben wir Atmungsstillstand bis zu 6 Minuten Dauer (Versuch Nr. 78) gesehen. In den meisten Fällen pflegt sich aber nach einer Umschnürung von Aorta und Pulmonalarterie, die die Dauer von $2 \frac{1}{2}$ Minuten überschreitet, die Atmung nicht wieder herzustellen.

Wie wir schon früher geschildert haben, wird nach der Umschnürung von Aorta und Arteria pulmonalis die Herzaktion schwächer. Die Kontraktionen erfolgen langsamer und pflegen schließlich ganz oder doch nahezu aufzuhören. Diese Schädigung der Herzfunktion hängt mit der starken Füllung des Herzens und der Unmöglichkeit seinen Inhalt zu entleeren, zusammen, sowie mit der gehemmten Ernährung des Herzmuskels infolge der fehlenden Arterialisierung des Blutes und vor allem mit einer asphyktischen Reizung des zentralen Vaguskernes. Die Form der Herzschädigung zeigt Ähnlichkeit mit der von M a res bei Sauerstoffmangel beschriebenen. Ganz regelmäßig wurden nun von uns gewisse zeitliche Beziehungen zwischen den auf die Arterienkonstriktion folgenden Veränderungen der Atmung und Herztätigkeit beobachtet, die darin bestanden, daß ungefähr in demselben Moment, wo die terminalen Atemzüge einsetzten, auch die Herztätigkeit wiederkehrte oder besser wurde. In anderen Fällen leitete die Wiederkehr der Herzaktion die terminalen Atemzüge ein. Eine Erklärung für dieses Zusammentreffen vermögen wir nicht zu geben. Ein gegenseitiges Abhängigkeitsverhältnis beider Funktionen ist bei der benutzten Versuchsanordnung jedenfalls ausgeschlossen.

Ganz anders verhält es sich dagegen mit den Beziehungen, die zwischen der Herzaktion und dem Wiederauftreten spontaner Atemzüge $\mathrm{n}$ a $\mathrm{ch}$ Lösung der Konstriktion bestehen. Hier zeigt sich ganz zweifellos, daß die Atmung nur dann wieder in Gang kommen kann, wenn die Herztätigkeit und Blutzirkulation sich wieder hergestellt hat. Es sind das Tatsachen, die in derselben Weise bei der Erholung aus der Asphyxie durch Sauerstoffmangel beobachtet worden sind. Nur muß im Auge behalten werden, daß die Schädigung des Herzens bei unserer Versuchsanordnung 
Experiment. Untersuchungen üb. d. Wirkung von künstl. Atmung usw. I 8 I

viel schwerer ist als bei der Asphyxie durch Sauerstoffmangel, da sie sich aus den verschiedenen obenangeführten Komponenten zusammensetzt. Der Wiederbeginn der Atmung ist auf einen „B 1 u.tre i z“ zurückzuführen. Die Erregung der respiratorischen Zentren kann man sich dabei als auf $\mathrm{chemischem} \mathrm{oder}$ p h y s i k a l is c h e m Wege ausgelöst denken. Die Innervationszentren für die Atembewegungen können, wie vielfach experimentell erwiesen ist, durch den Sauerstoffmangel oder die Kohlensäureüberladung des an sie neu herantretenden Blutes gereizt

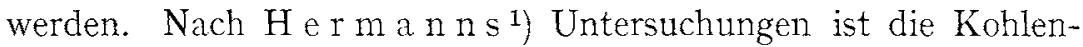
säure der ,normale Atemreiz", dessen Wirksamkeit allerdings abhängig ist von der vom $\mathrm{S}$ a u e r s t of $\mathrm{fgeh}$ a l t d e s B lutes erhaltenen Erregbarkeit des Atemzentrums. $\mathrm{DaB}$ die Kohlensäure ein mächtiges und relativ unschädliches Erregungsmittel der Innervationszentren der Atembewegungen sei, betont auch $\mathrm{W}$ e $\mathbf{i}^{2}{ }^{2}$ ). Ferner ist in dieser Hinsicht wichtig, daß der in seinen Ursachen viel umstrittene Zustand der Apnoe (nach ,Luxusatmung“) nach den Untersuchungen P. H e r i n g s ${ }^{3}$ ) nicht auf Sauerstoffüberladung, sondern auf ein stärkeres Gefälle der Kohlensäureausscheidung infolge kräftigerer Ventilation der Alveolenluft zurückzuführen ist. Da bei unseren Versuchen die Erregbarkeit des Atmungszentrums gerade durch Sauerstoffmangel herabgesetzt ist, kann der Kohlensäurereiz keinen Angriffspunkt finden. Möglicherweise übernehmen andere, während des Zirkulationsstillstandes an das Blut abgegebene Stoffe die Rolle des Blutreizes für die Atmung. Immerhin erscheint eine derartige chemische Erklärung nicht ganz befriedigend, weil ja alle diese Momente auch schon vor Wiederherstellung der Zirkulation auf das Zentralnervensystem wirksam waren. Vielleicht hat das mechanische Moment der Blutdurchspülung eine größere Bedeutung: es wäre denkbar, daß durch die Wiederherstellung des innergeweblichen Tonus die Atmungszentren zu neuer Tätigkeit erregt werden.

I) Hermann, Über die Krämpfe boi Zirkulationsstörungen im Gehirn. Pflügers Archiv f. Physiologie 1902, Bd. 9I, S. 529.

2) We il, Uber Apnoe und Kohlensäuregehalt der Atmungsluft. Arch. f. exper. Pathologie und Pharmakol. I906, Bd. 54, S. 285.

3) P. Hering, Zusammensetzung der Blutgase während der Apnoe. Diss. Dorpat 1867 . 
Wie bereits oben erwähnt, beobachteten wir in drei Versuchen eine besonders hohe Resistenz des Herzens gegen die Abschnürung der großen Arterien. Diese Versuchstiere zeigten schon im letzten Stadium der 3-4 Minuten langen Abschnürungszeit abnorm kräftige Herzaktion, so daß wir zu diesem Zeitpunkte die Wiederkehr normaler Herztätigkeit und spontaner Atmung und damit die Erhaltung des Tieres trotz abnorm langer Abklemmungszeit voraussagen konnten. Diese Beobachtung wurde auch bei späteren Versuchen mehrfach gemacht und mußte bei der Verwertung der Resultate bestimmter Versuchsreihen im Auge behalten werden.

$\mathrm{Da}$ sich aus unserer früheren Arbeit die Tatsache ergab, $\mathrm{da} B$ die Unterbrechung des Kreislaufs durch A b kle m m u $\mathrm{g}$

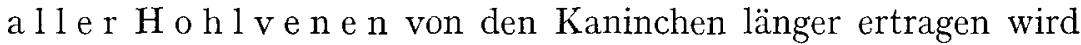
als die durch Abklemmung der Aorta und Pulmonalis, so wurden auch hierüber weitere Untersuchungen angestellt, die in Kapitel VI besprochen werden sollen.

II. Abklemmung von Aorta und Arteria pulmonalis mitkünstlicher Atmung.

Aus unserer ersten Versuchsreihe konnten wir also entnehmen, daß Kaninchen eine voll k o m me ne Kreis la u f s u $\mathrm{ter}$ brechung von $2^{1 / 2}$ Minuten Dauer ohne irgendwelche Schädigung ü bersteh e $\mathrm{n}$, daß aber bei Ausdehnung der Zeit über die genannte Grenze hinaus die große Mehrzahl zugrunde geht.

Als Todesursache mußten zwei ineinandergreifende und auch wieder getrennt wirksame Momente angesehen werden: die Schädigung des nervösen $Z$ entralorgans, nämlich des Zentrums der Atmung und der Zirkulation in der Med. oblongata einerseits, die direkte Schädigung des Herzens auf der anderen Seite.

In welcher Reihenfolge und in welchem Grade die beiden Faktoren in Wirksamkeit treten, ließ sich aus den ersten Versuchen nicht entnehmen. Immerhin stand der Atmungsstillstand, also die cerebrale Schädigung so im Vordergrunde, daß wir sie als das für das Leben des Tieres verhängnisvolle Agens ansahen. Spätere, schon mehrfach erwähnte Versuche (Nr. 80, 78, 72), in denen das Versuchstier den anämischen Schwellenwert" über- 
Experiment. Untersuchungen üb. d. Wirkung von künstl. Atmung usw. I 83

dauerte, belehrten uns aber eines anderen. War tatsächlich der Grenzwert der Resistenz der Med. oblongata einer Zirkulationsunterbrechung von $2 \frac{1}{2}$ Minuten gleichzusetzen $\mathbf{1}$ ), so mußten in den Fällen, wo das Herz seine Tätigkeit länger bewahrte, und sich wieder erholte, die cerebralen Funktionen, insbesondere die der Atmung, erloschen bleiben. Das war nicht der Fall. Setzte nach dem Versuch eine kräftige Herzaktion ein, so traten auch a $1 \mathrm{sba} 1 \mathrm{~d}$ die ersten A te mz üg e wieder auf. Damit war der Beweis erbracht, daß die Atmung auch nach über $2 \frac{1}{2}$ Minuten wiederkehren kann, wenn nur die Zirkulation sich wieder herstellt. Die Schädigung des Oblongatazentrums ist reparabel. Das Leben der Tiere muB also von dem anderen Faktor, der Widerstandsfähigkeit des Herzens, abhängig sein. Die Wiederkehr der Atm ung ist in unseren Versuchen absolut eine Funktion der Herztätigkeit.

Uberwand das Herz die primäre, durch die Gefäßkonstriktion gesetzte Schädigung, so war aber damit noch nicht immer eine Gewähr für Erhaltung der Herztätigkeit gegeben. Es kamen wohl manchmal nach Lösung der Arterienschnürung sehr kräftige rhythmische Herzkontraktionen zustande, die zur Entleerung der dilatierten Herzkammern führten; doch ließ dann nach einigen - bis zo - Sekunden die Herztätigkeit wie mit einem Schlage nach, die Kontraktionen wurden wieder oberflächlich, unregelmäßig, das ganze Herz erweiterte sich sehr stark und es trat der Tod ein. In diesen Fällen, und das ist die Mehrzahl der über 2/2 Minuten ausgedehnten Abklemmungen, wirkte nachträglich irgend eine Schädlichkeit auf das zunächst noch arbeitsfähige Herz ein. Zur Erklärung der Natur dieser Schädigung konnten verschiedene Momente herangezogen werden.

Es ist aus den Versuchen von $\mathrm{W}$ a $1 \mathrm{le} \mathrm{r}$ und $\mathrm{Reid}{ }^{2}$ ) (cf. auch $\mathrm{L}$ a $\mathrm{ng}$ e $\mathrm{ndorf} \mathrm{f}^{3}$ ), B o ck ${ }^{4}$ ), Hering ${ }^{5}$ )) am ausgeschnittenen, nicht blutdurchströmten Kaninchenherzen bekannt,

I) Immer unsere Versuchsanordnung (Umschnürung der Aorta und Art. pulmonalis) vorausgesetzt.

2) W a $11 \mathrm{er}$ und R c i d. Philosoph. Transact. I887, B., S. 217.

3) La ng e nd orff. Pflügers Arch. f. Physiol. 1895, Bd. 61.

4) Bock. Arch. f. exper. Pathol. und Pharmakol. I898, Bd. 4I.

5) Hering, Pflügers Arch. f. Physiol. I898, Bd. 72. 
daß seine Aktion in weiten Grenzen unabhängig ist von den nervösen Verbindungen; deswegen mußte von der Möglichkeit, daß der A usfall der cerebralen Herzregulierungszentren hier eine wesentliche Rolle spielt, von vornherein abgesehen werden. Eher war denkbar, daß der durch die Anämie bedingten Lähmung des Vaguszentrums bei beginnender Zirkulation wiederum eine $\mathrm{V}$ ag us reizung folgt. Bei den Versuchen, wo zeitig (nach $2 \frac{1}{2}$ Min.) die Klemme gelöst wurde, machte sich, wie bereits angeführt, die Vagusreizung an der Blutdruckkurve immer sehr bald bemerkbar, stärker noch bei den Cavaabklemmungen als bei den Arterienversuchen (cf. Kurve I-3 unserer früheren Arbeit). Die Vaguswirkung hätte sich also auch in jenen Fällen an der Blutdruckkurve ausprägen müssen, sie fehlte aber völlig: die kleinen Pulsschwankungen des steilen Anstiegs der Kurve bei Beginn der Herzaktion bleiben unverändert in Abstand und Höhe bestehen auch bei dem allmählichen Absinken des Drucks. (Vgl. K u r ve 2, Versuch 79.) Es fehlen die charakteristischen „Vaguspulse“, die bekanntlich durch Vagusreizung entstehen.

Demnach müssen nervöse Einflüsse als unwesentlich angesehen werden, es bleiben $\mathrm{ch}$ e $\mathrm{m}$ is $\mathrm{ch}$ e oder mechanische. Die einfachste und nächstliegendste Erklärung war die, daß das Herz nach Wiederaufnahme seiner Tätigkeit durch die aus den Venen zuströmende kohlensäurereiche Blutmenge vergiftet wird, wenn nicht alsbald die wiederbeginnende Atmung das Blut oxydiert. Wahrscheinlich enthält auch das einströmende Blut besondere schädliche Abbauprodukte des unter Zirkulationsabschluß stehenden Gewebes. Wir vermuten, daß dieses Moment der chemischen Herzschädigung auch eine Rolle spielt bei den Todesfällen, die nach der Momburgschen Blutleere beobachtet sind. Ein erhebliches mechanisches Hindernis für das Herz bedeutet der Stillstand der Atmung und damit der Ausfall der von den Atmungsbewegungen besorgten Unterstützung des Kreislaufs durch Druck und Saugkraft. Auch dürfte sich die Querschnittsvergrößerung des linksseitigen Lungenkreislaufs infolge des Pneumothorax zu dem ersten Hindernis hinzuaddieren.

An diesem Widerstand erlahmt das Herz sekundär, wenn er nicht bei Wiederentfaltung der Lunge durch Einsetzen spontaner 
Experiment. Untersuchungen üb. d. Wirkung von künstl. Atmung usw. I 85

Atemzüge wieder ausgeglichen wird. Endlich kann aber auch eine Lähmung der Vasomotoren mechanisch zur Herzschwäche führen. Gelang es uns, den eben diskutierten, sekundär auf das Herz einwirkenden Schädigungen zu begegnen, so war damit die Aussicht verknüpft, auch länger dauernde Zirkulationsun terbrechungen in Aorta und Art. pulmonalis für das Versuchsticr ertragbar zu gestalten.

Von den verschiedenen schädigenden Momenten trat am augenfälligsten die durch das Fehlen derOxydation bedingte Blutveränderung hervor. War es möglich, diese durch geeignete Maßnahmen einzuschränken oder zu vermeiden, so konnte damit die gestellte Aufgabe mit Wahrscheinlichkeit bis zu einer gewissen Grenze gelöst werden.

Die natürlichste Lösung dieser Aufgabe bestand in Zuführung von Sauerstoff in Form der $\mathrm{k} u ̈ \mathrm{~ns} t \mathrm{i}$ chen Atmung. In dieser Richtung gab uns der Versuch II unserer früheren Arbeit einen ganz bestimmten Hinweis. Bei dem Kaninchen kehrten nach 3 M i n u te n langer Abklemmung der großen Arterienstämme die Cornealreflex e wieder. Es wurde also der durch die neue Vcrsuchsreihe festgelegte $\mathrm{Sch}$ w e $11 \mathrm{e} \mathrm{n} \mathrm{w} \mathrm{e} \mathrm{r} \mathrm{t} \mathrm{von} 2^{1 / 2} \mathrm{Min}$. um $1 / 2$ M in. bereits überschritten. Da die Wiederkehr der Lidreflexe ganz konstant mit der Wiederkehr sämtlicher Funktionen einhergeht, so wäre auch in jenem Fall II das Tier nach 3 Minuten langer Zirkulationsblockierung wahrscheinlich am Lcben zu erhalten gewesen. Es konnte sich natürlich in diesem Falle wie in Nr. 80, 78, 72 um eine besondere Widerstandsfähigkeit des Kaninchens gehandelt haben. Näher lag es, gerade in Hinsicht auf unsere Fragestellung, die Ursache des Uberlebens des Tieres in einer Differenz der Versuchsanordnung zu suchen, die darin bestand, daß der ganze Versuch un ter künstlicher Atmung a usgeführtwurde.

Inwiefern kann aber die künstliche Respiration diesen Vorsprung gewähren? W äh re n d der Abklemmung ist der kleine Kreislauf ebenso wie der große unterbrochen. Eine Ventilation der Lungen kann also zur Arterialisierung des Blutes nicht führen. Durch die künstliche Respiration kann, solange die Umschnürung an Aorta und Pulmonalis liegt, nur die kleine Blutmenge arterialisiert erhalten werden, die in den Pulmonalvenen zwischen Lungen und linkem Vorhof hin- und hergeworfen wird. 
Daß eine solche Arterialisierung statthat, beweisen die Versuche mit künstlicher Sauerstoffatmung (s. u.), wo wir fast regelmäßig bald nach Einsetzen derselben eine Hellrotfärbung des linken Herzohrs beobachteten. Es kann natürlich keine eigentliche Zirkulation, sondern nur ein Hin- und Herfluten derselben Blutmenge unterhalten werden. Immerhin wirkt dies Blutquantum decarbonisierend auf den Muskel des Vorhofs und wahrscheinlich auch in mäßigerem Grade auf den der linken Kammer. Wie nämlich die Versuche mit partieller Abklemmung der Pulmonalis (vgl. Nr. II9-I2I) lehren, kommt es durch die starke Dilatation des Herzens zu einer Insuffizienz der Segelklappen, zum positiven Venenpuls. Auf diese Weise ist auch die wünschenswerte Kommunikation zwischen linkem Vorhof und Kammer garantiert; immerhin bleibt die Arterialisierung im linken Ventrikel unvollkommen. Jedoch dürfen wir annehmen, daß schon während der Abklemmung die künstliche Atmung eine gewisse ausgleichende Wirkung hat.

Wäre es möglich, daß eine durch die künstliche Atmung vor Anlegung der Kompression entstandene Anreicherung des Blutes mit Sauerstoff eine verlängerte Lebensfähigkeit der nervösen Organe herbeiführt? - die Wahrscheinlichkeit hierzu ist nicht groß. Obgleich es wohl möglich ist, den S a u ers t of $f$ $\mathrm{g}$ e halt des B lutes durch lebhafte künstliche Atmung v o n I9,2 Vol.-Proz. auf über $23 \mathrm{zu}$ treiben $\left(\operatorname{Herman}{ }^{1}\right)$ ), wissen wir doch aus Versuchen von F allo is e ${ }^{2}$ ), daß die Gewebszellen nicht imstande sind, Sauerstoff aufzuspeichern und infolgedessen eine Sauerstoffanreicherung des Blutes den Zeitpunkt der Asphyxie nicht hinausschieben kann.

Durchaus plausibel ist aber die günstige Einwirkung der künstlichen Atmung $\mathrm{na} \mathrm{ch}$ Lösung der Gefäßabklemmung. Sie schafft einerseits die Möglichkeit der Oxydation der Blutmengen, wenn sie vom Herzen wieder ausgeworfen werden und erleichtert ferner mechanisch die Herztätigkeit. So werden die zu Erlahmung des Herzens führenden Schädlichkeiten schnell beseitigt und das nervöse Zentralorgan alsbald mit arteriellem Blute gut versorgt,

I) Hermann. Lehrb. der Physiol., S. II 2-IIz.

2) Falloise. Zit. nach: Heinz, Handbuch d. experim. Pathol. u. Pharmakologie, III, S. 382. 
Experiment. Untersuchungen üb. d. Wirkung von künstl. Atmung usw. I87

so daß auch die Lähmung des Vasomotorenzentrums zugleich mit der des Atmungszentrums aufgehoben wird.

Die Vers u c h s a n or d n u n g blieb dieselbe wie in unserer ersten Versuchsreihe. Da wir auch jetzt als Prüfstein für die endgültige Wirksamkeit der künstlichen Atmung auf Erhaltung des Lebens der Versuchstiere das größte Gewicht legen mußten, so war von vornherein die Einführung einer Trachealkanüle als unzweckmäßig zu verwerfen, da es selten gelingt, Tiere mit größerer Verletzung der Trachea durchzubringen. Wir behalfen uns deswegen mit einer weniger eingreifenden, freilich recht primitiven, aber wie sich zeigte, sehr brauchbaren Methode: in die durch Längsspaltung der Haut und Weichteile entblößte Trachea wurde vor Beginn der Kompression der Gefäße eine $\mathrm{I}-2 \mathrm{~mm}$ lichte Weite haltende, spitze Injektionsnadel eingestochen, die mit einem Doppelgebläse in Verbindung stand. Die Aufblasung der Lungen erfolgte durch Ausdrücken des Gebläses unter mit zwei Fingern ausgeübter seitlicher Kompression der Luftröhre über der Nadel; die elastische Retraktion der Lungen in Verbindung mit der Schwere des Brustkorbs treibt die Luft durch die freigelassene Luftröhre zum Maule wieder aus. Luftquantum und Häufigkeit der Luftzufuhr richteten sich nach der im Operationsfeld sichtbaren Lunge.

Auf Grund der oben berücksichtigten Überlegungen begannen wir in den ersten Versuchen erst be i L ös ung des G e $f \ddot{a} B v$ vershlusses mit der künstlichen Respiration, versuchten dann, als bei den 4-Minuten-Versuchen einige Mißerfolge eintraten, durch Einleitung von künstlicher Atmung $\mathrm{schon}$ vorder Gefä Babsch n ür ung weiter zu kommen (Nr. 42, 43), sahen aber keine n Vorteil darin. Die Herztätigkeit in dem letzten Stadium der Abklemmung war e h e r s c h lech $\mathrm{t}$ e $\mathrm{r}$ als bei den voraufgegangenen Versuchen. Wir wählten dann einen Mittelweg, indem wir die künstliche Ausatmung einsetzen ließen, unmittelbar nach Erlöschen jeglicher spontanen Atembewegungen, also nach SchluB der terminalen Atmung.

Aus unserer Tabelle II ergibt sich folgendes $\mathrm{R}$ es ultat: Nach einer Zirkulationsunterbrechung von $3 \frac{1}{2}$ M in u t e $n$ gelang es, 5 von 9 Tieren mit Hilfe von künstlicher Atmung am Leben zu erhalten resp. sie wiederzubeleben. In den 4 Versuchen, 
Tabelle II. Abklemmung von Aorta und

\begin{tabular}{|c|c|c|c|c|c|c|c|c|c|c|}
\hline \multirow[b]{2}{*}{ 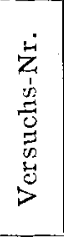 } & \multirow[b]{2}{*}{$\begin{array}{l}\text { Datum des } \\
\text { Versuchs }\end{array}$} & \multirow[b]{2}{*}{ 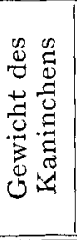 } & \multicolumn{6}{|c|}{ Künstliche Atmung } & \multirow[b]{2}{*}{$\begin{array}{l}\text { Herzaktion } \\
\text { während der } \\
\text { terminalen } \\
\text { "Atempause" }\end{array}$} & \multirow{2}{*}{ 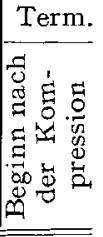 } \\
\hline & & & 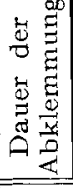 & mit & 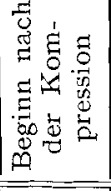 & 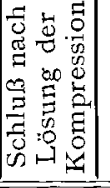 & $\begin{array}{l}\infty \\
7 \\
0 \\
0 \\
0 \\
3 \\
4 \\
4\end{array}$ & $\begin{array}{l}\text { Wirksam- } \\
\text { keit }\end{array}$ & & \\
\hline 34 & I8. XII. 08 & 2950 & $3^{\prime}$ & Luft & vorher & $\mathrm{I}^{\prime}$ & lebt & & $\begin{array}{l}\text { frequent, ober- } \\
\text { flächlich }\end{array}$ & $2^{\prime}$ \\
\hline 35 & I9. XII. 08 & 2200 & $3 / z^{\prime}$ & ," & $3^{\prime} 30^{\prime \prime}$ & $I^{\prime} 5^{\prime \prime}$ & " & & ," & $\mathrm{I}^{\prime} 35^{\prime \prime}$ \\
\hline 90 & 5. X. 09 & 1600 & $3 \frac{1 / 2}{2}$ & ," & $2^{\prime} 30^{\prime \prime}$ & & $\dagger$ & $\begin{array}{c}\text { d. Versuchsf. } \\
\text { beeinträchtigt }\end{array}$ & gut & $50^{\prime \prime}$ \\
\hline $9 \mathrm{I}$ & 6. X. 09 & 1600 & $3 \frac{1 / 2}{2}$ & ," & $2^{\prime}$ & $3^{\prime} 30^{\prime \prime}$ & lebt & & oberflächlich & $50^{\prime \prime}$ \\
\hline 92 & 6. X. 09 & 1700 & $31 / 2^{\prime}$ & $"$, & $2^{\prime} 45^{\prime \prime}$ & & $\dagger$ & $\begin{array}{l}\text { d. Versuchs- } \\
\text { fehler beein- } \\
\text { trächtigt }\end{array}$ & $\begin{array}{l}\text { Vorhof schlägt } \\
2-3 \text { mal häufiger } \\
\text { als Kammer }\end{array}$ & $\mathrm{I}^{\prime} 53^{\prime \prime}$ \\
\hline 93 & 8. X. 09 & 1500 & $31 / 2$ & ," & $2^{\prime} 30^{\prime \prime}$ & $\mathrm{I}^{\prime} 52^{\prime \prime}$ & lebt & & was & $55^{\prime \prime}$ \\
\hline 94 & 8. X. 09 & 1500 & $3 \frac{1}{2} z^{\prime}$ & ", & $2^{\prime} 50^{\prime \prime}$ & $\left|\begin{array}{lll}2^{\prime} & 10^{\prime \prime}\end{array}\right|$ & " & & $\begin{array}{l}\text { frequent ober- } \\
\text { flächlich }\end{array}$ & $I^{\prime} 20^{\prime \prime}$ \\
\hline 95 & 8. X. og & I 300 & $31 / 2$ & ," & $2^{\prime} 30^{\prime \prime}$ & $33^{\prime} 20^{\prime \prime} \mid$ &, & $\begin{array}{l}\text { keine } \\
\text { Wirkung }\end{array}$ & $\begin{array}{c}\text { zunächst frequ. } \\
\text { aber kräftig, } \\
\text { dann oberflächl. }\end{array}$ & $32^{\prime \prime}$ \\
\hline $9^{6}$ & 9. X. 09 & 1250 & $3 \frac{1}{2}$ & ", & $2^{\prime} 48^{\prime \prime}$ & & $\dagger$ & $\begin{array}{l}\text { Versuchs- } \\
\text { fehler }\end{array}$ & $\begin{array}{l}\text { Frequenz und } \\
\text { Kraft steigern } \\
\text { sich mit dem } 4 . \\
\text { term. Atemzug }\end{array}$ & $58^{\prime \prime}$ \\
\hline 97 & 9. X. 09 & 1000 & $3 / 2^{\prime}$ & " & $2^{\prime} 55^{\prime \prime}$ & & lebt & & $\begin{array}{c}\text { zunächst leidlich, } \\
\text { dann sehr oberfl. } \\
\text { starke Dilatat. }\end{array}$ & $1^{\prime} 36^{\prime \prime}$ \\
\hline 36 & 2I. XII. 08 & 2220 & $4^{\prime}$ & & $4^{\prime}$ & $8^{\prime}$ & $\dagger$ & & $\begin{array}{l}\text { frequent u. sehr } \\
\text { oberflächlich }\end{array}$ & \\
\hline $\begin{array}{l}37 \\
46\end{array}$ & $\begin{array}{c}2 \text { I. XII. } 08 \\
28 . \text { X. } 09\end{array}$ & $\begin{array}{l}2300 \\
2100\end{array}$ & $\begin{array}{l}4^{\prime} \\
4^{\prime}\end{array}$ & $\because$, & $\begin{array}{c}4^{\prime} \\
10^{\prime} 30^{\prime \prime}\end{array}$ & $I^{\prime} I^{\prime \prime}$ & $\begin{array}{c}\text { lebt } \\
\dagger\end{array}$ & keine Wirk. & ", & $\begin{array}{l}\mathrm{I}^{\prime} \\
\mathrm{I}^{\prime} 35^{\prime \prime}\end{array}$ \\
\hline 98 & I 2. X. $\mathrm{X} 8$ & 2100 & $4^{\prime}$ & ", & $2^{\prime} 50^{\prime \prime}$ & $5^{\prime} 40^{\prime \prime}$ & lebt & \begin{tabular}{|c} 
sichtl. Wirk. \\
auf die \\
Herzaktion
\end{tabular} & ", & \\
\hline 99 & 12. X. 09 & 2250 & $4^{\prime}$ & ", & $2^{\prime} 20^{\prime \prime}$ & $3^{\prime} 9^{\prime \prime}$ & ", & , & $\begin{array}{l}\text { oberfl. unregel- } \\
\text { mäBig }\end{array}$ & $40^{\prime \prime}$ \\
\hline 104 & 20. X. 09 & 1800 & $4^{\prime}$ & $"$ & $2^{\prime} 26^{\prime \prime}$ & $2^{\prime} 50^{\prime \prime}$ & ", & wirksam & kräftig & $45^{\prime \prime}$ \\
\hline 38 & 22. XII. o8 & 2100 & $4 \frac{1}{2}$ & ", & $4^{\prime} 30^{\prime \prime}$ & $12^{\prime} 30^{\prime \prime}$ & $\dagger$ & & unregelmäßig & $I^{\prime}$ \\
\hline 39 & 22. XII. o8 & 2020 & $4{ }^{1 / 2}$ & " & $4^{\prime} 30^{\prime \prime}$ & $9^{\prime}$ & $\dagger$ & & zieml. lebhaft & $I^{\prime}$ \\
\hline $4 \mathrm{I}$ & I2. III. 09 & 2600 & $4 \frac{1 / 2^{\prime}}{}$ & $\begin{array}{l}\text { Sauer- } \\
\text { stoff }\end{array}$ & $4^{\prime} 30^{\prime \prime}$ & $15^{\prime}$ & $\dagger$ & $\begin{array}{c}\text { Flimmern des } \\
\text { Vorhofs; keine } \\
\text { Wirkung. }\end{array}$ & $\begin{array}{c}\text { Flimmern, dann } \\
\text { Verlangsamung } \\
\text { der Aktion }\end{array}$ & $I^{\prime}+5^{\prime \prime}$ \\
\hline
\end{tabular}


Experiment. Untersuchungen üb. d. Wirkung von künstl. Atmung usw. I 89

Pulmonalis mit künstlicher Atmung.

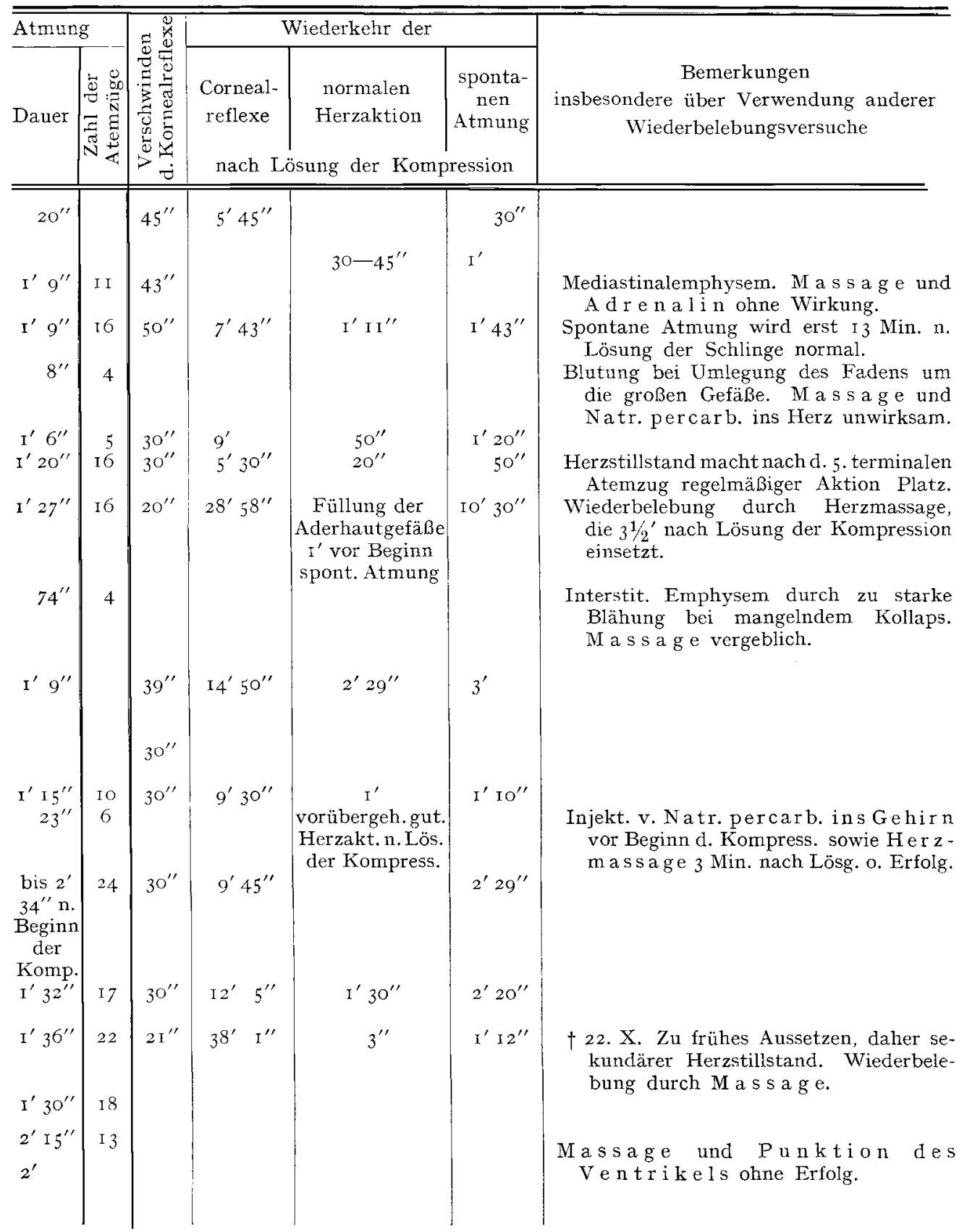


Tabelle II. Abklemmung von Aorta und

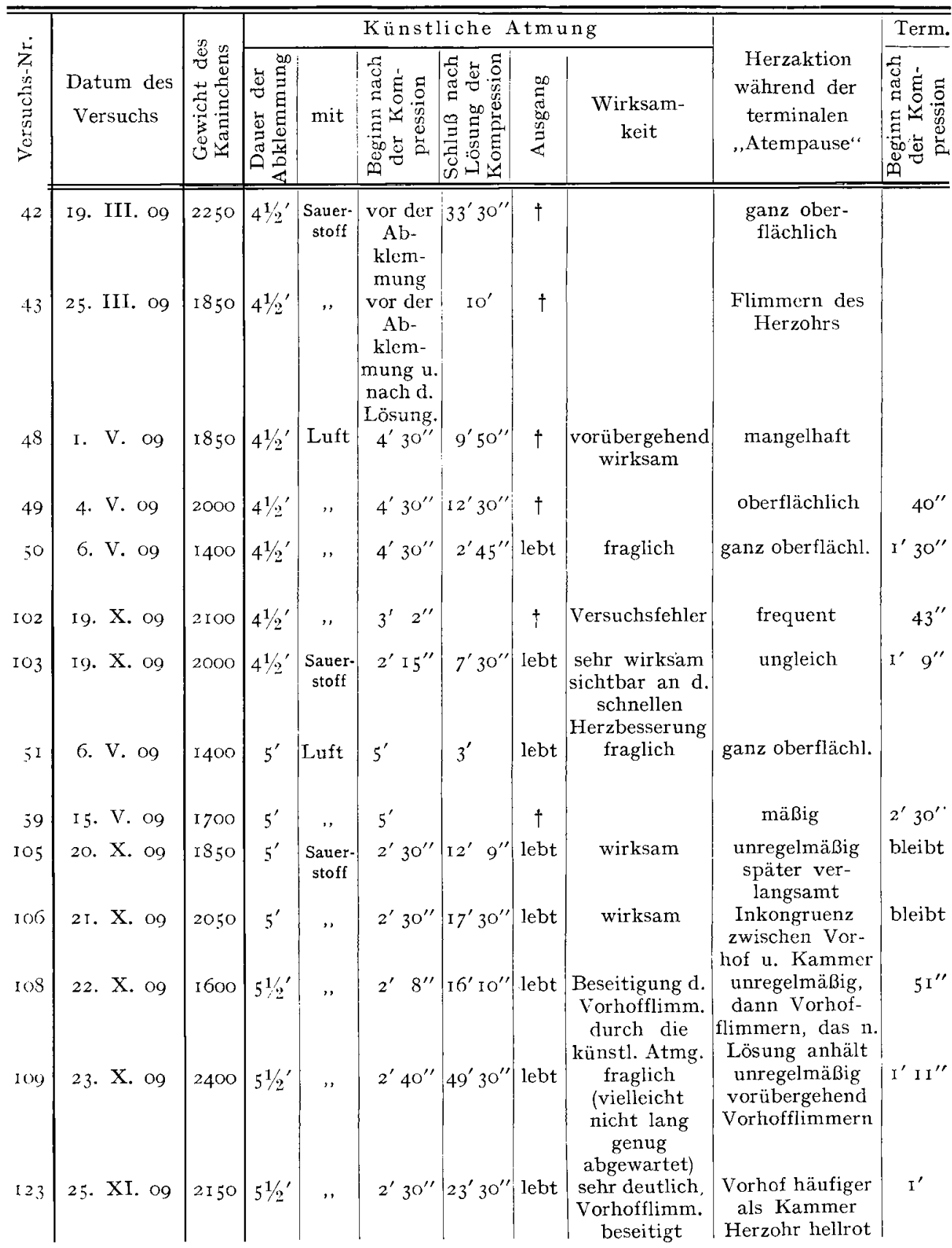


Experiment. Untersuchungen üb. d. Wirkung von künstl. Atmung usw. I9I

Arteria pulmonalismitkünstlicher Atmung.

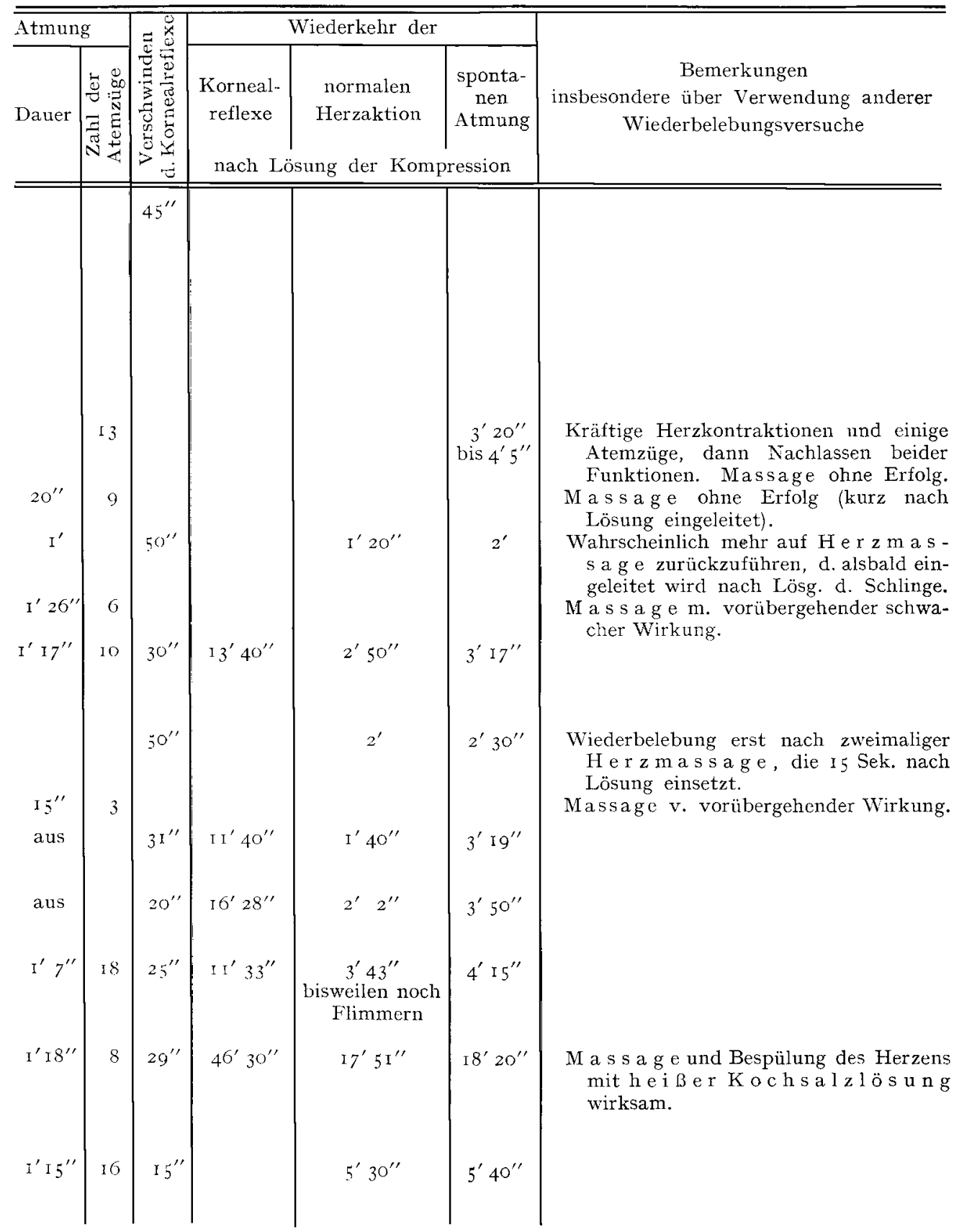


Tabelle II. Abklemmung von Aorta und

\begin{tabular}{|c|c|c|c|c|c|c|c|c|c|c|}
\hline \multirow[b]{2}{*}{ 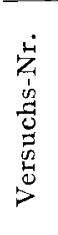 } & \multirow[b]{2}{*}{$\begin{array}{l}\text { Datum des } \\
\text { Versuchs }\end{array}$} & \multirow[b]{2}{*}{ 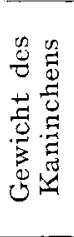 } & \multicolumn{6}{|c|}{ Künstliche Atmung } & \multirow[b]{2}{*}{$\begin{array}{l}\text { Herzaktion } \\
\text { während der } \\
\text { terminalen } \\
\text { Atemzüge }\end{array}$} & \multirow[b]{2}{*}{ 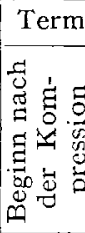 } \\
\hline & & & 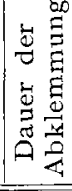 & mit & 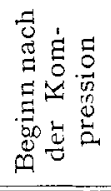 & 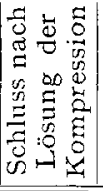 & 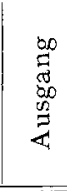 & $\begin{array}{l}\text { Wirksam- } \\
\text { keit }\end{array}$ & & \\
\hline 125 & 26. XI. 09 & I 200 & $51 / 2$ & $\begin{array}{l}\text { Sauer- } \\
\text { stoff }\end{array}$ & $2^{\prime} 30^{\prime \prime}$ & $19^{\prime}$ & lebt & $\begin{array}{l}\text { schnelle } \\
\text { Wirkung }\end{array}$ & $\begin{array}{l}\text { frequent, ober- } \\
\text { flächlich; } \\
\text { starke Dehnung }\end{array}$ & $I^{\prime} 45^{\prime \prime}$ \\
\hline 127 & 2. XII. og & I 500 & $51 / 2$ & , & $2^{\prime} 15^{\prime \prime}$ & & $\dagger$ & $\begin{array}{l}\text { funktioniert } \\
\text { nicht gut }\end{array}$ & $\begin{array}{c}\text { oberflächlich } \\
\text { dann } \\
\text { unregelmäßig }\end{array}$ & $I^{\prime} 5^{\prime \prime}$ \\
\hline I 28 & 6. XII. O9 & 2000 & $5 / 2^{\prime}$ & , & $2^{\prime} \mathrm{I} \mathrm{O}^{\prime \prime}$ & & $\dagger$ & $\begin{array}{l}\text { vorübergeh. } \\
\text { Besserung der } \\
\text { Herzaktion }\end{array}$ & sehr oberflächlich & $\mathrm{I}^{\prime} 3 \mathrm{O}^{\prime \prime}$ \\
\hline 55 & I I. V. Og. & 2250 & $5^{3 / 4}$ & Luft & $5^{\prime} 45^{\prime \prime}$ & $\mathrm{I} 4^{\prime}$ & lebt & & $\begin{array}{l}\text { schlägt } 4 \frac{1}{2^{\prime}} \\
\text { lang relativ gut }\end{array}$ & $\mathrm{I}^{\prime} 5 \mathrm{O}^{\prime \prime}$ \\
\hline 54 & I0. V. O9 & 2200 & $6^{\prime}$ & ", & $6^{\prime}$ & $23^{\prime}$ I $5^{\prime \prime}$ & lebt & ohne Erfolg & $\begin{array}{l}\text { ganz ober- } \\
\text { flächlich }\end{array}$ & $I^{\prime}$ \\
\hline 56 & I2. V. 09 & 1950 & $6^{\prime}$ & , & $6^{\prime} 3^{\prime \prime}$ & $14^{\prime} 30^{\prime \prime}$ & $\dagger$ & $"$ & $\begin{array}{l}\text { oberflächlich } \\
\text { ruckweise }\end{array}$ & $\mathrm{I}^{\prime} 58^{\prime \prime}$ \\
\hline 57 & I 3. V. O9 & 2000 & $6^{\prime}$ & ", & $6^{\prime}$ & $20^{\prime} 30^{\prime \prime}$ & $\dagger$ & ", & $\begin{array}{l}\text { oberflächlich, } \\
\text { dann } \\
\text { Herzstillstand }\end{array}$ & $I^{\prime} 20^{\prime \prime}$ \\
\hline I07 & $2 \mathrm{I} \cdot \mathrm{X} \cdot \mathrm{OO}$ & 2100 & $6^{\prime}$ & $\begin{array}{l}\text { Sauer- } \\
\text { stoff }\end{array}$ & $3^{\prime} \pm 5^{\prime \prime}$ & & $\dagger$ & $\begin{array}{c}\text { Vorhof hellrot } \\
\text { u. flotter }\end{array}$ & $\begin{array}{c}\text { Vorhofflimmern, } \\
\text { Inkongruenz }\end{array}$ & $I^{\prime} 29^{\prime \prime}$ \\
\hline I 26 & 30. XI. 09 & I 500 & $6^{\prime}$ & ", & $2^{\prime} 30^{\prime \prime}$ & & $\dagger$ & ohne Wirkung & $\begin{array}{c}\text { ganz unregel- } \\
\text { mäBig }\end{array}$ & $I^{\prime} 58^{\prime \prime}$ \\
\hline 110 & $25 . X \cdot 09$ & I 850 & $61 / 4^{\prime}$ & ," & $2^{\prime} 30^{\prime \prime}$ & $12^{\prime} 53^{\prime \prime}$ & lebt & fraglich & $\begin{array}{c}\text { unregelmäBig u. } \\
\text { oberflächlich }\end{array}$ & $\mathrm{I}^{\prime} 52^{\prime \prime}$ \\
\hline I I I & 25. X. 09 & I 750 & $61 / 2^{\prime}$ & ", & $2^{\prime} 30^{\prime \prime}$ & I $7^{\prime} 35^{\prime \prime}$ & lebt & kein Erfolg & $\begin{array}{l}\text { nach Einsetzen } \\
\text { der } \mathrm{K} \text {. A. etwas } \\
\text { kräftiger und } \\
\text { frequenter }\end{array}$ & \\
\hline 53 & 8. V. og & I $45^{\circ}$ & $8^{\prime}$ & Luft & $8^{\prime}$ & $10^{\prime} 30^{\prime \prime}$ & $\dagger$ & " & $\begin{array}{c}\text { ganz oberfläch- } \\
\text { lich }\end{array}$ & $I^{\prime} 30^{\prime \prime}$ \\
\hline I I 2 & 25. X. O9 & $\mathrm{I} 600$ & $8^{\prime}$ & $\begin{array}{c}\text { Sauer- } \\
\text { stoff }\end{array}$ & $2^{\prime} 30^{\prime \prime}$ & & $\dagger$ & " & $\begin{array}{c}\text { oberflächlich } \\
\text { nach Einsetzen } \\
\text { der K.A.vorüber- } \\
\text { gehend gebessert }\end{array}$ & $I^{\prime} 56^{\prime \prime}$ \\
\hline 52 & 7.V. V. 09 & I 800 & $\mathrm{IO}^{\prime}$ & Luft & I $0^{\prime}$ I $5^{\prime \prime}$ & $25^{\prime}$ & $\dagger$ & $"$ & $\begin{array}{c}\text { bald kräftiger, } \\
\text { bald oberfläch- } \\
\text { licher, } \\
\text { späternurVorhof- } \\
\text { kontraktionen }\end{array}$ & $\mathrm{I}^{\prime} 3 \mathrm{O}^{\prime \prime}$ \\
\hline
\end{tabular}


Experiment. Untersuchungen üb. d. Wirkung von künstl. Atmung usw. I93

monalis mit künstlicher Atmung.

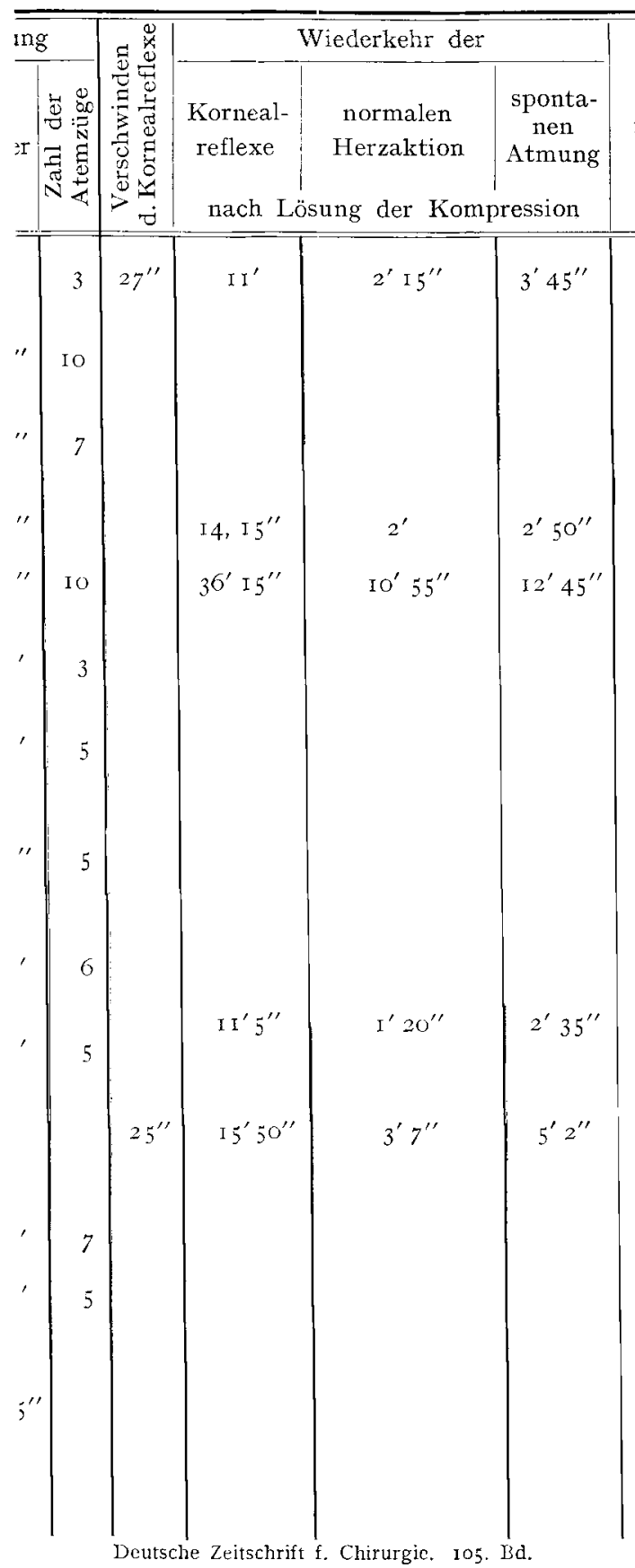

Bemerkungen

insbesondere von Verwendung anderer

Wiederbelebungsversuche

Sehr lang dauernder abnormer Typ der spontanen Atmung.

H er z m a s a g e, 8 Min. nach Lösung einsetzend, ohne Erfolg.

$\mathrm{H}$ er z m as a ge I 5 Min. 45 Sek. nach Lösung vergeblich.

4 St. nach Versuch gestorben. H e r z massage sofort nach Lösung wirksam.

Herzm assage, nach 45 Sek. einsetzend, von vorübergehendem Erfolg.

H e r z m a s a ge sofort nach Lösung der Abschnürung ohne bleibenden Erfolg.

M a s a ge fast ohne Wirkung. Monburgsche Umschnürung. A d r c n a l i n ohne Erfolg.

Massage nach ro Min. 5o Sek., vorübergehende Herzwirkung.

Wahrscheinlich Wirksamkeit der Herzm. a s a g e.

Erfolg der $\mathrm{H}$ er z mas s g e.

Massage ohne Erfolg.

Massage, Kochsalzbespülung und Adrenalin ohne Erfolg.

Vorübergehende Wirkung der Mas s a g e auf die Herzaktion. 
in denen dies nicht glückte, müssen Versuchsfehler beschuldigt werden: dreimal gelang die künstliche Atmung nicht (90, 95, 96), einmal war es bei der Umschnürung der größeren Gefäße zu einer sehr reichlichen Blutung gekommen und außerdem hatten die technischen Schwierigkeiten den Versuch unangenehm in die Länge gezogen und die Widerstandskraft des Tieres stark herabgesetzt. In 4 Experimenten mit 4 Minuten dauernder Kompression blieben 3 Tiere am Leben, I ging zugrunde, ohne da $B$ besondere ungünstige Einflüsse beschuldigt werden konnten. Über diese Zeit hinaus konnte nur in einem Versuch (5) ein günstiger Einfluß der künstlichen Respiration nachgewiesen werden. Der scheidet aber wohl aus, weil das Versuchstier jedenfalls, wie wir das ja schon bei unseren ersten Versuchen mehrfach beobachteten, ein besonders widerstandsfähiges Herz besaß. Die Abschnürung in diesem Falle hatte $5 \%{ }_{4} \mathrm{M}$ in u te $\mathrm{n}$ ged a uert und das Tier blieb a $m$ L e be n.

Diese Variationsbreite der Widerstandsfähigkeit der Versuchstiere ist überhaupt ein für die Beurteilung der Wirksamkeit von Wiederbelebungsmethoden sehr erschwerender Umstand. Immerhin glauben wir doch, bestimmte Schlüsse ziehen zu dürfen, einerseits aus dem zahlenmä Bigen Vergleich der positiven und negativen Resultate bei dem einen oder anderen Verfahren und andererseits aus dem Verhalten des Herzens vor und besonders nach Lösung der Gefäßumschnürung.

Berücksichtigen wir, daß nach 3 Minuten währender Abklemmung der Gefäße ohne Anwendung von Wiederbelebungsmitteln von 7 Tieren 6 z u gr und e gingen (vgl. Tab. I), daß aber unter Einwirkung künstlicher Respiration eigentlich alle Kaninchen am Leben bleiben, die einer $3^{1 / 2} \mathrm{M}$ i n u t e $\mathrm{n}$ langen Arterienkompression ausgesetzt werden, so dürfen wir schon daraus das wichtige Ergebnis entnehmen, daß durch die Einleitung künstlicher Atmung eine ganze Minute gewonnen wird, was immerhin einen Gewinn von $7: 5$ bedeutet. Die künstliche Atmung muß also die durch die Kompression von Aorta und Art. pulmonalis bedingten $S \mathrm{ch}$ ä $\mathrm{d} l \mathrm{i} \mathrm{c} \mathrm{h-}$ $\mathrm{k}$ eit e $\mathrm{n}$ um ein $\mathrm{B}$ ed e ut endes reduzieren.

$\mathrm{DaB}$ das Resultat nicht durch die Variationsbreite der Resistenz beeinflußt ist, können wir mit aller Bestimmtheit auch des- 
wegen behaupten, weil in den in Frage stehenden Versuchen 35, 9I, 93, 94, 97 das Verhalten des Herzens in der Zeit zwischen terminaler Atmung und Wiederkehr seiner Funktion ein ungünstiges war oder wenigstens nicht die auffallend kräftige und anhaltende Herzaktion beobachtet wurde, wie wir sie als charakteristisches Merkmal der besonders hohen Widerstandskraft des Versuchstieres kennen lernten; vgl. Vers.-Nr. 72, 78, 80 und den erwähnten Versuch Nr. 55 mit $5 \%$ Minuten. In den Protokollen ist überall auf die äußerst frequente und oberflächliche Herzaktion in der „terminalen Atempa use" — wie wir sie zum Unterschied von der präterminalen bezeichnen möchten - hingewiesen.

Dasselbe gilt von den drei 4-Minuten-Versuchen bei denen es gelang, unter künstlicher Atmung die Tiere am Leben zu erhalten, so daß wir hier wohl ein Plus von $\mathrm{I}^{1} \frac{1}{2}$ Minuten verzeichnen dürfen. Das numerische Verhältnis ist aber hier ungünstiger, indem I Versuchstier von 4 zugrunde ging, ohne daB irgendwelchen äußeren Zufällen die Schuld beigemessen werden konnte. Es wäre ja durchaus berechtigt, in einem solchen Falle auch eine besonders geringe Widerstandskraft des Tieres zu supponieren und man könnte auf Grund der Beobachtung, daß die durchschnittliche Dauer der agonalen Atmung gerade identisch ist mit der Abklemmungszeit, welche von den Tieren ohne Kunsthilfe ertragen wird, geneigt sein, einen Indikator für die möglicherweise geringere Widerstandsfähigkeit in einem abgekürzten Auftreten der präterminalen Atmung zu suchen.

Um uns über die Berechtigung einer solchen Annahme ein Urteil zu bilden, haben wir die Verhältnisse der präterminalen Atmung bei Versuchstieren von größerer Resistenz und solchen von geringerer tabellarisch miteinander verglichen. (Tab. III.) Die Zahlen geben uns keinen Anhaltspunkt in der fraglichen Richtung. Es sind zwar in den Versuchen der Tabelle III, I die üblichen Werte für das Spatium zwischen Anlegung der Umschnürung und Schluß der agonischen Atmung ziemlich eingehalten $\left(2^{\prime} 5^{\prime \prime}-3^{\prime}\right)$ : der Durchschnitt beträgt $2^{\prime} 29^{\prime \prime}$, übersteigt also nicht den angegebenen sonstigen Wert von $2^{1} /_{2}^{\prime}$. Ebensowenig bleibt das Mittel aus Spalte 6 von Tab. III 2 mit $2^{\prime}$ I5" wesentlich unter iedem Werte. Aus den anderen Zahlen der Tabellen läßt sich ebensowenig eine verwertbare Differenz berechnen. Auch 


\section{T a belle III.}

Beziehungen der präterminalen Atmung zur Resistenz des Versuchstieres.

I. Tieremit hoher Resistenz.

\begin{tabular}{|c|c|c|c|c|c|c|c|}
\hline \multirow{2}{*}{$\begin{array}{c}\dot{\vec{n}} \\
\dot{1} \\
\dot{D} \\
\dot{0} \\
\vec{b}\end{array}$} & \multirow{2}{*}{$\begin{array}{l}\text { Ablklem- } \\
\text { mungs- } \\
\text { dauer }\end{array}$} & \multirow{2}{*}{ Ausgang } & \multirow{2}{*}{$\begin{array}{c}\text { Künstliche Maß- } \\
\text { nahmen }\end{array}$} & \multicolumn{3}{|c|}{ Agonale Atmung } & \multirow{2}{*}{ 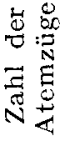 } \\
\hline & & & & $\begin{array}{l}\text { Beginn 1) } \\
\text { p. c. }\end{array}$ & $\begin{array}{c}\text { Aufhören } \\
\text { p.c. }\end{array}$ & Dauer & \\
\hline 80 & $3^{\prime}$ & lebt & ohne Hilfe & $1^{\prime}$ & $2^{\prime} 30^{\prime \prime}$ & $I^{\prime} 30^{\prime \prime}$ & I 2 \\
\hline 78 & $31 / 2^{\prime}$ & ", & & $I^{\prime} 45^{\prime \prime}$ & $2^{\prime} 55^{\prime \prime}$ & $\mathrm{I}^{\prime} \mathrm{IO}^{\prime \prime}$ & 12 \\
\hline 72 & $4^{\prime}$ & ", & & & & & 25 \\
\hline 37 & $4^{\prime}$ & ," & künstl. Respirat. & $I^{\prime}$ & $2^{\prime}$ I $5^{\prime \prime}$ & $I^{\prime}$ I $5^{\prime \prime}$ & IO \\
\hline 98 & $4^{\prime}$ & , & ", & & $2^{\prime} 34^{\prime \prime}$ & & 24 \\
\hline 99 & $4^{\prime}$ & " & ," & $40^{\prime \prime}$ & $2^{\prime}$ г $2^{\prime \prime}$ & $I^{\prime} 32^{\prime \prime}$ & I 7 \\
\hline 50 & $4 \frac{1}{2}$ & , & Herzmassage & & & & \\
\hline 55 & $5 \% 4$ & ", & künstl. Respirat. & $I^{\prime} 50^{\prime \prime}$ & $2^{\prime} 5^{\prime \prime}$ & $15^{\prime \prime}$ & \\
\hline 54 & & ," & Herzmassage & $\mathrm{I}^{\prime}$ & $2^{\prime} 8^{\prime \prime}$ & $\mathrm{I}^{\prime} 8^{\prime \prime}$ & IO \\
\hline
\end{tabular}

2. Tiere mit geringer Resistenz.

\begin{tabular}{|c|c|c|c|c|c|c|c|}
\hline 92 & $3 / 2^{1}$ & tot & künstl. Respirat. & $\mathrm{I}^{\prime} 53^{\prime \prime}$ & $2^{\prime} \quad I^{\prime \prime}$ & $8^{\prime \prime}$ & 4 \\
\hline 36 & $4^{\prime}$ & ", & & & $\mathrm{I}^{\prime} 3 \mathrm{O}^{\prime \prime}$ & & \\
\hline $4 \mathrm{I}$ & $4 \frac{1 / 2}{1}$, & , & Herzmassage & $I^{\prime}$ I $5^{\prime \prime}$ & $3^{\prime} \pm 5^{\prime \prime}$ & $2^{\prime}$ & \\
\hline 48 & $4 \frac{1 / 2}{1}$ & ", & " & & $2^{\prime} 50^{\prime \prime}$ & & I3 \\
\hline 49 & $4 \frac{1}{2^{\prime}}$ & $"$ & ", & $40^{\prime \prime}$ & $60^{\prime \prime}$ & $20^{\prime \prime}$ & 9 \\
\hline 59 & $5^{\prime}$ & " & ", & $2^{\prime} 30^{\prime \prime}$ & $2^{\prime} 45^{\prime \prime}$ & $15^{\prime \prime}$ & 3 \\
\hline
\end{tabular}

die Vermutung, daß bei den scheinbar widerstandslosen Tieren das Einsetzen der agonalen Atmung durchschnittlich später erfolgt als bei denen der Tabelle I I, dementsprechend die Dauer der Atmung verkürzt, die $Z$ ahl der Atemzüge verringert ist, bestätigte sich nicht.

Rückwärts darf man nun wohl aus dieser Statistik schließen, daß auch die Übereinstimmung zwischen durchschnittlicher Dauer der terminalen Atmung nach der Zirkulationsunterbrechung und der Maximaldosis der Zirkulationsunterbrechung von $2{ }^{1}{ }_{2}^{\prime}$ mehr eine zufällige ist als eine auf einem gegenseitigen Abhängigkeitsverhältnis beruhende. Wir wissen über die Entstehung und Bedingungen des eigenartigen Atmungstypus zu wenig, um in dieser Frage AufschluB zu erhalten.

r) post compressionem. 
Das endgültige Ergebnis a us der ja immer nochkleinen $Z$ ahl von Versuchen istalsodas, da $\beta$ beikünstlicher Respiration die vollkommeneKreisla $\mathrm{K}$ unterbrechung durch Abklemmung von A orta und Pulmonalis $\mathrm{I}-\mathrm{I}^{1} / 2 \mathrm{M}$ in $\mathrm{m}$ e $\mathrm{n}$ länger ertragen wird als ohne Kunsthilfe.

Inwiefern bedeutet dieses Ergebnis etwas Neues?

Um uns ein Urteil bilden zu können, ob die obigen Resultate neue, physiologisch und klinisch verwertbare Erfahrungen darstellen, müssen wir darüber Klarheit uns zu verschaffen suchen, inwieweit die künstliche Respiration als Wiederbelebungsmittel oder als lebensrettendes Mittel im physiologischen Experiment und in der klinischen Therapie angewandt ist und inwiefern die Bedingungen, die zu der Anwendung von künstlicher Atmung führten, denen unsere Experimente ähnlich oder gleichartig sind. Bei dem Vergleich müssen wir davon ausgehen, da $B$ wir bei unseren Versuchen vor allem eine sehr schwere $H$ e r zschädigung zu bekämpfen hatten, an die sich s e k u n d är eine Alteration des $\mathrm{Z}$ en tralnervens ys tems mit ihren Folgen für A t m u n g und $Z$ irkulation anschloß.

Das ist das Wesentliche. Die künstliche Respiration tritt nicht lediglich an die Stelle der fehlenden Atmung, sondern soll in erster Linie das ge schädigte und erlahm te Herz wiederzurFunktion anregen. Wenn wir also nach ähnlichen Bedingungen anderer Experimentatoren suchen, so können es ebenfalls nur Fälle von primärer Herzlähmung sein. Differenzen würden dann in erster Linie durch den Grad und die Qualität der Herzschädigung bedingt sein.

Auf diesen Überlegungen fußend, müssen wir ausschließen solche Versuche, die auf Erstickung beruhen, sei es durch Abschluß der Luftröhre, sei es durch schädliche Zusammensetzung der Atmungsluft (Wasserstoff-, Stickstoff-Atmung oder Mangel an Sauerstoff und Überschuß von Kohlensäure). In allen diesen Fällen ist das zunächst geschädigte Organ das Cerebrum, resp. die Med. oblongata; Herz und Atmung erlahmen erst auf Grund der Schädigung der Zentren. Vergiftungen mit Cyankali und Curare sind ebenfalls vom Vergleich auszuschließen.

Wir kommen dann zu den zahlreich und physiologisch höchst 
interessanten Versuchen über $\mathrm{An}$ äm is ierung des $Z$ en tral organs durch Ligatur der vier Halsarterien oder auch 'durch Suspension des Versuchstieres (Hi111)). Es sind hierbei im allgemeinen keine Wiederbelebungsversuche gemacht. Es dürften also nur die absoluten Zeiten in Frage kommen, während deren nach den Autoren das Gehirn die Anämie verträgt. Die ältesten Versuche stammen von C o o p e ${ }^{2}$ ). Sie enthalten keine näheren Zeitangaben. Aus den berühmten Unter-

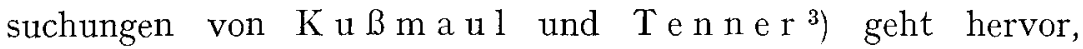
daß noch nach $2 \mathrm{M}$ in ute $\mathrm{n}$ Unterbrechung der Blutz uf u h r z u m Ge hirn (Trunc. anonym. und Carotis und Subclavia) eine Restitution stattfindet. Den einen Versuch, in dem nach 7 Minuten dauernder Abklemmung die Atmung, das Bewußtsein und die „Willenskraft über die Muskeln des Körpers" wiederkehrten, erklären sich die Autoren mit Recht daraus, daß eine Blutzufuhr auf Nebenwegen stattgefunden haben muß, da auch die anämischen Krämpfe erst nach 5 Minuten eingesetzt hatten.

Sehr eingehend hat $\mathrm{H}$ ill die Wirkung der Anämie auf das Cerebrum studiert, die er nicht wie die anderen Autoren durch Unterbindung der vier Arterien hervorrief, sondern durch A uf $\mathrm{h}$ ä $\mathrm{n}$ g e $\mathrm{n}$ de $\mathrm{r} \mathrm{K}$ a $\mathrm{n}$ i $\mathrm{n} \mathrm{ch}$ e $\mathrm{n}$ an den Ohren und den Vorderbeinen mit aufrechtem Kopf und Fixation der unteren Extremitäten in Streckstellung. Durch die Ansammlung des Blutes in der Bauchhöhle und den unteren Extremitäten kommt es zu völliger Anämie des Cerebrums und der Med. oblongata. Die Ursache des darauffolgenden Todes ist, wie $\mathrm{H}$ ill annimmt, das Versagen des Respirationszentrums.

Schon aus dieser Tatsache ergibt sich der wesentliche Unterschied der $\mathrm{H}$ illschen Versuche von den unseren von selbst, ganz besonders aber dadurch, daß die Anämisierung des Gehirns bei dieser Versuchsanordnung eine ganz allmähliche ist. Es ist

I) Hi 11, On cerebral anaemia and the effects, which follow Ligation of the cerebral arteries. Philosoph, transact. Roy. soc. London I93 B. 1900, S. 69.

2) Cooper. Zit. nach $\mathrm{Hill}$.

3) $\mathrm{KuBmaul}$ und $\mathrm{Tenner}$, Untersuchungen über Ursprung und Wesen der fallsuchtartigen Zuckungen bei der Verblutung sowie der Fallsucht überhaupt. Moleschotts Untersuch. III, I-I 24, I857. 
daher die Ansicht Hills, daß die Tiere sich nach einem Io-2o Minuten dauernden Ausfall der Pupillenlichtreaktion wieder völlig erholten, ganz anders zu bewerten. Dem entspricht auch, daß der Ausfall der Atmung dem ersteren erst nach Minuten folgt. Merkwürdigerweise schließt Hill aus diesen Versuchen, daß die einmal sistierende selbständige Atmung ohne künstliche Respiration nicht wiederkehren kann; er sagt wörtlich: ,the respiratory centre, when it ceases to act, becomesirrevocably paralysed unless artificial respiration be at once applied". Aus den mitgeteilten Versuchsprotokollen ist nun $\mathrm{zu}$ sehen, daß $\mathrm{Hill}$ in einem Versuch (I. S. 77), wo die Atmung nach 20 Minuten sistierte, unmittelbar die künstliche Atmung hat einsetzen lassen. Abwartende Versuche sind gar nicht mitgeteilt.

Die Hillschen Versuche scheiden aus obigen Gründen beim Vergleich mit den unserigen aus. Was nun die übrigen durch Ligatur erzeugten Anämisierungsversuche angeht, so ist auch bei ihnen das Versagen der M e d. o blong a ta die primäre Todesursache und $\mathrm{KuBm}$ a ul und $\mathrm{T}$ e $\mathrm{n}$ ner erwähnen ausdrücklich, daß die Herztätigkeit noch lange nach Erlöschen der Reflexe und der spontanen Atmung anhielt. Bei uneröffnetem Thorax erlosch der durch die Erschütterung der Brustwand sichtbare Herzschlag ,,selten vor etwa Io Minuten“. Nach Eröffnung schlug es bei einem Kaninchen ,noch eine ganze Stunde in allen seinen Teilen kräftig fort". Ähnliche Beobachtungen von M a y e r aus dem Jahre 1833 teilen die beiden Autoren mit und schließen mit dem Resumé: „In diesen Fällen fand somit eine Ausnahme von der Regel statt, wonaç das linke Herz das ,primum moriens' zu sein pflegt".

Wie wesentlich sich die Versuchsanordnung bei jenen Experimenten von den unserigen unterscheidet, geht mit Prägnanz aus der Mitteilung S. M a ye r $\mathbf{S}^{\mathbf{1}}$ ) hervor. M a y e r stellte fest, daß 5-IO-I5 Minuten nach Lösung der Hirnarterienkompression die spontane Atmung sich sehr bald wieder einstellt, wenn während der Dauer des Arterienverschlusses künstliche Respiration ausgeführt war. Unter diesen Umständen — sagt M a y e r - geht

I) S. M a y e r. Zentralbl, der med. Wissensch. I880, S. I 33. 
während der Kompression der Kreislaufgut vonstatten. Diedirekte Schädigung des HerzensfälltalsobeikünstlicherAtmung völlig for t.

M a ye $\mathrm{r}$ hat aber, wie er nur kurz andeutet, auch weitergehende Versuche angestellt, in denen er jede kollaterale Blutversorgung des Gehirns dadurch ausschaltete, da $B$ er den Truncus anonymus und die Aorta zwischen dem Abgang von Truncus und Art. subclavia sin. abklemmte und so ,,jeglichen arteriellen Abfluß“ aus dem linken Ventrikel unmöglich machte. Mit dieser Versuchsanordnung kommt M a y e $\mathrm{r}$ der unseren näher, erwähnt aber leider nicht, wie lange diese Abklemmungszeit unter künstlicher Atmung ertragen wurde, da es ihm nur auf die Klarstellung der Symptomatik w äh re n d der Anämisierung des Gehirns ankam. Die Abklemmung von Aorta und Pulmonalis gleichzeitig, wie sie in unseren Versuchen ausgeführt wurde, bedeutet natürlich eine noch viel größere Schädigung des Herzens, insofern der Lungen$\mathrm{k}$ reislauf und die Arterialisierung des Coronarblutes ausgeschaltet wird. Uber die Wirkung des Aortenverschlusses für sich haben wir keine Versuche angestellt, da wir in Hinblick auf die Embolieoperation kein praktisches Interesse daran haben. Daß sie viel weniger schädlich sein $m u B$, geht aus den Versuchen $S$ u st s chinskys ${ }^{1}$ ) hervor, der den Aortenverschluß in der Nähe des Herzens vornahm, um die Wirkung des erhöhten Herzinnendrucks auf die Erregbarkeit des Herzvagus zu prüfen. Die Protokolle zeigen, daß die Herzen der Tiere sich noch nach mehrere Minuten dauernder Abklemmung in kurzer Zeit wieder erholten. Nur einmal ist hier a $\mathrm{ch}$ e in e $\mathrm{Abkle} \mathrm{m} \mathrm{mung}$ des Arcus aortae und der Art. pulmonalis gle ichzeitig ausgeführt (Versuch XIV, S. r69), die Kompression aber nur eine Minute lang liegen gelassen. Die Erregbarkeit des Vagus war nach 3 Minuten wieder normal.

Soweit die Anämisierungsversuche. Sie haben für uns insofern Interesse, als sie die überraschende $W$ iderstandsfähig keit des $Z$ entralnervensystems zeigen, die auck

I) Susts chinsky, Untersuchungen aus dem physiologischen Laboratorium in Würzburg. 3, $1868, \mathrm{~S} .165-\mathrm{I} 80$. 
wir nachweisen konnten und als Grundlage zu unseren Wiederbelebungsversuchen benötigten.

Wir möchten aber ausdrücklich darauf hinweisen, daß die erwähnten Methoden zur Anämisierung des Cerebralorgans keine absolut zuverlässigen sind. Auch v. $\mathrm{Cackowic}^{1}$ ) ist der Meinung, daß z. B. die Resultate B r own-Séquards ${ }^{2}$ ), der nach dem arteriellen Verschluß unter Zuhilfenahme der künstlichen Atmung noch nach I7 Minuten Wiederbelebungen des Gehirns erzielte und Hertzens ${ }^{3}$ ), wonach durch mehrere Stunden hindurch bei Erwärmung der Versuchstiere die Abklemmung der Hirnarterien ertragen wurde, keine einwandsfreien seien, weil keine vollkommene Anämie erzeugt sei. Demgegenüber gebe die Versuchsanordnung $\mathrm{B}$ atellis${ }^{4}$ ), bei der die komplette Anämie durch Unterdrückung der Herzpulsation durch Chloroform bewirkt wird, ,der Wirklichkeit mehr entsprechende Resultate". B a telli kommt zu dem Ergebnis, da B der Schwellenwert für die Widerstandsfähigkeit des Rückenmarks gegen Anämie zwischen ro und 20 Minuten liegt, der des Gehirns mehrere Stunden beträgt.

Es geht also auch aus B a t e 11 is Versuchen die überraschende Resistenz der zentralen Nervenzellen gegenüber Anämisierung hervor. Unsere Versuchsanordnung ist aber in der absoluten $\mathrm{Zu}$ verlässigkeit der Blutleere des Gehirns noch wirksamer. Denn mit dem Momente der Umschnürung beider großen Arterien dringt auf dem normalen Wege kein Blut mehr ins Gehirn und andererseits entleeren bekanntlich die Kapillaren ihr gesamtes Blut in die Venen, was tatsächlich eine vollkommene Blutleere in dem Gebiete der inneren Atmung des Cerebrums herstellt. Selbst wenn es möglich wäre, daß der rechte Ventrikel rückwärts infolge relativer Insuffizienz der Tricuspidalis Blut in den Vorhof und in die Jugularis würfe (vgl. positiver Venenpuls bei Pulmonalisverschluß, Versuch Nr. II9, I20, I2I), würde selbst, wenn einige

I) v. Cack owic, Über die direkte Massage zur Wiederbelebung. Arch. f. klin. Chir. 1909, Bd. 88, S. 9i 7 .

2) Brown-Sequardt. Zit. nach v. Cackowic.

3) Hertzen, A propos des observationes de M. Laborde sur la tête d'un supplicié. Revue medicale de la suisse Romana I885, S. 467.

4) B a telli. Journ. de physiologie et de patholog. générale Igoo. 
Blutwellen bis in die Kapillaren vordrängen, nur venöses Blut dahin gelangen, da das Herz aus der Pulmonalis oder aus den Koronargefäßen kein arterialisiertes Blut erhält.

Obwohl wir also auch mit Anämie des Cerebrums zu rechnen haben, und vielleicht mit leichter Karbonisation, können unsere Wiederbelebungszeiten nicht im Geringsten mit denen anderer Experimentatoren übereinstimmen, eben weil in unserem Falle die Hauptschädigung das Herz trifft.

Es fragt sich nun, ob ähnliche Herzschädigungen bereits in anderen Experimenten zu Wiederbelebungsversuchen hervorgerufen, insbesondere mit künstlicher Respiration bekämpft worden sind.

Diese Frage ist zu verneinen. Bei unseren Versuchen resultiert die Herzschädigung aus 3 Faktoren. Der Herzmuskel entbehrt - (vgl. frühere Arbeit) - der Ernährung und erliegt einer starken Kohlensäureintoxikation und zweitens wird er mechanisch geschädigt durch stärkste Überdehnung, sowie die nach dem Beginn der Abschnürung einsetzende nutzlose Arbeit gegen die maximalen Widerstände. Diesen Faktoren reihen sich dann noch die Reizung und folgende Lähmung der Herzzentren an. Ein solcher kombinierter Angriff auf die Leistungsfähigkeit des Herzens liegt weder in $\operatorname{der} \mathrm{Chl}$ or of ormlähmung noch bei Erstickungsversuchen vor, noch wird durch den elektrischen Strom ein ähnlicher Zustand des Herzens bedingt. Daß bei den sämtlichen angedeuteten Versuchen auch die künstliche Atmung zur Verwendung gekommen ist, ist selbstverständlich. Die Resultate sind aber nicht vergleichbar und meist auch dadurch beeinträchtigt, daß mit der künstlichen Atmung die direkte oder indirekte Herzmassage kombiniert wurde. Da wir auf diese später zurückgreifen, kann hier von diesen Versuchen abstrahiert werden.

Wir kommen also zu dem Ergebnis, daß unseren Resultaten über die Wirkung der künstlichen Atmung auf das durch Abklemmung der großen Gefäße geschädigte Herz und Nervensystem andere nicht zur Seite gestellt werden können. Daß die Methode der Kreislaufsunterbrechung durch Kompression der Hohlvenen, wie sie Sauerbruch und Häcker benutzt haben, infolge des Fehlens der Herzdehnung und zeitweiligen Erhalten- 
Experiment. Untersuchungen üb. d. Wirkung von künstl. Atmung usw. 203

bleibens des Koronarkreislaufs eine erheblich geringere Herzschädigung bedeutet, haben wir in unserer früheren Arbeit ausgeführt.

Es bedarf kaum einer weiteren Begründung, daß nunmehr der Versuch gemacht wurde, das obige Resultat noch zu verbessern durch Insufflation reinen Sa uerstoffs. Die erhöhte Wirksamkeit der reinen Sauerstoff-Atmosphäre gegenïber derjenigen der atmosphärischen Luft ist durch die klinische Erfahrung (2I) festgelegt, erhellt am deutlichsten aus den Volh a $\mathrm{r}$ d schen Versuchen ${ }^{1}$ ), die nachwiesen, daß das curaresierte Tier unter Ventilation der Lungen mit Luft (Ausschaltung eigentlicher Atembewegungen) nach $\mathrm{I}^{\prime}$ 'zugrunde geht, bei $\mathrm{V}$ en $\mathrm{t} \dot{\mathrm{i}}-$ lation mit Sauerstoff $\mathrm{sich}$ aber 2 Stunden le bend hält.

Ebenso beweiskräftig für die Überlegenheit der Sauerstoffatmosphäre über die Luftatmosphäre sind die Versuche des einen von uns (Läwe $\left.\mathrm{n}^{2}\right)$ ), die sich mit dem Einfluß des Curarins auf den Tetanus der Mäuse in der Sauerstoffatmosphäre beschäftigen und die ergeben haben, daß der Curarintod unter Sauerstoff später eintritt als in der atmosphärischen Luft, daß Curarindosen, die unter gewöhnlichen Bedingungen das Versuchstier töten, in der Sauerstoffatmosphäre ausgeschieden werden können.

Die Versuch s a n or d n u n g, wie wir sie im Abschnitt II, S. I 87 , geschildert haben, wurde nur insoweit abgeändert, als es die Zuführung von Sauerstoff unter geeignetem Druck erforderte. Das zur Aufblasung der Lunge dienende Doppelgebläse stand durch einen Gummischlauch mit einem sauerstoffhaltenden Glasglocken-Gasometer in Verbindung.

Die Resultate der I7 Sauerstoffversuche sind im einzelnen unter den übrigen Versuchen mit künstlicher Atmung in der Tabelle II untergebracht. Der Ubersicht halber seien sie kurz in der folgenden Tabelle IV nebeneinander gestellt.

I) Volhardt, Künstliche Atmung durch Ventilation der Trachea und eine einfache Vorrichtung zur rhythmischen künstlichen Atmung. Münchn. med. Wochenschr. 1908, S. 209.

2) L äwe n, Exper. Untersuchungen über die Möglichkeit, den Tetanus durch Curarin zu behandeln. Mitteil. aus den Grenzgebieten 1906, Bd. I6, S. 809. 
T a belle IV.

Abklemmung von Aortaund Arteriapulmonalis mitkünstlicher Sauerstoffatmung.

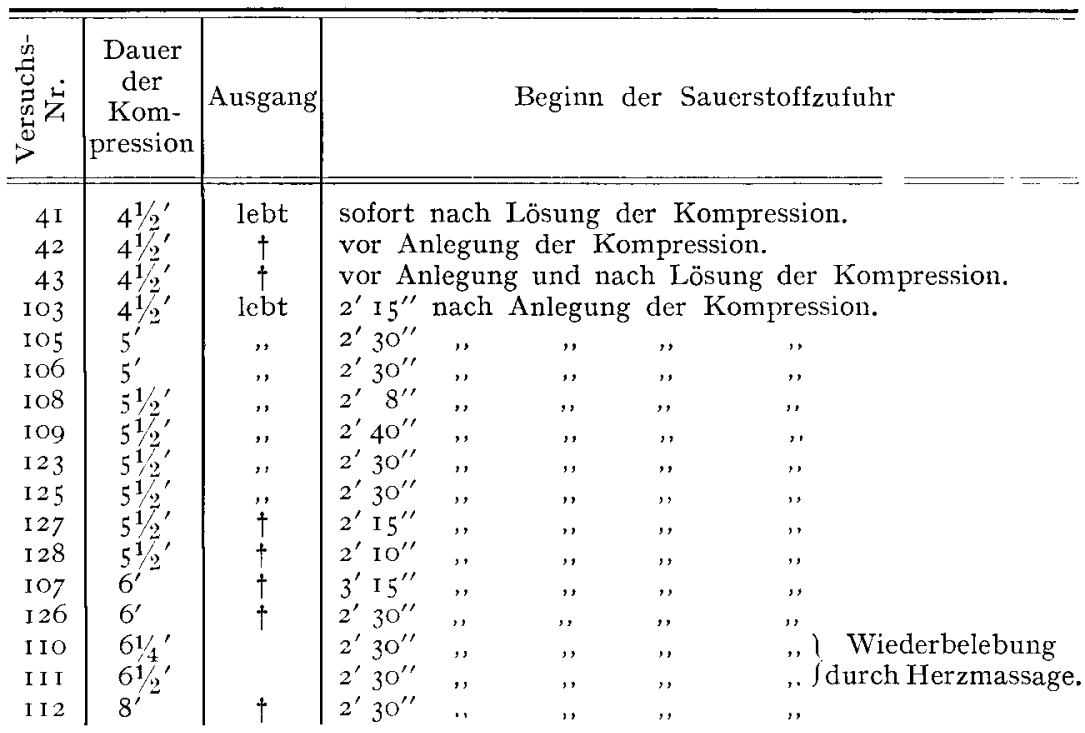

Nehmen wir die positiven Resultate vorweg, so haben wir neben je zwei $4^{1 / 2}$ Minuten- und 5-Minuten-Versuchen in 4 Fällen die Kaninchen eine $5^{1 / 2}$ Minuten dauernde totale Kreislaufunterbrechung durch Abklemmung von Aorta und Pulmonalis am Herzen überleben sehen, wenn die künstliche Respiration mit reinem Sauerstoff nach Schluß der terminalen Atmung einsetzte. Es bedeutet das gegenüber den Resultaten der künstlichen Atmung mit atmosphärischer Luft einen weiteren Gewinn von $\mathrm{I}^{1} / 2-2$ Minuten und einen absoluten Wiederbelebungserfolg von 3 Minuten und bestätigt damit die kräftige Wirksamkeit der Atmung reinen Sauerstoffs.

Das Ergebnis ist physiologisch und praktisch interessant und überraschend genug, um als Beleg an dieser Stelle ein ausführlicheres Protokoll eines solchen Versuches einzufügen:

Versuchs-N r. I23. Graues Kaninchen 2I50 g. 25. XI. Igo9. $2 \mathrm{ccm}$ Urethan subkutan.

Freilegung der Trachea und Einstechen der mit dem Doppelgebläse armierten Kanüle in die Trachea. Das Gebläse saugt den Sauerstoff aus dem Glasglocken-Gasometer. Eröffnung der linken Pleura- 
Experiment. Untersuchungen üb. d. Wirkung von künstl. Atmung usw. 205

höhle mittels Durchschneidung der dritten Rippe ca. I cm nach außen vom Sternum. Zurückklappen des Rippenfragments unter Luxieren im Sternalgelenk über das Sternum. Eröffnung des Perikards über dem Conus arteriosus. Umführung des Ölwollfadens um Aorta und Art. pulmonalis.

6h 49' Totale Abschnürung von Aorta und Pulmonalis durch Anziehen und Kreuzen des Olfadens. Herzaktion wird lebhafter, Atmung vertieft und verlangsamt.

6h $49^{\prime}$ I $5^{\prime \prime}$ Starke, anhaltende, klonische und tonische Krämpfe.

Kornealreflex fehlt.

6h $5^{\circ} \quad$ Beginn der agonalen Atmung, die besonders tief und krampfhaft ist.

Herz schlägt noch kräftig, aber unregelmäßig.

Herz schlägt dann frequenter und oberflächlicher.

$6 \mathrm{~h} 5 \mathrm{I}^{\prime} \mathrm{I} 5^{\prime \prime} \mathrm{I} 6$. (letzter) agonaler Atemzug.

Vorhofflimmern.

6h $5^{\mathrm{r}^{\prime}} 3^{\prime \prime}$ Beginn der künst 1 ichen A t m ung mit Sa u e r$\mathrm{s} t$ of $\mathrm{f}$. Herzaktion unregelmäßig. Linkes Herzohr schneller als Ventrikel.

6h 53' Herzaktion ganz oberflächlich.

6 h 53' 50" Tätigkeit des linken Ventrikels aussetzend.

6 h $54^{\prime}$ I5" Vorhof färbt sich rot.

6 h $54^{\prime} 30^{\prime \prime}$ A bschn ürung gelöst.

6h $55^{\prime}$ Io" $^{\prime \prime}$ Vereinzelte kräftige Herzkontraktionen.

$6 \mathrm{~h} 55^{\prime} 20^{\prime \prime}$ Vorhof hellrot, zeitweise flimmernd.

$6 \mathrm{~h} 55^{\prime} 30^{\prime \prime}$ Vorhof hellrot, zeitweise flimmernd.

$6 \mathrm{~h} 55^{\prime} 55^{\prime \prime}$ Vorhofflimmern andauernd, vereinzelte kräftige Kontraktionen des linken Ventrikels. Herz noch sehr gedehnt.

6h $5^{\prime} \quad$ Kammer färbt sich ebenfalls heller rot.

$6 \mathrm{~h} 56^{\prime} 40^{\prime \prime}$ Vorhofflimmern hat aufgehört.

$6 \mathrm{~h} 5^{\prime} \mathrm{I}^{\prime \prime}$ " Herzvolumen hat sich etwas verringert.

6h 58' $20^{\prime \prime}$ Wiederum Flimmern des linken Herzohrs, Kammerzusammenziehungen kräftiger.

$6 \mathrm{~h} 59^{\prime} \quad$ Kammerkontraktionen bedeutend kräftiger.

6 h $59^{\prime}$ Io' Flimmern hört auf. Vorhof schlägt gleichzeitig mit dem Ventrikel.

$7^{\text {h }} \quad$ Herzaktion kräftig. Herzverkleinert.

$7^{\text {h }} \quad 5^{\prime \prime} \mathrm{Herzaktionerschüttert} \mathrm{die} \mathrm{Brustwand.}$

$7^{\text {h }}$ IO $^{\prime \prime} \mathrm{I}$. spontaner Atemzug.

$7 \mathrm{~h} 30^{\prime \prime} 2 . \quad, \quad$,

$7^{\text {h }} \quad 42^{\prime \prime} 3 . \quad, \quad$,

7 h I' 4 . , , ,

$7 \mathrm{~h} \mathrm{I} \mathrm{I}^{\prime} \mathrm{I} 5^{\prime \prime} 5 . \quad, \quad$,

$7^{\mathrm{h}} \mathrm{I}^{\prime} 2 \mathrm{O}^{\prime \prime} 6 . \quad$, 
$7^{\text {h }} I^{\prime} 30^{\prime \prime} 7$. spontaner Atemzug.

7 h I' $45^{\prime \prime}$

$7^{\text {h }} \mathrm{I}^{\prime} 5^{\prime \prime}$

8.

$7^{\text {h }} 2^{\prime}$

9.

$7 \mathrm{~h} \quad 2^{\prime} 45^{\prime \prime}$

Io.

, "

,

,

Atmung wird allmählich frequenter, behält aber noch den terminalen Charakter.

$7^{\text {h }} 4^{\prime} 20^{\prime \prime}$ Noch starker Exophthalmus.

$7^{\text {h Io' }}$ Künstliche Respiration ausgesetzt.

Kornealreflexist wiedergekehrt.

Neben den Atemzügen von terminaler Form häufigere und oberflächlichere normale Atemzüge.

7 h II' Io" Ventilation der Lungen mit Sauerstoff; alsbald werden die normalen Atemzüge unterdrückt.

7 $\mathrm{h} 3^{\prime} \quad$ Lidspalten weit, starker Exophthalmus.

$7^{\text {h }} 14^{\prime}{ }^{\prime \prime} 5^{\prime \prime}$ Noch Ventilation.

25 tiefe Atemzüge p. Min.

$7^{\mathrm{h}} \mathrm{1} 6^{\prime} 30^{\prime \prime}$ Ventilation wieder ausgesetzt.

Lidspalten verkleinert.

$7 \mathrm{~h} \mathrm{I} 7^{\prime} \mathrm{I}^{\prime \prime} 5$ o normale A te mz üge p. Min.

7 h $18^{\prime}$ Versuch beendigt. Kanüle entfernt. Thoraxwunde geschlossen.

Auffallend lebhafte Lichtempfindlichkeit.

(Pupillen- und Lidschluß).

Extremitäten schlaff, gelähmt. Kopf wird etwas bewegt. Tier erholt sich.

Der wiedergegebene Versuch ist typisch und beweiskräftig für die Tatsache der unmittelbaren Wirksamkeit der Sauerstoffzufuhr auf die schwere Kreislaufstörung, aber gibt auch Hinweise für die Art der Wirksamkeit. Es handelt sich um ein Versuchstier von offenbar nicht besonders hoher Widerstandsfähigkeit, wie das Verhalten des Herzens während der terminalen Atmung und in der terminalen Atempause beweist. Die Kontraktionen des linken Herzens - dieses ist stets gemeint, da es ausschließlich von der Wunde aus sichtbar ist - sind ganz oberflächlich, sehr frequent und unregelmäßig, nach dem letzten terminalen Atemzug tritt Flimmern des linken Herzohrs ein. Mit Einsetzen der künstlichen Atmung mit Sauerstoff nach $2 \frac{1}{2}$ Minuten hört das Flimmern auf. Die Inkongruenz zwischen Vorhof und Kammern bleibt aber bestehen, indem die Zusammenziehungen des Vorhofs viel häufiger sind als die der Kammern. Kurze Zeit vor Lösung der Gefäßschnürung wird eine Veränderung bemerkbar, die wir fast regel- 
mäßig beobachteten und die wir als direkte Ein wi r k u ng d e r S a u e rst off - Insufflation aufzufassen haben, eine Hellrotfärbung des linken Herzohrs. Wir wiesen schon im Abschnitt II, S. I86 auf diese Erscheinung hin, die beweist, daB cine gewisse Menge arteriellen Blutes zwischen Lunge und linkem Herz hin- und hergeworfen wird und einen Teil des Herzmuskels entgiftet.

Eine deutliche Besserung der Tätigkeit des linken Ventrikels setzt erst $\mathrm{x}^{1 / 2}$ Minuten nach Lösung der Abschnürung ein, nachdom vorher schon cinzelne kräftige Zusammenziehungen vorangegangen waren. Während das Delirium des Vorhofs noch immer wiederkehrt, färbt sich auch der Ventrikel heller und schlägt allmählich immer kräftiger und häufiger. Erst nach fast 5 Minuten tritt gleichmäßiger Rhythmus der Herzteile ein und nun kommt es schnell zur Verkleincrung des Herzvolumens und damit zur richtigen Verteilung der Blutmenge, zur K o m pensation.

Dicser Zeitpunkt ist bei genauer Beobachtung meist fast auf wenige Sekunden genau festzulegen und in den Tabellen als Zeitpunkt des Wiederbeginns normaler Herzaktion eingetragen. Von jetzt ab erst, ist anzunehmen, bekommen alle Organe ihre gchörige Blutzufuhr wicder. Die Unterbrechung der Blutzufuhr darf man also nahezu bis an diesen Zeitpunkt rechnen, sic wird in diesem Falle II $\mathrm{M}$ i n u t e $\mathrm{n}$ betragen haben. Jetzt läßt meist die Wiederkehrspontaner A temzüge nicht lange auf sich warten (diesmal nur Io"), während die Kornealreflexc crst fast Io Minuten später wieder nachweisbar wurden.

Die künstliche Atmung darf um diese Zeit noch nicht ausgesetzt werden, denn wir haben verschiedentlich die Erfahrung gemacht: wenn die Atmung noch terminalen Typ hat (abnorme Tiefe, Krampfhaftigkeit der Inspiration mit weitem Aufsperren des Maules und der Nasenlöcher, lange Pausen), so geht das Tier noch nachträglich wicder zugrunde. In Nr. I23 war dieser Atmungstyp noch nicht überwunden und es bestand starker Exophthalmus mit Weite der Lidspalte. Erst nach dem Rückgang dieser Symptome konnte das Leben des Tieres als gesichcrt angesehen, das Tier seiner eigenen Atmung anvertraut werden. 
Die Gefahr bei zu frühzeitigem Aussetzen der künstlichen Respiration zeigt recht anschaulich der $\mathrm{V}$ e r s u ch ro4, aus dessen Protokoll hier die entscheidende Stelle eingefügt werden mag:

Versu chs-N r. I04. Gelbbraunes Kaninchen I800 g. 20. X. I909. Versuchsanordnung wie in Versuchs-Nr. I23. (S. 204).

Ioh 35' Totale Abschnürung von Aorta und Pulmonalis.

IOh $37^{\prime} 2 \mathbf{I}^{\prime \prime} 22$. (letzter) terminaler Atemzug.

Ioh $37^{\prime} 26^{\prime \prime}$ Einleitung künstlicher A t mung mit L uft. Ioh $39^{\prime} \quad$ A b s chn ü rung gelöst.

Ioh $39^{\prime} 3^{\prime \prime}$ Kräftige Herzaktion.

Ioh 40' I2" 2. Atemzug.

IOh $40^{\prime} 2 \mathrm{I}^{\prime \prime} 4$. ,

IOh $40^{\prime} 28^{\prime \prime} 7 . \quad$,

IOh $40^{\prime} 3 I^{\prime \prime} 8 . \quad$,

IOh $40^{\prime} 36^{\prime \prime} 9$. ",

Ioh $4 \mathrm{I}^{\prime} 5^{\mathrm{O}^{\prime \prime}} \mathrm{K}$ ünst 1 iche Atmung a usgesetzt.

Ioh 43' In der Minute 32 Atemzüge von termi$\mathrm{n}$ a le m $\mathrm{T}$ y $\mathrm{p}$.

Ioh 43' 40" Unveränderter Exophthalmus.

IOh 5I' 50" Kornealreflexe fehlen noch.

IOh 52' ${ }^{\prime} 0^{\prime \prime}$ Atmung in längeren Pausén und stark schnappend.

Ioh 53' 3" S pontane A t mung hat a u f gehört.

Ioh 53' I5" Künstliche Atmung wieder eingeleitet.

roh $55^{\prime}{ }^{\prime} 7^{\prime \prime}$ Keine Herzpulsationen $\mathrm{füh} \mathrm{lb}$ a r.

Ioh $56^{\prime} 2^{\prime \prime}$ Herzmassage durch den bereits verschlossenen Thorax hindurch.

Ioh $5^{\prime}$, Nach Offnung der Wunde direkte Herzmass a ge mit kräftiger Antwort des stillstehenden Herzens. Nur das Herzohr pulsiert frequent und oberflächlich.

IOh $59^{\prime} 20^{\prime \prime}$ Herzaktion kräftiger und gleichmäßig.

II 2 2' $3^{\prime \prime} 2$. spontaner Atemzug.

$\operatorname{IIh} 2^{\prime} 4^{\prime \prime} 7$.

IIh I2' 5 Atemzüge in der Minute.

IIh I4' $30^{\prime \prime}$ Künstliche Atmung mit Sauerstoff.

II I $4^{\prime} 50^{\prime \prime}$ Spontane Atmung wird frequenter.

IIh I $7^{\prime} I^{\prime \prime}$ Kornealreflex wiedergekehrt. Tränensekretion.

IIh I9' I0" Terminale Atemzüge wieder selten.

IIh 22' 50" Apnoe durch Sauerstoff.

In dem Versuch wurde also die künstliche Atmung ausgesetzt, während noch ausgesprochen terminaler Atmungstyp bestand, die Kornealreflexe noch fehlten und starker Exophthalmus vorhanden war. Die Folge war, daß bald Atmung und Herz aussetzten. Mit Hilfe von Herzmassage und später noch Sauerstoffatmung wurde 
clas Tier wiederbelebt. Die Korncalreflexe fehlte $\mathrm{n}$ in diesem Versuche 4I Minuten 40 Sekunden.

Diese Erfahrung haben wir mehrfach gemacht und ist für die praktische Verwertung der künstlichen Atmung bei der Embolieoperation zu beachten. Es erhellt aber so viel in physiologischer Richtung daraus, daß die terminale Atmungsform nicht auf jeden Fall zum normalen Typ überführen muß. Daraus ist mit größter Wahrscheinlichkeit zu entnehmen, daß es sich um verschiedene Zentren handelt, deren eines widerstandsfähiger ist als das andere. Würde die agonale Form eine Folge der Schädigung des Atmungszentrums in der Medulla sein, so wäre nicht einzusehen, warum, nachdem überhaupt einmal die Funktion wieder begonnen hat, sie nicht auch allmählich wieder normal werden solle. Gegen diesen Schluß kann allerdings eingewendet werden, daß die agonale Atmung nicht ausreichend ist, um die Zentren der Medulla oblongata zu ernähren und daher nachträglich eine neue Schädigung die weitere Erholung der Zentren hintanhält.

III. Abklemmung von Aorta und Arteria pulmonalis mit Sauerstoffzuführung in die Blutbahn.

Die weiteren Versuche befaßten sich mit der Frage, ob es gelingt, durch geeignete Einführung von sauerstoffhaltiger Flüssigkeit in die zum Gehirn führenden Blutbahnen während oder kurz vor der Zirkulationsaufhebung die Schädigung der Anämisierung zu verringern und die Dauer der ertragbaren Abklemmung von Aorta und Pulmonalis zu verlängern.

Im Anschluß an Untcrsuchungen über Wiederbelebung von Tieren mittelst arterieller Durchströmung des Herzens und der

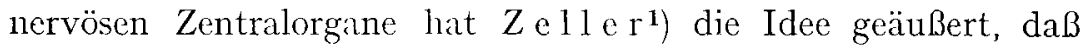
man die unter Druck erfolgende arterielle Infusion geeigneter sauerstoffhaltiger Lüsungen auch beim Herzstillstand nach der Tr e n d e l e $\mathrm{n}$ b u $\mathrm{r} g$ schen Embolieoperation versuchen solle. Als geeignete Injektionsflüssigkeit empfiehlt $Z$ eller ein Gemenge von hirudinhaltiger Lockescher Lösung mit Aderlaßblut, das mit

1) Zeller, Versuche zur Wiederbelebung von Tieren mittelst arterieller Durchströmung des Herzens und der vemösen Zentralorgane. Deutsche Zeitschr.

f. Chir. I go8, Bd. 95, S. 488 . 
Sauerstoff durchströmt werden soll. Diese Flüssigkeit hat er bei Hunden von einer dem B r o d i e schen Durchströmungsapparate nachgebauten Vorrichtung aus zentripetal unter einem Druck von IIO- I40 mm Hg in eine Carotis und damit in die Koronararterien des Herzens tranfundiert. Er konnte auf diese Weise erfolgreiche Wiederbelebungsversuche an entbluteten und an durch Chloroform getöteten Hunden ausführen. Wie aus seinen Versuchsprotokollen hervorgeht, sind aber bei dieser Versuchsanordnung infolge zu hohen Sauerstoffdruckes im Apparat auch mehrere Fälle von tödlicher Sauerstoffgasembolie vorgekommen. Im Hinblick auf diese Möglichkeit und vor allem auf die zeitraubende Herstellung der Lösung und ihre umständliche Applizierung glauben wir nicht an eine praktische Bedeutung der Z elle rschen Idee für die Behebung eines Herzstillstandes nach der Trendele n burgschen Operation. Zudem ist die bei unseren Versuchstieren und auch beim Menschen nach der Trendelenburgschen Operation vorhandene Herzschädigung, wie wir oben ausführlich auseinandergesetzt haben, viel schwererer Natur als die bei der Zellerschen Anordnung (Chloroform, Verblutung).

Wir haben ebenfalls, wenn auch unter anderen Gesichtspunkten wie $Z$ el1er arterielle Durchströmungsversuche an Tieren vorgenommen. Wir führten unter einem Druck, der den normalen Blutdruck etwas überstieg, arterielle Infusionen in zentrifugaler Richtung durch eine Carotis ins Gehirn aus zu einer Zeit, wo die Abschnürung an der Aorta und Art. pulmonalis noch lag oder einige Male auch ganz kurz vor Anlegung dieser Konstriktion. Diese Infusionen und Injektionen bezweckten also nicht eine Wiederbelebung der alterierten Gehirnzentren, sondern sie sollten die schädigende Wirkung der Anämisierung von vornherein hintanhalten oder wenigstens abschwächen.

Wir ordneten zunächst eine Reihe von Versuchen so an, daß wir, während die Umschnürung an den großen Gefäßen lag, von einer Carotis aus das Gehirn durchströmen und die Flüssigkeit aus der Jugularvene der anderen Seite abfließen ließen. Der Kreislauf war dabei durch Umschnürung der Bauchaorta und der oberen Extremitäten verkleinert worden. Zur Durchströmung benutzten wir eine durch den Sauerstoffstrom arterialisierte erwärmte L o ckesche Lösung, in der sich eine Suspension von einem 
Experiment. Untersuchungen üb. d. Wirkung von künstl. Atmung usw. 2 I I

anderen Kaninchen entnommener roter Blutkörperchen (auf $600 \mathrm{ccm}$ L o ck e scher Lösung $40 \mathrm{ccm}$ Blut) befanden. In einer anderen Versuchsreihe injizierten wir nun mehrere $\mathrm{ccm}$ dieser Lösung während der Abklemmung durch eine Carotis ins Gehirn. Durch beide Versuchsanordnungen lie $B$ sich die Abklemmungszeit nicht bis zu einer Grenze verlängern (4-5 Minuten), die wir bei der viel einfacheren künstlichen Sauerstoffatmung noch überschreiten konnten.

Macht man während der Abklemmung mit der angegebenen arterialisierten Blutsuspension eine Injektion durch eine Carotis in die Hirngefäße, so kommt der Sauerstoff zweifellos in durchaus physiologischer Form an die Gehirnzentren heran. Da aber eine Anreicherung der Erythrocyten mit Sauerstoff nicht möglich ist, so könnte ein Mehr von Sauerstoff nur in der Suspensionsflüssigkeit absorbiert ins Gehirn kommen. Diese Menge ist wahrscheinlich nicht sehr groß und wird bald verbraucht sein. Unser Bestreben ging aber dahin, den Sauerstoff in unschädlicher Form i m Ü b e r s ch u $B$ ins Gehirn zu bringen, um womöglich auf diese Weise für eine Zeitlang einen Ersatz für die fehlende Sauerstoffzufuhr vom Blute aus zu schaffen.

Gärtner ${ }^{1}$ ) hat gezeigt, daß man ohne Schaden gasförmigen Sauerstoff in periphere Venen bringen kann. Küttner ${ }^{2}$ ) empfahl auf Grund experimenteller Untersuchungen die Infusion von sauerstoffgesättigter Kochsalzlösung. Für unsere Zwecke kamen alle Applikationsarten, bei denen der Sauerstoff durch Vermittlung der venösen Bahnen in den Körper verbreitet wird, nicht in Betracht, weil dann, wenn ein Embolus in der Lungenarterie den Kreislauf verlegt, kein Sauerstoff ins Gehirn gelangen kann. Zeller fand bei Anwendung der Küttnerschen Sauerstoff-Kochsalzlösung zu seiner unter Sauerstoffdruck erfolgenden zentripetalen Durchströmung (s. o.) in den Koronararterien zahlreiche kleine Glasbläschen, die nach seiner Ansicht aus der benutzten Lösung frei geworden sind. Wir fürchteten, daß bei intravenöser

I) Gärtner, Čber intravenöse Sauerstoffinfusionen. Wiener klin. Wochenschrift igo2, S. $696-727$.

2) Küttner, Zur Frage des künstlichen Blutersatzes. Verhandl. der Deutschen Gesellsch. f. Chir., 32. Kongr. Ig03. 
Sauerstoffzuführung die Lungenkapillaren doch gelegentlich verstopft werden könnten; das Intaktbleiben der Lunge aber war für unsere Versuche eine unerläßliche Voraussetzung.

Um möglichst unabhängig von allen zeitraubenden Vorbereitungen in der Herstellung sauerstoffhaltiger Lösungen zu sein, suchten wir nach einer Substanz, die bei der Lösung in Wasser möglichst feine Sauerstoffbläschen entwickelt und zugleich das Lösungsmittel durch Absorption stark mit Sauerstoff anreichert. Eine derartige Substanz fanden wir auf den Rat von Herrn Privatdozenten D r. O. Gros im Natrium percarbonicum. Dieser Körper (Natrium percarbonicum purissimum), den wir luftdicht in kleinen braunen Flaschen verschlossen von Merck in Darmstadt bezogen, stellt ein weißes Pulver dar, das bei der Lösung in Wasser oder physiologischer Kochsalzlösung unter starkem Aufschäumen reichlich Sauerstoff entwickelt. Läßt man die erste stürmische Entwicklung des Gases vorübergehen, so bleibt dann eine außerordentlich feinblasige Sauerstoffemulsion übrig. Diese Flüssigkeit enthält auch dann, wenn der Sauerstoff vollkommen abgeschäumt ist, noch sehr reichlich absorbiertes Sauerstoffgas. Wir konnten uns hiervon häufig dadurch überzeugen, daß wir die nicht mehr schäumende Flüssigkeit im Reagenzglas mit Blut zusammenbrachten. Es entstand dann unter neuer Bläschenbildung eine hellrote Verfärbung des vorher dunklen Blutes. Nach der Sauerstoffabgabe bleibt nur eine bei den gewählten Konzentrationen harmlose Sodalösung übrig. Vielleicht entfaltet die so im Blute gebildete Sodalösung sogar wünschenswerte Eigenschaften, indem sie seine Kohlensäureüberladung verringert. Denn nach W e il soll Soda die Eigenschaft des Blutes, die während der Apnoe gebildete Kohlensäure zu binden, erhöhen. Er hat durch Injektion von Soda in die Blutbahn eine durch Ventilation mit atmosphärischer Luft erzeugte Apnoe von 26 auf 42 Sekunden verlängern können.

Voraussetzung für die Brauchbarkeit der mit Natrium percarbonicum hergestellten Sauerstoffemulsion war natürlich die, daß die Sauerstoffbläschen die Gehirnkapillaren passierten. Zur Prüfung dieser Verhältnisse stellten wir besondere Versuche an, deren Resutat wir vorweg nehmen wollen: ideal waren die Sauerstofflösungen nicht. Es wurden eine Reihe von cerebralen Störun- 
gen beobachtet, die einen embolischen Verschluß der Gehirnkapillaren wahrscheinlich machten. Alle diese Störungen waren aber reparabler Natur; sie gingen ziemlich rasch wieder zurück und die Tiere blieben am Leben. Die mit Natrium percarbonicum bereiteten Lösungen zeigten jedenfalls eine große Überlegenheit gegenüber den Wasserstoffsuperoxydsuspensionen, die, ins Gehirn gebracht, wie Fettemulsionen rasch den Tod der Versuchstiere herbeiführen. Ganz geringfügiger Natur waren die Hirnstörungen dann, wenn gut abgeschä um te Natrium-percarbonicumLösungen zur Verwendung kamen.

Die Versuche nahmen wir so vor, daß wir bei Kaninchen in Urethannarkose eine Carotis durchschnitten, in das zentrale Stück zur Registrierung des Blutdrucks eine Kanüle einbanden und von dem peripheren Teil aus die Sauerstofflösungen langsam in die Hirngefäße injizierten.

Wir geben im folgenden kurz die Auszüge einiger Versuchsprotokolle wieder:

Versuch Nr. I32. Nach der Injektion von $1 / 2 \mathrm{ccm}$ frischer und nach der $2 \frac{1}{2}$ Minuten später vorgenommenen zweiten, von $\mathrm{I}, 5 \mathrm{ccm}$ abgeschäumter I proz. Natrium-percarbonicum-Lösung durch die linke Carotis ins Gehirn erfolgt keine Änderung der Blutdruck- und Pulskurve. 9 Minuten später werden in derselben Weise $2 \mathrm{ccm}$ frischer Lösung injiziert. Kurzer Krampfanfall mit geringer Blutdrucksteigerung. Tier bleibt leben.

$\mathrm{V}$ ersuch $\mathrm{Nr}$. I33. Injektion von $3 \mathrm{ccm}$ I proz. Natrium-percarbonicum-Lösung ins Cerebrum. Kurzer Krampfanfall. 3 Minuten währende, dann vorübergehende Steigerung des Blutdruckes und $I^{1} / 2$ Minuten dauerndes Aufhören der Atmung. Dann normale Verhältnisse. $1 / 2$ Stunde nach der ersten neue Injektion von $3 \mathrm{ccm} 1 / 2$ prozentiger Lösung. Kurze Krämpfe. Mäßige Steigerung des Blutdruckes; nach I Minute wieder normaler Druck. Nach weiteren 8 Minuten Injektion von $2 \mathrm{ccm}$ Fettemulsion. Krämpfe. Kornealreflexe, Atmung verschwinden dauernd. Tod 8 Minuten nach der Injektion.

Versuch Nr. I34. Zwei in einer Pause von $4 \frac{1 / 2}{2}$ Minuten vorgenommene Injektionen von je $3 \mathrm{ccm}$ I proz. Natrium-percarbonicumLösung ins Gehirn bringen bei einem Kaninchen das erstemal eine erhebliche, das zweitemal eine geringere vorübergehende Blutdrucksteigerung hervor. Kornealreflexe, Pulse, Atmung wurden nicht beeinflußt. Nach einer an demselben Tiere in gleicher Weise vorgenommenen Injektion von Fettemulsion steigt der Blutdruck nach Io Sekunden stark an und fällt dann allmählich zum Nullwert ab. Kornealreflexe 
und Atmung verschwinden rasch, die Pulse nach etwas längerer Zeit. Tod 6 Minuten nach der Injektion.

V e r s u ch Nr. I35. Injektion von $3 \mathrm{ccm}$ I proz. Natrium-percarbonicum-Lösung durch die linke Carotis ins Gehirn. Sofort eine etwa 2 Minuten anhaltende Blutdrucksteigerung; sonst bleibt das Tier normal. $81 / 2$ Minuten später neue Injektion von $3 \mathrm{ccm}$ einer $1 / 2$ proz. Lösung. Geringe, etwa $1 / 2$ Stunde andauernde Steigerung des Blutdruckes mit vereinzelten kurzen Krampfanfällen. Dann Injektion von $2 \mathrm{ccm} 1 / 2$ proz. Wasserstoffsuperoxydlösung. Blutdruck steigt vorübergehend ziemlich stark an, fällt aber dann rasch ab. Atmung und Kornealreflexe verschwinden 20 Sekunden nach der Injektion. Tod 3 Minuten nach der Injektion.

Als Resultat dieser Versuche sehen wir also im Gefolge der Natrium- percarbonicum-Injektionen in die Hirngefäße Erscheinungen auftreten, die als Reizerscheinungen des Gehirns, veranlaßt durch vorübergehende Zirkulationsstörungen infolge Kapillarembolie mit Sauerstoffbläschen aufzufassen sind. Am regelmäßigsten, wenn auch nicht immer, wurde eine Steigerung des Blutdruckes beobachtet. Während der Injektion sistierte häufig die Atmung, doch stellte sie sich immer in kurzer Zeit wieder her. Auch motorische Reizerscheinungen, wie kurze Zuckungen der Schwanz-, Bauch- und Extremitätenmuskulatur sowie ganz kurze Krampfanfälle wurden namentlich bei der wiederholten Injektion der Sauerstofflösungen gesehen. Einige Male schrien die Tiere, eine Beobachtung, die Nysten bei Sauerstoffinfusionen im Blut verzeichnet und $\mathrm{G}$ ä r $\mathrm{t} n$ e r als Gehirnreiz durch zu große und zu stoßweise ausgeführte Einspritzung des Sauerstoffs aufgefaßt hat. Alle diese Erscheinungen stehen aber in starkem Gegensatz zu denen, die nach Injektionen von Wasserstoffsuperoxyd oder Fettemulsion in die Gehirnarterien zu beobachten sind. Hier geht regelmäßig der Blutdruck stark in die Höhe und fällt dann ziemlich rasch zum Nullwert ab. Atmung und Cornealreflexe verschwinden einige Sekunden nach der Injektion dauernd und die Tiere gehen nach einigen Minuten zugrunde. Als Beleg für die relative Unschädlichkeit der Natrium-percarbonicum-Lösungen können wir dann weiterhin die Versuche anführen, bei denen die Lösung nach A n legung der Gefäßkonstriktion in die Hirngefäße injiziert wurde. Überschritten hier die Abklemmungszeiten nicht einen gewissen Wert, so blieben die Tiere am Leben. 
T a be 1 l e $\mathrm{V}$.

Abklemmung von Aorta und Pulmonalis mit Injektion von Natrium percarbonicum ins Gehirn.

\begin{tabular}{|c|c|c|c|c|c|c|c|c|}
\hline \multirow{2}{*}{ 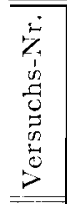 } & \multirow[b]{2}{*}{ Datum } & \multirow[b]{2}{*}{$\begin{array}{c}\text { Ge- } \\
\text { wicht }\end{array}$} & \multirow{2}{*}{ 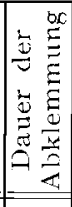 } & \multicolumn{3}{|c|}{ Injektion } & \multirow[b]{2}{*}{ Ausgang } & \multirow[b]{2}{*}{ Bemerkungen } \\
\hline & & & & Ort & Menge & Zeitpunkt & & \\
\hline I I & $30 . \mathrm{X} .08$ & 2050 & $3 / 2$ & 1. Carotis & $\begin{array}{l}\text { I ccm } \\
\text { I proz. }\end{array}$ & a. compr. & lebt & \\
\hline I 3 & 4. XI. & 1800 & 312 &, & $\begin{array}{l}\text { I } \\
\text { I } \\
\text { I proz }\end{array}$ & 112 & $\dagger$ & $\dagger$ nach $4: 2$ \\
\hline I 4 & I6. XI. & I 900 & $3 \%$ & , & $\begin{array}{l}1 / \mathrm{ccm} \\
\text { I proz. }\end{array}$ & a. compr. & $\operatorname{leb} t$ & \\
\hline 16 & 19. XI. & I950 & $31 \%$ & ," & $\begin{array}{l}1 \\
1 \\
\text { I }\end{array}$ & $1 \because \quad$, & lebt & $\begin{array}{l}4 \frac{1}{9} \text { Aussetzen } \\
\text { der Atmung. }\end{array}$ \\
\hline I 29 & I3. I. IO & 1800 & $31 / 2$ & , & $\begin{array}{l}4 \mathrm{ccm} \\
\text { I proz. }\end{array}$ & $\begin{array}{c}\mathrm{I}^{\prime} \mathrm{p} \\
\mathrm{compr}\end{array}$ & lebt & $\begin{array}{c}6^{\prime} \text { Aussetzen } \\
\text { der Atmung } \\
\text { Kornealreflexe } \\
\text { fehlen I } 2^{\prime} \text {. }\end{array}$ \\
\hline 130 & I 5. I. 10 & 1850 & $3 \%$ & ", & $\begin{array}{l}3 \mathrm{ccm} \\
\text { I proz. }\end{array}$ & $\begin{array}{l}\mathrm{I}^{\prime} 5^{\prime \prime} \mathrm{p} . \\
\text { compr. }\end{array}$ & lebt & $\begin{array}{l}3^{\prime} 50^{\prime \prime} \text { Fehlen } \\
\text { der Atmung } \\
\text { Kornealrefl. feh- } \\
\text { len } 0^{3 / 4} \text { ' lang. }\end{array}$ \\
\hline I 3 I & II. I. IO & 1600 & $31 / 2$ & ," & $\begin{array}{l}3 \mathrm{ccm} \\
1 \mathrm{croz} .\end{array}$ & I'p.compr. & $\dagger$ & $\operatorname{nach} 51 / \mathbf{y}^{\prime} \dagger$ \\
\hline 15 & I $7 . \mathrm{XI} .08$ & 3820 & 4 & ", & $\begin{array}{l}3 \mathrm{ccm} \\
\text { I proz. }\end{array}$ & , & $\dagger$ & nach $5^{\prime}+$ \\
\hline 12 & 2. XI. & 2 I 50 & 4 & ", & $\begin{array}{l}3 \mathrm{ccm} \\
\text { I proz. }\end{array}$ & $5:$ p. cpr. & $\dagger$ & nach $71^{\prime} \dagger$ \\
\hline 17 & 20. XI. & 1900 & 4 & ", & $\begin{array}{l}3 \mathrm{ccm} \\
\text { I proz. }\end{array}$ & ", & $\dagger$ & Herz luxiert. \\
\hline I8 & 24. XI. & 1850 & 4 & ," & $\begin{array}{l}3 \mathrm{ccm} \\
1 \text { proz. }\end{array}$ & , & $\dagger$ & $\operatorname{nach} 7^{\prime} \dagger$ \\
\hline I9 & 25. XI. & 2400 & 4 & ", & $\begin{array}{l}3 \mathrm{ccm} \\
1 \text { proz. }\end{array}$ & ," & $\dagger$ & $\operatorname{nach} 53 / 4 \dagger$ \\
\hline 20 & $27 . \mathrm{XI}$. & 2350 & 4 & , & $\begin{array}{l}2^{1}: \mathrm{cc} \\
1 \text { proz. }\end{array}$ & 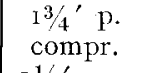 & $\dagger$ & \\
\hline $\begin{array}{l}2 \mathrm{I} \\
23\end{array}$ & $\begin{array}{l}\text { 30. XI. } \\
\text { 2. XII. }\end{array}$ & $\begin{array}{l}2550 \\
1850\end{array}$ & $\begin{array}{l}4 \\
4\end{array}$ & 1. Ventr. & & $\begin{array}{l}\text { I } 1 / 2, \text { p. c. } \\
21 / 2, \text { a. c. }\end{array}$ & $\begin{array}{l}\dagger \\
\dagger\end{array}$ & \\
\hline 24 & 2. XII. & 1300 & 4 & & & $\mathrm{I} / \mathrm{i}^{\prime} \mathrm{a}, \mathrm{c}$ & $\dagger$ & $\begin{array}{c}\text { Künstliche } \\
\text { Atmung. }\end{array}$ \\
\hline 46 & 28. IV.09 & 2100 & 4 & 1. Carotis & & a. compr. & + & $\begin{array}{l}\text { Kombinat. mit } \\
\text { H. M. u. K. A., } \\
\text { vorh. vorüber- } \\
\text { gehende Herz- } \\
\text { erholung. }\end{array}$ \\
\hline 44 & 26. III.09 & 1700 & $4:$ & "' & \begin{tabular}{|}
$5 \mathrm{ccm}$ \\
I proz. \\
abge- \\
stan- \\
den
\end{tabular} & $\begin{array}{l}\text { a. compr. } \\
2 \mathrm{ccm} \\
15^{\prime \prime} \mathrm{p} . \mathrm{c} \\
3 \mathrm{ccm}\end{array}$ & $\begin{array}{c}\dagger \\
\text { vorüber- } \\
\text { gehende } \\
\text { Herz- } \\
\text { erholg. }\end{array}$ & $\begin{array}{l}\text { Agonale Atem- } \\
\text { züge während } \\
\text { d. Kompress. }\end{array}$ \\
\hline
\end{tabular}


Alles Nähere über diese Versuche geht aus $\mathrm{T}$ a b e 11 e V hervor. Diese Tabelle zeigt, daß bei Injektion der Sauerstofflösung ins Gehirn in 7 Versuchen 5 Tiere eine $3^{1 / 2}$ Minuten währende Abklemmung der Aorta und Pulmonalarterie vertragen haben. Die Injektion erfolgte hier kurz vor oder nach der Abschnürung der Gefäße. Eine Zirkulationsaufhebung von 4 Minuten Dauer hat dagegen kein Tier ausgehalten. Aus diesen Versuchen geht hervor, daß bei der Sauerstoffzuführung die Tiere die Abklemmung von Aorta und Art. pulmonalis I Minute länger vertragen haben als ohne Sauerstoff. Als Erklärung müssen wir die trotz der fehlenden Blutzirkulation erzeugte Sauerstoffversorgung der Cerebralmasse anführen. Die Resistenz der Hirnelemente ist durch die Sauerstoffinjektion gesteigert worden.

Das Ergebnis der Versuche betrachten wir nur als theoretisch interessant. Am Menschen wären die Natrium-percarbonicumInjektionen in die Hirngefäße, wenn auch technisch ausführbar, doch wegen der Gefahr einer Hirngefäßembolie nicht zulässig. Ihre günstige Wirkung können wir, wie aus dem vorigen Kapitel hervorgeht, auf bequemere Weise durch die künstliche Atmung erreichen und noch übertreffen.

Immerhin möchten wir die mit Natrium-percarbonicum in der beschriebenen Weise hergestellten Lösungen für Infusionen in p e r i p h e r e Venen empfehlen. Sie sind außerordentlich einfach und rasch herstellbar und bieten deswegen einen geeigneten Ersatz für die unbequemen Kombinationen der $K$ ü $t \mathrm{t} n$ e $r$ schen und $\mathrm{Z}$ e 11 e r schen Sauerstofflösungen.

IV. Abklemmung von Aorta und Pulmonalis mit $n$ ach folgender Herzmassage.

In dem von dem einen von uns ( $\mathrm{S}$ i e ve r $\mathrm{s}^{1}$ ) nach der Tre nd e l e n b u r g schen Methode operierten Falle von Lungenarterienembolie, bei dem es zum ersten Male gelang, den Kranken I4 Stunden am Leben zu erhalten, wurde der während der Extraktion der Embolie eingetretene Herzstillstand durch einige auf den Herzmuskel rhythmisch ausgeübte Kompression beseitigt. Es kehrte

I) Sievers, Ein Fall von Embolie der Lungenarterie nach der Methode von Trendele n burg operiert. Deutsche Zeitschr, f. Chir. I908, H. 3. 
in kurzer Zeit die normale Herzaktion wieder. Dieser Erfolg und die in den letzten Jahren insbesondere von $\operatorname{Prus}^{1}$ ), v. Cackowic, d'Halluin²), Kemp und Gardner ${ }^{3}$ ), sowie B. Müller ${ }^{4}$ u. a. publizierten, zum Teil recht günstigen Erfahrungen veranlaßten uns, die Brauchbarkeit dieses Mittels auch bei unseren Wiederbelebungsversuchen nach länger dauernden Kompressionen von Aorta und Pulmonalis zu studieren.

Gerade auf Grund der beiden Arbeiten von Prus und v. C a c k ow ic mußten wir uns von vornherein sagen, daß die bei Tierversuchen erhaltenen Resultate nicht ohne weiteres auf den Menschen übertragen werden durften. Prus, der an Hunden experimentierte, erhielt folgende Resultate: von 44 durch Tracheaverschluß erstickten Tieren gelang es, 33 wiederzubeleben, und zwar nachdem zum Teil längere Zeiträume, in einem Fall I Stunde zwischen Herzstillstand und Beginn der Wiederbelebungsversuche verstrichen war. In 2I Versuchen mit Chloroformstillstand des Herzens gelang $16 \mathrm{mal}$ die Wiederbelebung; hierunter fanden sich 2 Tiere, bei denen I Stunde lang der Herzstillstand angedauert hatte. Sehr viel schlechter waren die Resultate Pru s' bei 'Todesfällen durch elektrischen Schlag, indem bei 35 Versuchen nur $5 \mathrm{mal}$ selbständige regelmäßige Herzaktion wiederkehrte.

Stellen wir demgegenüber die an Menschen erzielten Erfolge mit der direkten Herzmassage, wie sie v. $\mathrm{C} \mathrm{a} \mathrm{ck} \mathrm{ow} \mathrm{i} \mathrm{c} \mathrm{aus} \mathrm{der}$ Literatur gesammelt und kritisch gesichtet hat, so tritt das Mißverhältnis sehr hervor: nur in $2 \mathrm{~F}$ ällen, wo zwischen Eintritt der Synkope und Erfolg der Massage wenigstens Io Minuten verstrichen sind, voller Wiederbelebungserfolg, in + mehrstündiger und in 3 kurzdauernder Erfolg, wobei die ver-

I) Prus, Über die Wiederbelebung in Todesfällen infolge von Erstickungen, Chloroformvergiftung und elektr. Schlage. Wiener klin. Wochenschr. I900, Heft $20-21$.

2) d' Hallu in, I te massage du coeur. La presse médicale I904, Nr. 44. - Journ. de sciences médicales de Lille 1905. - Thèse de Lille 1904.

3) Ke m p und $\mathrm{Gar}$ in $\mathrm{er}$, Exper. researches on resuccitation after de ath chloroform. New-York and Philadelphia medic. journal 1904, Nr. 19-200.

4) B. I ûl I er, Über Herzmassage bei Tod durch Ersticken und Vergiftung, scwie bei Synkope in der Narkose. Wiener klin. Rundschau I 905. Nr. 50- 52. 
schiedenen Massagemethoden bei eröffnetem und uneröffnetem Thorax vereint gerechnet sind.

In erster Linie waren es die überraschenden Erfolge P r u s', die uns die Anwendung der Massage zur Bekämpfung der Herzschwäche nach Abklemmung von Aorta und Pulmonalis aussichtsvoll erscheinen ließen. Andererseits war zu erwarten, daß gerade unsere Versuchsanordnung geeignet war, die Natur und den Grad der Herzwirkung der Massage zu ergründen resp. kritisch zu beleuchten.

$\mathrm{Da} B$ für uns der thorakale Weg der Massage der gegebene war, verstand sich von selbst. Andererseits waren wir, da es uns, wie immer, auf die Erhaltung der Tiere ankam, darauf angewiesen, die Massage von der linksseitigen Thoracotomiewunde aus vorzunehmen. Wir führten sie dann so aus, wie $\mathrm{Prus}$ in einzelnen Fällen bei seinen Hunden, daß der Zeigefinger der rechten Hand in die linke Pleurahöhle ein- und hinter das Perikard geführt, der Daumen auf das Brustbein gelegt wurde. War die zur Unterbindung der Arterien gesetzte Perikardwunde nicht zu groß, so gelang es ohne Schwierigkeit, die Kammern gleichzeitig mittelst leichten Druckes des von unten nach oben über das Herz weggleitenden Zeigefingers zu entleeren. Weniger günstig lagen die Verhältnisse bei größerer Perikardialwunde, indem das Herz dann die Möglichkeit hatte, nach oben auszuweichen. Doch bereitete das keine unüberwindbare Schwierigkeit, es mußte in solchen Fällen nur mehr oder weniger das Ausstreichen von unten nach oben durch das reine Auspressen von hinten nach vorne gegen das Brustbein ersetzt werden. Wir sind der Überzeugung, daß die geschilderte Technik bei dem kleinen Kanịnchenherzen völlig ausreichend ist, vorausgesetzt, daß eben eine wirkliche Entleerung der Kammern erreicht wird und sie hat man sicher im Gefühl. Eine eigentliche konzentrische Verkleinerung der Kammerlumina, wie sie bei den selbständigen Kontraktionen der Kammerwandungen und Septummuskulatur zustande kommt, kann man mit der Massage doch nicht erzielen, es ist daher auch indifferent, ob das Ausdrücken durch Druck von hinten nach vorne oder wie es Prus bei der Mehrzahl seiner Experimente gemacht hat, durch seitliche Kompression bewirkt wird. Die letztere Anwendungsform bietet bei größeren Herzen wie dem des Hundes 
Experiment. Untersuchungen üb. d. Wirkung von künstl. Atmung usw. 219

nur den Vorteil, daß man mehrere Finger resp. die ganze Hand zur Massage benutzen kann und in solchen Fällen mehr Garantie für die wirkliche Entleerung hat. Beim Kaninchenherzen genügt vollkommen der eine Finger.

Unwahrscheinlich erscheint es uns auch, daß die beiden Formen der Massage in ihrer Beeinflussung des Atrioventrikularverschlusses einen Unterschied involvieren. Es ist sehr wahrscheinlich, daß in beiden Fällen dieser Verschluß kein vollkommener ist und ein Teil der Blutmenge in die Vorhöfe zurückgeworfen wird. Der Verschluß der Segelklappen erfolgt beim gesunden Herzen ja folgendermaßen: im Momente des Uberdrucks in den Kammern legen sich die Segel aneinander und werden durch die Chordae tendineae am Umschlagen gehindert. Die dauernde Spannung letzterer während der durch die Kammerkontraktion bedingten Annäherung der Herzspitze an die Basis wird durch aktive Kontraktion der Papillarmuskeln garantiert. Dieser letzte Faktor fällt beim gelähmten Herzen weg und es wirft sich nun die Frage auf, ob das Fehlen der Papillarmuskelaktion durch das Fehlen der Längsachsenverkürzung des Herzens gerade kompensiert wird, oder ob durch das Ausdrücken des Herzens in der Längsrichtung die Chordae derartig gespannt werden, daß die Segel am Zusammenklappen gehindert werden. Mit der Beantwortung dieser Frage steht und fällt die der Herzmassage nachgerühmte, , $\mathrm{k}$ ü nstlic he $\mathrm{Zirk}$ ul a t i on “. Eine solche kann natürlich nur vorhanden sein, wenn die in die Aorta geworfene Blutmenge jedesmal eine ganz neue ist, wenn also dem linken Vorhof stets frisch arterialisiertes Blut aus der Lungenvene zugeführt wird.

Außer durch ,,künstliche Zirkulation“ durch den Körper und besonders die Koronararterien hindurch soll nach d'Hallu in die Massage auf folgende Weise wirksam sein:

I. Durch die Entleerung deserweiterten Herz e n s und die damit aufgehobene Schädigung des Myokards durch Dehnung;

2. durch mechanisch ex $\mathrm{c}$ itie ren $\mathrm{de} W$ irkung auf den Muskel.

v. Cack ow i c nimmt an, daß alle Faktoren gemeinschaftlich in Aktion treten. Wir werden zu dieser Frage erst Stellung 
nehmen, nachdem wir kurz die Resultate unserer Vers u ch e mitgeteilt haben.

Zunächst sei hervorgehoben, daß es nicht gelang, mittelst direkter thoracaler Herzmassage a ll e in eine Verlängerung des Spatiums zu erhalten, welches wir als den Grenzwert für die Widerstandsfähigkeit der Kaninchen gegen totale Abklemmung von Aorta und Pulmonalis im I. Abschnitt kennen gelernt hatten, nämlich über $2 \frac{1}{2}$ Minuten hinaus. Wurde nach 3 Minuten währender Abklemmung mit der Massage begonnen, ohne daß gleichzeitig künstliche Atmung eingeleitet wurde, so kam es wohl zunächst zu kräftigen Kontraktionen des Herzmuskels, die aber genau wie bei den obenerwähnten Versuchen ohne Massage bald nachließen, mochte die Massage fortgesetzt werden oder nicht. Der Herzmuskel wurde schlaff und antwortete auf die mechanischen Reize bald nicht mehr.

Dies Ergebnis hat nichts Überraschendes, sagt nur soviel, $\mathrm{da} B$ in diesem Stadium des Scheintodes durch Zirkulationsunterbrechung die beiden ersten wirksamen Faktoren der Massage, die Entleerung des Herzens und die mechanische Reizung des Muskels das Leben nicht wieder anzufachen vermögen. Die Kohlensäureintoxikation steht im Vordergrund und muß durch Zuführung von Sauerstoff in erster Linie gehoben werden. Daher kann auch eine allenfalls durch die Massage erzielte künstliche Zirkulation nichts fruchten.

Andererseits hat natürlich die Anwendung der Massage bei gleichzeitiger Einleitung künstlicher Respiration nach 3 Minuten keine Beweiskraft für ihre Wirksamkeit, da die Wiederbelebung durch künstliche Atmung ohne Herzmassage nach dieser Zeit keine Schwierigkeiten macht. Absolut bewiesen ist der wiederbelebende Einfluß der Herzmassage nur dann, wenn, wie in einzelnen Versuchen von $\mathrm{Prus}$, bei kombinierter Anwendung von künstlicher Atmung und Herzmassage die spontane At mung wiederkehrt vor dem Wjedereintritt normaler Herzaktion. Denn die künstliche Respiration kann natürlich nur auf dem Umwege über die normale selbsttätige Herzaktion zu einer Restitution der Funktionen der Medulla oblongata führen. Nun haben wir in u n s e re n Versuchen n i e - 
m a ls eine spontane Atmung vor der Herzaktion wiederkehren sehen. Es muß dabei aber eine Differenz in der Versuchstechnik berücksichtigt werden, die diesen Unterschied bedingen kann. Wir haben die Massage nur ausnahmsweise in Form der $\mathrm{D}$ a u e $\mathrm{r}$ $m$ ass a ge angewendet, für gewöhnlich aber auf die Herstellung einer länger dauernden ,k ü nstlichen $Z$ irkulation" verzichtet und in erster Linie das $\mathrm{mechan}$ is $\mathrm{che}$ Moment im Auge behaltend, nur in der Weise massiert, daß immer nach einzelnem, auch häufigerem Ausdrücken des Herzens das Verhalten des Herzmuskels beobachtet wurde. Erfolgten kräftige Antworten in Form von Herzmuskelkontraktionen, so wurde nicht weiter massiert, sondern die Massage erst dann wieder aufgenommen, wenn die spontanen Zusammenziehungen wieder schwächer wurden resp. sich nicht verbesserten. Diese Technik basierte darauf, daß wir bei unseren ersten Versuchen mit der Massage mehrfach die Beobachtung machten, daß die nach einigen rhythmischen Reizen einsetzenden kräftigen Zusammenziehungen bei Fortsetzung der Massage (jetzt natürlich unter Kombination mit künstlicher Atmung) unwiederbringlich aufhörten, so daß wir uns des entschiedenen Eindruckes der Schädigung durch die Fortsetzung der Massage bei resp. gegen die spontane Herztätigkeit nicht erwehren konnten.

So in Vers u ch Nr. 49. (4. V. I909, Kaninchen 2000 g.) Dauer der Abklemmung 4/1/2'.

6h $32^{\prime} 30^{\prime \prime}$ Lösung der Schlinge um Aorta und Pulmonalis.

Einleitung künstlicher Atmung.

6h $3 z^{\prime} 45^{\prime \prime}$ Herzschläge oberflächlich.

6h 33' Herzmassage.

6h $33^{\prime} 25^{\prime \prime}$ Kräftige Herzaktion.

Massage fortgesetzt.

6h $34^{\prime} 45^{\prime \prime}$ Herztätigkeit wird schlecht. Kammer zieht sich kaum zusammen. Vorhof, der h e $11 \mathrm{r}$ ot g e f ä r b t ist, flimmert.

6h 45' Herz ganz schlecht. Abbrechen des Versuchs.

Da es sich um einen $4 \frac{1}{2}-\mathrm{M}$ in u $\mathrm{t}$ e $\mathrm{n}$-Versuch handelte, bei dem freilich die künstliche Atmung nach Lösung der Arterienschnürung eingeleitet worden war, war gerade von der Herzmassage ein Erfolg zu erwarten. Vergleichen wir mit dem Obigen 
das Protokoll eines Versuches mit der veränderten Technik, so wird ihre Berechtigung damit erwiesen.

Versuch Nr. 5I. Kaninchen I400 g., 6. V. Igog. Dauer der Abklemmung 5'.

I $2 \mathrm{~h} 46^{\prime} \quad$ Lösung der Schnürung.

Sofortige Einleitung der künstlichen Atmung mit atmosphärischer Luft.

I $2 \mathrm{~h} 46^{\prime} \mathrm{I}^{\prime \prime}$ Herzmassage in Form von 4 mal Ausdrücken des Herzens in schneller Aufeinanderfolge.

I2h 46'45" Herztätigkeit besser.

I $2 \mathrm{~h} 46^{\prime} 5 \mathrm{O}^{\prime \prime}$ Herz noch sehr erweitert.

I $2 \mathrm{~h} 46^{\prime} 53^{\prime \prime}$ Einmaliges Ausdrücken des Herzens.

I $2 \mathrm{~h} 47^{\prime} 3 \mathrm{O}^{\prime \prime}$ Herzaktion viel kräftiger.

I $2 \mathrm{~h} 48^{\prime} \quad$ Herzvolumen verkleinert.

Lebhafte Kontraktionen mit annähernd normalem Rhythmus.

I $2 \mathrm{~h} 48^{\prime} 30^{\prime \prime}$ I. spontaner Atemzug.

I2h $49^{\prime} \quad$ Künstliche Atmung fällt weg.

I $2 \mathrm{~h} 55^{\prime} \quad$ Kornealreflex vorhanden.

Ih $5^{\prime}$, Versuch beendet. Tier lebt.

Auf Grund dieser Erfahrung haben wir uns bei allen weiteren Versuchen auf diese Technik der fraktionierten Massage unter Anpassung an das Verhalten des $\mathrm{H}$ e r z m u s k e l s beschränkt, und Dauermassage nur ausnahmsweise, insbesondere in den bereits erwähnten Versuchen mit 3 Minuten währender Zirkulationssperre ohne künstliche Respiration angewandt.

Bei der Anwendung der Massage hatten wir folgende beiden Fragen zu lösen:

I. Ist bei unserer Versuchsanordnung überhaupt der direkten Herzmassage eine günstige Einwirkung auf Herztätigkeit oder Zirkulation zuzuerkennen?

2. Gelingt es auf Grund solcher Wirksamkeit der Massage, den Spielraum für die Abklemmungszeit von Aorta und Art. pulmonalis $\mathrm{zu}$ erweitern?

Für die Beantwortung der ersten Frage ergaben sich zwei gangbare Wege: die Massage wurde in solchen Fällen eingeleitet, 
wo nach Lösung der Gefäßschnürung das Tier sich trotz Anwendung anderer Wiederbelebungsmittel, speziell der künstlichen Respiration mit Luft oder Sauerstoff nicht wieder erholte; vor Beginn der Massage mußte dann eine entsprechend lange Zeit verstreichen, während derer die Herztätigkeit sich sichtbar zum Schlechteren wandte resp. völlig versagte, oder der $\mathrm{z}$ w e it e W e g bestand darin, daß von vornherein Abklemmungszeiten gewählt wurden, welche von den Versuchstieren nur dann überstanden werden konnten, wenn die künstliche Atmung durch ein weiteres Adjuvans ergänzt wurde, Zeiten, welche die für das jeweilig angewandte Wiederbelebungsmittel (Luft oder Sauerstoff) als Grenzwerte erkannten überschritten. Bei dieser Versuchsanordnung mußte resp. konnte die Massage sofort nach Lösung der Konstriktion einsetzen, um somit zeitig ihre Wirkung zu entfalten.

Die letzte Anordnung diente uns gleichzeitig zur Beantwortung der zweiten Frage.

Auf Grund obiger Fragestellung ergaben sich die folgenden beiden Versuch sanordnungen:

I. Die Massage wurde zu einem beliebigen Zeitpunkte eingeleitet, nämlich dann, wenn es sich im Verlaufe des Experimentes ergab, daß das erste Wiederbelebungsmittel (Sauerstoffzuführung durch künstliche Atmung oder Natrium percarbonicum) versagte, d. h. keine anhaltende Besserung der Herzaktion oder gar keine Besserung, eher Verschlechterung beobachtet wurde.

2. Mit der Massage wurde alsbald nach Freigabe der Zirkulation des seit Schluß der terminalen Atmung unter künstlicher Respiration sich befindenden Tieres begonnen, teilweise nach kürzer dauernden Abklemmungszeiten, teilweise nach Vaximalzeiten.

Die erste Anwendungsform hat immer etwas Willkürliches, da es in keinem Augenblicke mit absoluter Sicherheit sich sagen läßt, ob nicht doch noch bei weiterer Anwendung der künstlichen Atmung eine Besserung der Herzaktion einsetzen kann, insbesondere bei der Atmung reinen Sauerstoffs haben wir noch Erholungen des Herzens beobachtet, wenn das Herz schon eine ganz verzweifelt schlechte Aktion zeigte. 
TabelleVI. Abklemmung von Aortaund Arter

\begin{tabular}{|c|c|c|c|c|c|c|c|c|c|}
\hline \multirow[b]{2}{*}{ 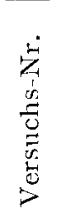 } & \multirow[b]{2}{*}{$\begin{array}{c}\text { Datum des } \\
\text { Versuchs }\end{array}$} & \multirow[b]{2}{*}{ 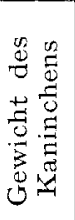 } & \multirow[b]{2}{*}{ 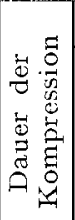 } & \multicolumn{4}{|c|}{ Verhalten des Herzens vor der Massage } & \multicolumn{2}{|c|}{ Massage } \\
\hline & & & & $\begin{array}{c}\text { I. in der } \\
\text { präterminal. } \\
\text { Atempause }\end{array}$ & $\begin{array}{l}\text { 2. während } \\
\text { der } \\
\text { terminalen } \\
\text { Atmung }\end{array}$ & $\begin{array}{c}\text { 3. in der } \\
\text { terminalen } \\
\text { Atempause }\end{array}$ & $\begin{array}{c}\text { 4. nach } \\
\text { Lösung der } \\
\text { Kompression }\end{array}$ & $\begin{array}{c}\text { erste } \\
\text { nach } \\
\text { Lösung }\end{array}$ & $\begin{array}{l}\text { letzte } \\
\text { nach } \\
\text { Lösung }\end{array}$ \\
\hline 90 & 5. X. 09 & 1600 & $3 \frac{1}{2} !$ & $\begin{array}{l}\text { erst lebhaft, } \\
\text { dann träge }\end{array}$ & $\begin{array}{c}\text { wird regel- } \\
\text { mäBig }\end{array}$ & \begin{tabular}{|l|} 
relativ gut \\
(künstliche \\
Atmung)
\end{tabular} & $\begin{array}{l}\text { allmählich } \\
\text { kräftiger } \\
\text { werdend }\end{array}$ & I $5^{\prime} 4 \mathrm{I}^{\prime \prime}$ & $18^{\prime}:$ \\
\hline 92 & 6. X. 09 & 1700 & $3 \frac{1 / 2}{\prime}$ & $\begin{array}{l}\text { Inkongruenz } \\
\text { zwisch.Vorh. } \\
\text { u. Kammern }\end{array}$ & & \begin{tabular}{|c|} 
Vorhof \\
$2-3 \mathrm{mal}$ \\
häufig. als \\
Kammern
\end{tabular} & $\begin{array}{l}\text { Flimmern des } \\
\text { 1. Herzohrs, } \\
\text { dann sehr } \\
\text { schlecht }\end{array}$ & $\mathrm{I} 3^{\prime} 2 \mathrm{O}^{\prime \prime}$ & $2 \mathrm{I}^{\prime} \mathrm{1} \mathrm{O}^{\prime \prime}$ \\
\hline 95 & 8. X. 09 & I 300 & $3 / \mathbf{2}^{\prime}$ & & $\begin{array}{c}2 \text { Sek. n. } \\
\text { Beginn } \\
\text { kräft., was } \\
\text { ziemlich } \\
\text { vorhält }\end{array}$ & $\begin{array}{c}\text { Erst kräft. } \\
\text { dann } \\
\text { oberflächl. }\end{array}$ & $\begin{array}{l}\text { stark dilatiert } \\
\text { Kammerstill- } \\
\text { stand, Vor- } \\
\text { hof rot, } \\
\text { schlägt }\end{array}$ & $3^{\prime} 30^{\prime \prime}$ & $5^{\prime}$ \\
\hline 96 & 9. XI. 09 & 1250 & $3 \frac{1}{2}{ }^{\prime}$ & $\begin{array}{l}\text { Stillstand, } \\
\text { dann ober- } \\
\text { flächlich }\end{array}$ & $\begin{array}{c}\text { Besserung } \\
\text { d. Aktion } \\
\text { nach d. 4. } \\
\text { terminalen } \\
\text { Atemzug }\end{array}$ & & $\begin{array}{c}\text { starke Dila- } \\
\text { tation, sehr } \\
\text { mangelhafte } \\
\text { Aktion }\end{array}$ & $6^{\prime} 30^{\prime \prime}$ & $16^{\prime} 42^{\prime \prime}$ \\
\hline 40 & 28. IV. o9 & 2100 & $4^{\prime}$ & $\begin{array}{l}\text { I' dauernder } \\
\text { Stillstand } \\
\text { Wiederbeg. } \\
\text { der termin. } \\
\text { Atmung }\end{array}$ & & & $\begin{array}{c}\text { Erst sehr } \\
\text { kräftige Ca- } \\
\text { rotispulse, } \\
\text { dann verlang- } \\
\text { samt }\end{array}$ & $3^{\prime}$ & $I 2^{\prime}$ \\
\hline 104 & 20. X. 09 & I 800 & $4^{\prime}$ & Stillstand & $\begin{array}{c}\text { wird kräf- } \\
\text { tiger }\end{array}$ & $\begin{array}{l}\text { kräft. wer- } \\
\text { dend nach } \\
\text { Einleitg.d. } \\
\text { künstlich. } \\
\text { Respirat. }\end{array}$ & $\begin{array}{l}\text { kräftig, nach } \\
\text { I Min. 3 Sek. } \\
\text { nachträgl. } \\
\text { Herzstillst. }\end{array}$ & $20^{\prime}$ & \\
\hline $4 \mathrm{I}$ & I2. III. 09 & 2600 & $4 \frac{1}{2}$ & $\begin{array}{l}\text { Vereinzelte } \\
\text { Kontrakti- } \\
\quad \text { onen }\end{array}$ & $\begin{array}{c}\text { Frequenter } \\
\text { u. ober- } \\
\text { flächlich }\end{array}$ & $\begin{array}{l}\text { Flimmern } \\
\text { d. Vorhofs, } \\
\text { dann Ver- } \\
\text { langsam. d. } \\
\text { Herzschlag. }\end{array}$ & $\begin{array}{c}\text { Dilatiert und } \\
\text { irregulär } \\
\text { Stillstand } \\
\text { Flimmern }\end{array}$ & IO & \\
\hline $4^{8}$ & I. V. 09 & 1850 & $4 \frac{1}{2^{\prime}}$ & & & mäßig & & $50^{\prime \prime}$ & \\
\hline 49 & 4. V. 09 & 2000 & $4^{1 / 2} \mathbf{2}^{\prime}$ & & & oberflächl. & oberflächlich & $30^{\prime \prime}$ & \\
\hline 50 & 6. V. 09 & 1400 & $4^{1 / 2} 2^{\prime}$ & & & $\begin{array}{l}\text { ganz ober- } \\
\text { flächlich }\end{array}$ & $\begin{array}{c}\text { stark } \\
\text { erweitert }\end{array}$ & $30^{\prime \prime}$ & \\
\hline
\end{tabular}


Experiment. Untersuchungen üb, d. Wirkung von künstl. Atmung usw. 225

pulmonalis mit nachfolgender Herzmassage.

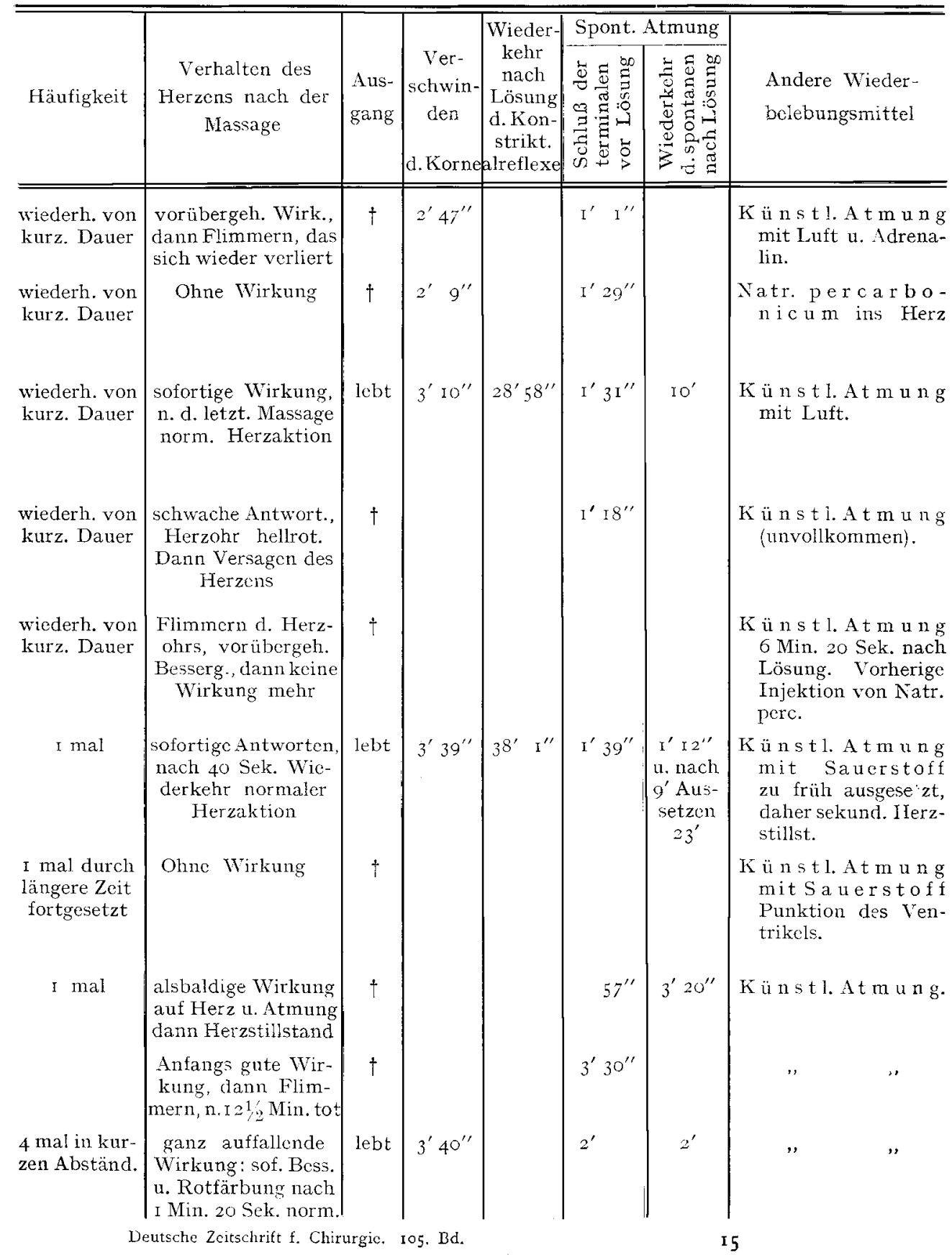


Tabelle VI. Abklemmung von Aorta und Arteri

\begin{tabular}{|c|c|c|c|c|c|c|c|c|c|}
\hline \multirow[b]{2}{*}{ 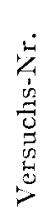 } & \multirow[b]{2}{*}{$\begin{array}{c}\text { Datum des } \\
\text { Versuchs }\end{array}$} & \multirow[b]{2}{*}{ 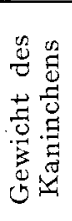 } & \multirow[b]{2}{*}{ 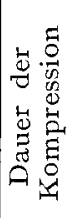 } & \multicolumn{4}{|c|}{ Verhalten des Herzens vor der Massage } & \multicolumn{2}{|c|}{ Massage } \\
\hline & & & & $\begin{array}{c}\text { I. in der } \\
\text { präterminal. } \\
\text { Atempause }\end{array}$ & $\begin{array}{l}\text { 2. während } \\
\text { der } \\
\text { terminalen } \\
\text { Atmung }\end{array}$ & $\begin{array}{c}3 . \text { in der } \\
\text { terminalen } \\
\text { Atempause }\end{array}$ & $\begin{array}{c}\text { 4. nach } \\
\text { Lösung der } \\
\text { Kompression }\end{array}$ & $\begin{array}{c}\text { erste } \\
\text { nach } \\
\text { Lösung }\end{array}$ & $\begin{array}{r}\text { letzt } \\
\text { nac } \\
\text { Lösu }\end{array}$ \\
\hline $\mathrm{JO} 2$ & 9. X. og & 2100 & $4 \frac{1 / 2}{2}$ & $\begin{array}{l}\text { n. } 50 \text { Sek. } \\
\text { Herzstillst. } \\
\text { Fängt kurz } \\
\text { vor termin. } \\
\text { Atmung an } \\
\text { zu schlagen }\end{array}$ & $\begin{array}{l}\text { kräftiger } \\
\text { nach d. } 3 . \\
\text { Atcmzug, } \\
\text { frequenter } \\
\text { n. dem } 6 .\end{array}$ & & $\begin{array}{l}\text { ganz ober- } \\
\text { flächlich }\end{array}$ & $4^{\prime} \mathrm{x} y^{\prime \prime}$ & 62 \\
\hline $5 \mathrm{I}$ & 6. V. og & 1400 & $5^{\prime}$ & $\begin{array}{l}\text { Erst verlang- } \\
\text { samt, dann } \\
\text { Stillstand } \\
\text { (nach I Min.), } \\
\text { d. Flimmern } \\
\text { v. termin. } \\
\text { Atmung } \\
\text { kräftiger }\end{array}$ & & $\begin{array}{l}\text { ganz ober- } \\
\text { flächlich }\end{array}$ & & I $5^{\prime \prime}$ & \\
\hline 59 & I 5. V. 09 & 1700 & $5^{\prime}$ & & & & stark gedehnt & $35^{\prime \prime}$ & $7^{\prime} 4 c$ \\
\hline 109 & 23. X. 09 & 2400 & $51 / 2$ & $\begin{array}{c}\text { Nach } 2 \text { Min. } \\
45 \text { Sck. Herz- } \\
\text { stillstand, } \\
\text { Wiederbeginn } \\
\text { vor d. term. } \\
\text { Atmung }\end{array}$ & $\begin{array}{c}\text { Nach 2. } \\
\text { Atemzug } \\
\text { frequenter, } \\
\text { nach dem } \\
\text { 3. wieder- } \\
\text { um, nach } 7 \\
\text { Flimmern }\end{array}$ & $\begin{array}{c}\text { Flimmern } \\
\text { hört auf, } \\
\text { Vorhof } \\
\text { häufiger } \\
\text { als } \\
\text { Kammer }\end{array}$ & $\begin{array}{l}\text { wird besser; } \\
\text { Vorhof hell- } \\
\text { rot, d. wieder } \\
\text { schlechter }\end{array}$ & II' & $11^{\prime} 5$ \\
\hline 54 & IO. V. 'o9 & 2200 & $6^{\prime}$ & & & $\begin{array}{l}\text { ganz ober- } \\
\text { flächlich }\end{array}$ & & $20^{\prime \prime}$ & $8^{\prime} 3^{\prime}$ \\
\hline 56 & I 2. V. 09 & 1950 & $6^{\prime}$ & $\begin{array}{l}\text { nach } 45 \text { Sek. } \\
\text { Stillstand, } \\
\text { d. Flimmern, } \\
\text { Besserung } \\
1 / 2 \text { Min. v. d. } \\
\text { term. Atm. }\end{array}$ & & $\begin{array}{l}\text { oberflächl. } \\
\text { ruckweise }\end{array}$ & $\begin{array}{c}\text { Stillstand d. } \\
\text { Kammer }\end{array}$ & $45^{\prime \prime}$ & $14^{\prime} 31$ \\
\hline 57 & I3. V. 09 & 2000 & $6^{\prime}$ & $\begin{array}{c}\text { nach } 40 \text { Sek. } \\
\text { Herzstillst., } \\
\text { I Min. } 30 \text { Sek. } \\
\text { dauernd, } \\
\text { dann Vorhof- } \\
\text { kontraktion. }\end{array}$ & & \begin{tabular}{|c|} 
oberflächl., \\
20 Min.vor \\
Lösung \\
wieder \\
Stillstand
\end{tabular} & & $0^{\prime \prime}$ & $20^{\prime} 3$ \\
\hline
\end{tabular}


pulmonalis mit nachfolgender Herzmassage.

\begin{tabular}{|c|c|c|c|c|c|c|c|}
\hline Häufigkeit & $\begin{array}{c}\text { Verhalten des } \\
\text { Herzens nach der } \\
\text { Massage }\end{array}$ & $\begin{array}{l}\text { Aus- } \\
\text { gang }\end{array}$ & $\begin{array}{c}\text { Ver- } \\
\text { schwin- } \\
\text { den } \\
\text { d. Korne }\end{array}$ & $\begin{array}{c}\text { Wieder- } \\
\text { kehr } \\
\text { nach } \\
\text { Lösung } \\
\text { d. Kon- } \\
\text { strikt. } \\
\text { alreflexe }\end{array}$ & 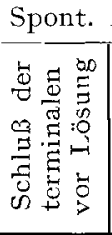 & 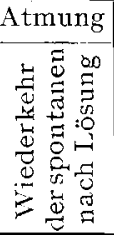 & $\begin{array}{l}\text { Andere Wieder- } \\
\text { belebungsmittel }\end{array}$ \\
\hline $\begin{array}{l}\text { öfter wieder- } \\
\text { holt, kurz }\end{array}$ & $\begin{array}{c}\text { anfängl. Wirkung, } \\
\text { dann Nachlassen u. } \\
\text { I Min. } 52 \text { Sek. nach } \\
\text { Beginn } 1 . \text { Massage } \\
\text { Flimmern }\end{array}$ & $\dagger$ & $4^{\prime} \mathrm{II}^{\prime \prime}$ & & $2^{\prime} \mathrm{I} \mathrm{I}^{\prime \prime}$ & & $\begin{array}{l}K \text { ü nst } 1 \text {. A t m u n g } \\
\text { (nicht gut funktio- } \\
\text { niercnd). }\end{array}$ \\
\hline $\begin{array}{l}\text { sofort } 4 \text { mal, } \\
\text { nach } 53 \text { Sck. } \\
\text { nochmals }\end{array}$ & $\begin{array}{l}\text { schwache Antwort } \\
\text { auf d. I. Massagc, } \\
\text { kräftiger auf die } 2 \text {, } \\
\text { normal nach } 2 \text { Min. }\end{array}$ & lebt & & & $2^{\prime} 40^{\prime \prime}$ & $2^{\prime} 30^{\prime \prime}$ & $\mathrm{K} \ddot{\mathrm{unst}} \mathrm{l}$. Atmung. \\
\hline wiederholt & $\begin{array}{l}\text { zunächst schlaff u. } \\
\text { untätig, nach } 2 \text { Min. } \\
45 \text { Sek. kräftiger, } \\
\text { dann Nachlasscn. }\end{array}$ & $\dagger$ & & & $2^{\prime}$ I $5^{\prime \prime}$ & & $\begin{array}{l}\text { K ünst } 1 \text {. Atmung } \\
\text { mit Luft. }\end{array}$ \\
\hline 2 mal & Wirkung fraglich. & lebt & $51^{\prime \prime}$ & $47^{\prime} 20^{\prime \prime}$ & $3^{\prime} \mathrm{I}^{\prime \prime}$ & $18^{\prime} 20^{\prime \prime}$ & $\begin{array}{l}\mathrm{Küstl.Atmung} \\
\text { m. Sa uerstoff. } \\
\text { Wirk. v. Betupfung } \\
\text { des Herzens mit } \\
\text { heiBer Koch- } \\
\text { salzlösung. }\end{array}$ \\
\hline $\begin{array}{l}\text { oft wieder- } \\
\text { holt, kurz }\end{array}$ & $\begin{array}{c}\text { Vorhof rot, Herz } \\
\text { schlägt kräftig }\left(50^{\prime \prime}\right) \\
\text { nach } 3 \text {. Mass. stärk., } \\
\text { n. Io Min. } 55 \text { Sek. } \\
\text { normal }\end{array}$ & $\begin{array}{l}\text { lebt } \\
\dagger 4 \text { St. } \\
\text { nach } \\
\text { Ver- } \\
\text { such }\end{array}$ & & $36^{\prime}$ I $5^{\prime \prime}$ & $3^{\prime} 52^{\prime \prime}$ & $12^{\prime} 45^{\prime \prime}$ & $\begin{array}{l}\mathrm{K} \text { ü } \mathrm{n} \mathrm{t} l \text {. A } \mathrm{t} \text { u } \mathrm{n} g \\
\mathrm{~m} \text { it } \mathrm{L} \text { u } \mathrm{t} \text {. Pupil- } \\
\text { lenreflexc bleib.aus, } \\
\text { Atmung nur } 8 \text { pro } \\
\text { Minute. }\end{array}$ \\
\hline $\begin{array}{l}\text { oft wieder- } \\
\text { holt, kurz }\end{array}$ & $\begin{array}{c}\text { vorübergehende } \\
\text { Wirliung }\end{array}$ & $\dagger$ & & & $3^{\prime} 52^{\prime \prime}$ & & $K$ ü n st $\mathrm{l}$. At $\mathrm{m}$ u $\mathrm{n} \mathrm{g}$. \\
\hline $\begin{array}{l}\text { oft wieder- } \\
\text { holt, kurz }\end{array}$ & $\begin{array}{l}\text { Zunächst kräftige } \\
\text { Antwort, dann Still- } \\
\text { stand, wied. Aktion } \\
\text { nach } 3 \text { Min. } 55 \text { Sek., } \\
\text { schließ3l. Nachlassen }\end{array}$ & $\dagger$ & & & $4^{\prime} 10^{\prime \prime}$ & & , \\
\hline
\end{tabular}


TabelleVI. Abklemmung von Aorta und Arteri

\begin{tabular}{|c|c|c|c|c|c|c|c|c|c|}
\hline \multirow[b]{2}{*}{$\begin{array}{l}\dot{H} \\
z \\
1 \\
0 \\
0 \\
0 \\
0 \\
0 \\
0 \\
0 \\
>\end{array}$} & \multirow[b]{2}{*}{$\begin{array}{l}\text { Datum des } \\
\text { Versuchs }\end{array}$} & \multirow[b]{2}{*}{ 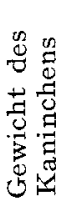 } & \multirow[b]{2}{*}{ 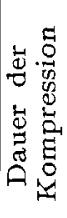 } & \multicolumn{4}{|c|}{ Verhalten des Herzens vor der Massage } & \multicolumn{2}{|c|}{ Massage } \\
\hline & & & & $\begin{array}{c}\text { I. in der } \\
\text { präterminal. } \\
\text { Atempause }\end{array}$ & $\begin{array}{l}\text { 2. während } \\
\text { der } \\
\text { terminalen } \\
\text { Atmung }\end{array}$ & $\begin{array}{c}3 . \text { in der } \\
\text { terminalen } \\
\text { Atempausc }\end{array}$ & $\begin{array}{c}\text { 4. nach } \\
\text { Lösung der } \\
\text { Kompression }\end{array}$ & $\begin{array}{c}\text { erste } \\
\text { nach } \\
\text { Lösung }\end{array}$ & $\begin{array}{r}\text { letzt } \\
\text { nacl } \\
\text { Lösur }\end{array}$ \\
\hline 107 & 2I. X. O9 & 2100 & $6^{\prime}$ & $\begin{array}{l}\text { nach } 49 \text { Sek. } \\
\text { Stillst., nach } \\
\text { I Min. I } 7 \text { Sek. } \\
\text { langsamer } \\
\text { schlagen } \\
\text { (1 } 2 \text { Sek. v. I. } \\
\text { Atemzug) }\end{array}$ & $\begin{array}{l}\text { n. 2. Atem- } \\
\text { zug langs., } \\
\text { regelmäßig } \\
\text { nach 3., } \\
\text { nach 5. } \\
\text { flotter u. } \\
\text { oberfläch- } \\
\text { licher }\end{array}$ & $\begin{array}{l}\text { nach K. A. } \\
\text { m.Okräft., } \\
\text { d. Inkon- } \\
\text { gruenz u. } \\
\text { Flimmern }\end{array}$ & $\begin{array}{c}\text { Zunächst } \\
\text { starke Dilat., } \\
\text { damn rhythm. } \\
\text { Kontrakt., } \\
\text { schlieBlich } \\
\text { schlecht }\end{array}$ & $6^{\prime} 40^{\prime \prime}$ & $24^{\prime}$ \\
\hline I IO & 25. X. O9 & 1850 & $61 / 4{ }^{\prime}$ & $\begin{array}{l}\text { nach } 28 \text { Sek, } \\
\text { Stillstand, } \\
22 \text { Sek. Dauer, } \\
\text { I } 5 \text { Sek. vor } \\
\text { termin. Atm. } \\
\text { flotter }\end{array}$ & $\begin{array}{c}\text { Beschleu- } \\
\text { nigung der } \\
\text { Herz- } \\
\text { aktion }\end{array}$ & $\begin{array}{l}\text { unregel- } \\
\text { mäßig }\end{array}$ & & $5^{\prime \prime}$ & $I^{\prime}$ I! \\
\hline I I I & 25. X. O9 & 1750 & $61 / 2$ & $\begin{array}{l}\text { Kcin vollk. } \\
\text { Stillstand; } \\
\text { frequent. } \\
\text { nach I Min. } \\
\text { 50 Sek. }\end{array}$ & $\begin{array}{l}\text { term. Atm. } \\
\text { fchlt, } \\
\text { n. } 2 \text { Min. I I } \\
\text { Sek. ober- } \\
\text { flächl. u. } \\
\text { flotter }\end{array}$ & $\begin{array}{c}\text { etwas } \\
\text { kräftiger }\end{array}$ & $\begin{array}{c}\text { schon vor d. } \\
\text { Herzmassage } \\
\text { kräftig, } \\
\text { (nach } 9 \text { Sek.) }\end{array}$ & I $3^{\prime \prime}$ & $I^{\prime} 4 c$ \\
\hline 53 & 8. V. 09 & $r_{450}$ & $8^{\prime}$ & $\begin{array}{c}\text { nach } 20 \text { Sek. } \\
\text { Stillstand }\end{array}$ & & & & $10^{\prime \prime}$ & $10^{\prime} 36$ \\
\hline I I 2 & 25. X. o9 & 1600 & $8^{\prime}$ & $\begin{array}{l}\text { nach I } 4 \text { Sek. } \\
\text { Stillstand - } \\
\text { I Min. 3 Sek. } \\
1 / 2 \text { Min. vor } \\
\text { term. Atm. } \\
\text { flott. Aktion }\end{array}$ & & $\begin{array}{c}\text { zunächst } \\
\text { kräftiger, } \\
\text { n. } 53 \text { Sek. } \\
\text { Nachlassen }\end{array}$ & $\begin{array}{l}\text { sof. geringe } \\
\text { Beschleuni- } \\
\text { gung }\end{array}$ & $\mathrm{I} 6^{\prime \prime}$ & $10^{\prime} 56$ \\
\hline 52 & 7. V. 09 & 1800 & $10^{\prime}$ & $\begin{array}{c}\text { Ver- } \\
\text { langsamung }\end{array}$ & $\begin{array}{c}\text { 8 Sek. nach } \\
\text { I. Atemz. } \\
\text { kräftiger } \\
\text { u. fre- } \\
\text { quenter }\end{array}$ & $\begin{array}{c}\text { ganz ober- } \\
\text { flächlich, } \\
\text { stark } \\
\text { gedehnt, } \\
\text { nach } 5 \text { Min. } \\
\text { 50 Sek. nur } \\
\text { Vorhof }\end{array}$ & & I $3^{\prime \prime}$ & $24^{\prime}$ \\
\hline
\end{tabular}

Wir kommen damit auf einen Punkt in der Beurteilung der Wirksamkeit der Herzmassage, auf den auch v. C a c kow ic gelegentlich der kritischen Durchsicht der Literatur über die Erfolge der Massage am Menschen ausdrücklich Gewicht legt. Er sieht nur solche Fälle in bezug auf Nützlichkeit der Massage als 
pulmonalis mit nachfolgender Herzmassage.

\begin{tabular}{|c|c|c|c|c|c|c|c|}
\hline \multirow[b]{2}{*}{ Häufigkeit } & \multirow[b]{2}{*}{$\begin{array}{l}\text { Verhalten des } \\
\text { Herzens nach der } \\
\text { Massage }\end{array}$} & \multirow[b]{2}{*}{$\begin{array}{l}\text { Aus- } \\
\text { gang }\end{array}$} & \multirow[b]{2}{*}{$\begin{array}{c}\text { Ver- } \\
\text { schwin- } \\
\text { den } \\
\text { d. Korn }\end{array}$} & \multirow[b]{2}{*}{$\begin{array}{c}\text { Wieder- } \\
\text { kchr } \\
\text { nach } \\
\text { Lösung } \\
\text { d. Kon- } \\
\text { strikt. } \\
\text { alreflexe }\end{array}$} & \multicolumn{2}{|c|}{ Spont. Atmung } & \multirow[b]{2}{*}{$\begin{array}{l}\text { Andere Wieder- } \\
\text { belebungsmittel }\end{array}$} \\
\hline & & & & & 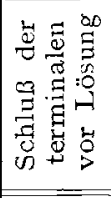 & 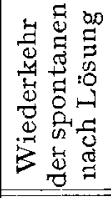 & \\
\hline $\begin{array}{l}\text { oft wieder- } \\
\text { holt, kurz, } \\
\text { einige von } \\
\text { läng. Dauer }\end{array}$ & $\begin{array}{c}\text { Vorhofflimmern, } \\
\text { dann schwache } \\
\text { Kontraktionen, } \\
\text { dann völliges Ver- } \\
\text { sagen }\end{array}$ & $\dagger$ & & & $3^{\prime} 24^{\prime \prime}$ & & $\begin{array}{l}\mathrm{K} \text { ï nst } 1 \text {. Atm ung } \\
\text { m. S a u e r s toff, } \\
\text { Bauchumschnürung, } \\
\text { Punktion des Ven- } \\
\text { trikels, Adrenalin. }\end{array}$ \\
\hline $2 \mathrm{mal}$ & $\begin{array}{l}\text { sofort kräft. Antw. } \\
\text { u. Verkleinerung d. } \\
\text { Herzens n. I Min. } \\
55 \text { Sek. normal. }\end{array}$ & $1 \mathrm{ebt}$ & & II' $5^{\prime \prime}$ & $4^{\prime} 5^{\prime \prime}$ & $2^{\prime} 35^{\prime \prime}$ & $\begin{array}{l}\text { Künstl. Atmung } \\
\text { m. Sauerstoff. }\end{array}$ \\
\hline $4 \mathrm{mal}$ & $\begin{array}{l}\text { nach } 2 . \text { Herzmassage } \\
\text { Antwort, nach } 4 . \\
\text { Fl im mern (2 Min. } \\
3 \text { Sek. nach Lösung) } \\
\text { nach } 3 \text { Min. } 7 \text { Sek. } \\
\text { n o r m a l }\end{array}$ & lebt & $55^{\prime \prime}$ & I $5^{\prime} 50^{\prime \prime}$ & fehlt & $4^{\prime}$ & $\begin{array}{l}\mathrm{Künstl.Atmung} \\
\quad \text { m. Sauerstoff. }\end{array}$ \\
\hline & & $\dagger$ & & & & & $\begin{array}{l}\text { Künstl. Atmung } \\
\text { m. Sauerstoff. }\end{array}$ \\
\hline $\begin{array}{l}\text { oft wieder- } \\
\text { holt }\end{array}$ & $\begin{array}{l}\text { vorübergeh. Wirk., } \\
\text { dann Flimmern u. } \\
\text { Stillstand }\end{array}$ & $t$ & & & $5^{\prime} 4 \mathrm{I}^{\prime \prime}$ & & $\begin{array}{l}\text { Künstl. Atmung } \\
\text { m. Sauerstoff, } \\
\text { Adrenalin ins } \\
\text { Herz. }\end{array}$ \\
\hline $\begin{array}{l}\text { oft wieder- } \\
\text { holt }\end{array}$ & $\begin{array}{l}\text { nach I. Massage } \\
\text { Kammersystole; } \\
\text { nach } 2 \text { Min. } 55 \text { Selk. } \\
\text { Flimmern und Ver- } \\
\text { sagen des Herzens }\end{array}$ & $\dagger$ & & & & & $\begin{array}{l}\text { KünstI. Atmung } \\
\text { mit Luft. }\end{array}$ \\
\hline
\end{tabular}

„,einwandsfrei und unzweifelhaft" an, ,,wo die direkte Herzmassage erst begonnen wurde, nachdem die übrigen Wiederbelebungsversuche schon durch wenigstens 5 Minuten ausgeführt wurden und wo der Erfolg nicht sofort nach der ersten Kompression, sondern erst nach einigen Minuten aufgetreten ist". Auf diese beiden Be- 
dingungen haben auch wir bei der Beurteilung unserer Resultate Wert zu legen.

In der Tabelle VI, die sämtliche Herzmassageversuche zusammenfaßt, finden sich zunächst 8 Versuche, bei denen nach einer Abklemmungszeit von über $5^{1} /_{2}^{\prime}$ die Massage sofort einsetzte. Die Resultate sind in folgender Übersicht noch einmal zusammengestellt:

\section{T a b e 11 e VII.}

Versuche mit Herzmassage und künstlicher Sauerstoffatmung direkt im AnschluB an eine über $5 \frac{1}{2}$ Min. dauernde $A b k l$ emmung von Aorta und Pulmonalis.

\begin{tabular}{|c|c|c|c|}
\hline $\begin{array}{l}\text { Versuchs- } \\
\text { Nr. }\end{array}$ & $\begin{array}{c}\text { Dauter } \\
\text { der } \mathrm{Ab}- \\
\text { klemmung }\end{array} \mid$ & Ausgang & Art und Dauer der Massage \\
\hline 54 & $6^{\prime}$ & lcbt & $\begin{array}{l}20^{\prime \prime}-8^{\prime} 30^{\prime \prime} \text { nach Lösung }{ }^{1} \text { ) oft wiederholt. } \\
\text { Nach I0 } 55^{\prime \prime} \text { kräftige Wirkung. } \\
\text { stirbt } 4 \text { Std. nach dem Versuch (war } \\
\text { nicht lebensfähig). }\end{array}$ \\
\hline 56 & $6^{\prime}$ & $\dagger$ & $\begin{array}{l}45^{\prime \prime}-141^{\prime} \text { nach Lösung wiederholt. Nur } \\
\text { vorübergehende Antwort des Herzens. }\end{array}$ \\
\hline 57 & $6^{\prime}$ & $\dagger$ & $\begin{array}{l}\text { Beginn mit Lösung }-20^{\prime} 30^{\prime \prime} \text { nach Lösung } \\
\text { wiederholt. Vorübergehender Erfolg nach } \\
3^{\prime} 5^{\prime \prime} \text {. }\end{array}$ \\
\hline I I I & $61 / 2^{\prime}$ & lebt & $\begin{array}{l}{ }^{1} 3^{\prime \prime}-\mathrm{I}^{\prime} 4 \mathrm{O}^{\prime \prime} \text { nach Lösung } 4 \mathrm{mal} \text { wiederhol } \\
\text { Zuerst Vorhofflimmern, nach } 3^{\prime} 7^{\prime \prime} \text { nor- } \\
\text { male Herzaktion. }\end{array}$ \\
\hline I IO & $61 / 2$ & ," & $\begin{array}{l}5^{\prime \prime} \text { - I' I 5" nach Lösung } 2 \text { mal wiederholt. } \\
\text { Nach I' } 55^{\prime \prime} \text { normal. }\end{array}$ \\
\hline 53 & $8^{\prime}$ & $\dagger$ & IO" nach Lösung begonnen. \\
\hline I I 2 & $8^{\prime}$ & $\dagger$ & $\begin{array}{l}16^{\prime \prime}-\mathrm{IO}^{\prime} 5 \mathrm{O}^{\prime \prime} \text { nach Lösung oft wiederholt; } \\
\text { anfänglich kräftige Antworten. Nach } \\
\text { ca. } 3^{\prime} \text { schlechte Herztätigkeit, dann Flim- } \\
\text { mern und Tod. }\end{array}$ \\
\hline 52 & $\mathrm{IO}^{\prime}$ & $\dagger$ & $13^{\prime \prime}-25^{\prime \prime}$ nach Lösung keine Wirkung. \\
\hline
\end{tabular}

In 3 Fällen ist es also gelungen, Tiere am Leben zu erhalten nach $6-6 \frac{1}{2}{ }^{\prime}$ langer Abklemmung von Aorta und Pulmonal-

I) Lösung auch im folgenden immer Lösung der Konstriktion von Aorta und Pulmonalis. 
Experiment. Untersuchungen üb. d. Wirkung von künstl. Atmung usw. 23 I

arterie. Der Gewinn von $1 \frac{1}{2}$-I Minute ist der direkten Herzmassage gutzuschreiben.

Bei dem ungleichen Verhalten der Kaninchen sagt eine so kleine Versuchszahl nicht viel, andererseits ist es uns aber nie geglückt, mit künstlicher Atmung allein die Abklemmungszeit auf 6 Minuten zu treiben. Wir sind also doch berechtigt, einen wirklichen Erfolg der Massage anzunehmen, zumal, wie die Tabelle Nr. VI zeigt, die Herztätigkeit in der terminalen Atmungspause in den 3 Versuchen mangelhaft war, es sich also wohl nicht um besonders resistente Tiere gehandelt hat. Die günstige Wirkung der rhythmischen Reize auf den Herzmuskel war gut zu beobachten, insbesondere im Versuch Nr. 54, wo die Chancen der Wiederbelebung dadurch noch reduziert waren, daß die künstliche Respiration mit Sauerstoff erst nach Lösung der Kompression einsetzte, nicht schon nach Schluß der terminalen Atmung, was wir als das günstigere erkannt haben. Ein kurzer Protokollauszug mag die Wirksamkeit der Herzmassage in diesem Versuch beleuchten.

Versuch Nr. 54. Io. V. Igog. Kaninchen 2200 g. Dauer der Abklemmung $6^{\prime}$.

I2h 36 Lösung der Gefäßklemmung und Beginn der künstlichen Respiration mit Sauerstoff.

I $2 \mathrm{~h} 36^{\prime} 20^{\prime \prime}$ Beginn der Herzmassage.

I $2 \mathrm{~h} 36^{\prime} 25^{\prime \prime}$ Herztätigkeit schlecht. Massage.

I $2 \mathrm{~h} 36^{\prime} 50^{\prime \prime}$ Vorhof rötet sich.

I2h $37^{\prime}$ Massage. Stärkere Herzkontraktionen.

I $2 \mathrm{~h} 37^{\prime} 55^{\prime \prime}$
I $2 \mathrm{~h} 38^{\prime} 30^{\prime \prime}$ Jedesmal Massage in Form mehrfachen Ausdrückens des I $2 \mathrm{~h} 39^{\prime}$ Herzens.

I2h $39^{\prime} 40^{\prime \prime}$ Seltene Kammerzusammenziehungen.

I $2 \mathrm{~h} 40^{\prime} 30^{\prime \prime}$ Massage wie oben.

I $2 \mathrm{~h} 4 \mathrm{O}^{\prime} 45^{\prime \prime}$ Massage wie oben.

I $2 \mathrm{~h} 4 \mathrm{I}^{\prime} \quad$ Immer nur vereinzelte schwache Kontraktionen.

I $2 \mathrm{~h} 44^{\prime}$ I $5^{\prime \prime}$ Herzmassage wird häufiger ausgeführt.

I 21 4 $45^{\prime} \quad$ Kräftigere aktive Zusammenziehungen.

I $2 \mathrm{~h} 45^{\prime} \mathrm{I}^{\prime \prime}$ " Herzohr flimmernd.

I $2 \mathrm{~h} 45^{\prime} 5 \mathrm{O}^{\prime \prime}$ Herzohr wieder ruhiger.

I $2 \mathrm{~h} 46^{\prime} 55^{\prime \prime}$ Kräftige, regelmäßige, wirksame Kontraktionen (z i e m lich normale Herzaktion).

I2ls $48^{\prime} 45^{\prime \prime}$ Beginn der spontanen Atemzüge.

Ils $12^{\prime}$ I $55^{\prime \prime}$ Kornealreflex wiedergekehrt. 
Bei Schluß des Versuchs fehlen die Pupillenreflexe, die Atmung hat noch schnappenden Charakter. Das Tier geht 4 Stunden später zugrunde.

Das Protokoll läßt erkennen, wie allmählich, den wiederholten mechanischen Reizen folgend, die Herztätigkeit sich hebt, um nach ca. II Minuten normal zu werden. Zugleich ist aber der Versuch insofern erwähnenswert, als $\mathrm{ke}$ in e vollkommene $\mathrm{R}$ e p a r a ti o n erfolgte, die Pupillenlichtreaktion ausblieb und das Versuchstier 4 Stunden nach dem Versuch einging. Wir haben das bei den Massagetieren öfter beobachtet, auch daß nach Wiederkehr der normalen Reflexe und Wiederkehr normaler Atemfrequenz die Tiere nach kürzerer oder längerer Zeit noch zugrunde gingen. Sie blieben dann an den Extremitäten schlaff gelähmt, auf der Seite liegen, fraßen nicht und starben an demselben oder an dem nächsten oder übernächsten Tage.

Wenn also die 3 Versuche auch einen $z$ we if e 11 o se $n$ Er folg von Her z mas a ge feststellen, so ist derselbe doch in mancher Hinsicht getrübt. Der $\mathrm{Z}$ e itgew in $\mathrm{n}$ is $\mathrm{t} \mathrm{n}$ ur e in $\mathrm{k} l$ e i n e $\mathrm{r}$, über $6 \frac{1}{2}$ Min. hinaus war es nicht möglich, die Tiere am Leben zu erhalten; zweitens war der Erfolg unzuverlässig, die Tabelle weist 2 Versuche auf, Nr. $5^{6}$ und 57 , die mit tödlichem Ausgang verliefen, trotz rechtzeitigen Einsetzens der Massage nach 6 Min. dauernder Abklemmung. Und endlich kommt in Betracht die herabgesetzte Widerstandskraft der Tiere $n a c h$ der Wiederbelebung.

Diesem letzten Umstand begegnen wir in der Literatur über die Massage am men s chlich en Herzen immer wieder. Die Zusammenstellung durch v. C a c k o w i c zeigt das deutlich. In den erfolgreichen Fällen, wo die thoracale direkte Massage angewandt wurde, kam es im besten Falle zu einer mehrstündigen Wiederbelebung. ( $\mathrm{M} \mathrm{a} \mathrm{a} \mathrm{g}^{1}$ ), II Stunden, Si ck ${ }^{2}$ ) 27 Stunden, Le n orman ${ }^{3}$ ) 5 Stunden, Sievers r $_{5}$ Stunden.) Die beiden Dauererfolge bei der subdiaphragmatischen Methode (S e n -

I) M a g , Ein Versuch der Wiederbelebung (ad modum Prus) cines in Chloroformnarkose gestorbenen Mannes. Zentralbl. f. Chir. 1901, S. 20.

2) P. S i c k, Zur operativen Herzmassage. Zentralbl. f. Chir. 1903, S. $98 \mathrm{r}$.

3) L e n orman $t$, Le massage du coeur chez l'homme en particulier dans la syncope chloroformique. Revue de chirurgie 1906, Nr. 3. 
$\operatorname{cert}^{1}$ ) und Gros-Senckert II ${ }^{2}$ ), können unserer Ansicht nach ebensogut auf die Wirkung der künstlichen Respiration wie auf die Massage bezogen werden und stehen überhaupt insofern günstiger da, weil kein Pneumothorax verhanden war, der beim Menschen ja sicher stets ein schädigendes Moment hinzufügt. Höchst charakteristisch für die mangelhafte Dauerwirkung der Massage bei eröffnetem Thorax ist der neuerlich von $\mathrm{Reh} \mathrm{n}^{3}$ ) in der Lexerschen Klinik beobachtete Fall. Es gelang hier, ein durch Chloroformsynkope stillstehendes Herz nach 45 Min. durch transdiaphragmatische Methode zum regelrechten Schlage zu bringen. Normale Atmung und Herzaktion halten ohne Wiederkehr des Bewußtseins 2 Std. lang an, dann wieder Nachlassen von Herz und Atmung, dem durch abermalige Massage nicht abgeholfen werden kann.

Die Ursache des nachträglichen Versagens der Herzkraft beim Menschen wie beim Tierexperiment können wir auf Grund unserer Versuche nicht angeben. Jedenfalls ist wohl mehr der Umstand in Rücksicht zu ziehen, daß die Massage meist die Ultima ratio bedeutet, resp. nur bei besonders schweren Herzschädigungen zur Verwendung kommt, wo die anderen Mittel versagen, als daß man eine direkte Schädigung des Herzmuskels durch die grobe mechannische Bearbeitung beschuldigen muß. Immerhin mag die Differenz zwischen unseren Resultaten und denen der Prusschen Versuche damit in Zusammenhang stehen, daß das kleine Kaninchenherz für die groben Einwirkungen der Massage doch empfindlicher ist als das größere robuste Herz der Hunde. Es besteht andererseits sicher eine größere Widerstandsfähigkeit der $\mathrm{H}$ u $\mathrm{n}$ de, wie unsere Cava-Versuche (s. Kap. VI) beweisen.

Noch weniger erfolgreich gestaltete sich die Anwendung der Massage bei der $z$ weiten Versuchsanordnung, wo sie stets erst eingeleitet wurde nach Versagen anderer Wiederbelebungsmittel. In der folgenden Tabelle VIII sind (s. S. 234) diese Versuche enthalten.

Die 3 der Tabelle angefügten Versuche Nr. 49, 5I, 59 nehmen eine Mittelstellung zwischen denen der oben beschriebenen und

1) Sencert. Zit. nach v. Cack ow ic.

2) Gros-Sencert. Zit. nach v. Cackowic.

3) R e h n. Münchn. med. Wochenschr. 1909, S. 2462. 
Tabelle VIII. Versuche, bei denen die Massage erst nach Versagen anderer Wiederbelebungsmittel angewandt wurde.

\begin{tabular}{|c|c|c|c|c|c|c|}
\hline 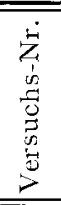 & 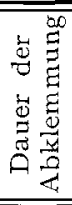 & $\begin{array}{l}\text { Aus- } \\
\text { gang }\end{array}$ & 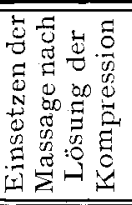 & $\begin{array}{l}\text { An- } \\
\text { wendungs- } \\
\text { weise }\end{array}$ & $\begin{array}{l}\text { Wirksam- } \\
\text { keit }\end{array}$ & $\begin{array}{c}\text { Andere Wiederbelebungs- } \\
\text { mittel }\end{array}$ \\
\hline 90 & $31 / 2$ & $\uparrow$ & I $5 \frac{1}{2}$ & wiederholt & $\begin{array}{l}\text { vorüber- } \\
\text { gehend }\end{array}$ & $\begin{array}{l}\left.\mathrm{KA}^{1}\right) 21 / 2 \text { nach Beginn } \\
\text { der Kompression. }\end{array}$ \\
\hline 92 & $31 / 2$ & $T$ & I $3 \frac{1}{2}$ & ", & keine & \\
\hline 95 & $3 \frac{1}{2}$ & lebt & $3 \frac{1}{2}$ & , & prompt & $\begin{array}{l}\mathrm{KA} 21 / 2{ }^{\prime} \text { nach Beginn der } \\
\text { Kompression. }\end{array}$ \\
\hline 96 & $3 / 2$ & $\dagger$ & $61 / 2$ & ," & $\begin{array}{l}\text { gering } \\
\text { vorüber- } \\
\text { gehend }\end{array}$ & $\begin{array}{l}\mathrm{K} \text { A } 2 \frac{1}{2} \text { nach Beginn der } \\
\text { Kompression (nicht voll- } \\
\text { kommen). }\end{array}$ \\
\hline 46 & 4 & $\dagger$ & 3 & ," & keine & $\begin{array}{l}\text { K A } 61 / 2 \text { ' nach Lösung. } \\
\text { Injektion von Natr. per- } \\
\text { carb. vor der Kompres- } \\
\text { sion. }\end{array}$ \\
\hline 104 & 4 & lebt & 20 & I $\mathrm{mal}$ & $\begin{array}{l}\text { scheinbar } \\
\text { prompt }\end{array}$ & $\begin{array}{l}\mathrm{KA} \text { zu früh ausgesetzt, } \\
\text { daher sekundäre Herz- } \\
\text { schwäche. }\end{array}$ \\
\hline $4 \mathrm{I}$ & $4 \frac{1}{2}$ & $\dagger$ & Io & $\begin{array}{c}\text { fortgesetzt } \\
\text { (I mal) }\end{array}$ & ke in e & $\begin{array}{l}\text { K A mit Sauerstoff nach } \\
\text { Lösung. }\end{array}$ \\
\hline 48 & $4 \%$ & $\dagger$ & I & I mal & $\begin{array}{l}\text { prompte } \\
\text { Wirkung, } \\
\text { sekundär } \\
\text { Herz- } \\
\text { stillstand }\end{array}$ & K A bei Lösung. \\
\hline 102 & $4 \frac{1 / 2}{2}$ & $\dagger$ & $4 \frac{1 / 4}{4}$ & wiederhoit & $\begin{array}{l}\text { vorüber- } \\
\text { gehend }\end{array}$ & $\begin{array}{l}\text { K A } 21 / 2^{\prime} \text { nach Beginn der } \\
\text { Kompression, nicht rich- } \\
\text { tig funktionierend. }\end{array}$ \\
\hline IO9 & $5 \frac{1 / 2}{1 / 2}$ & lebt & $51 / 2$ & $3 \mathrm{maI}$ & $\begin{array}{l}\text { vorüber- } \\
\text { gehend } \\
\text { wirksam } \\
\text { mit } \mathrm{NaCl}\end{array}$ & $\begin{array}{l}\mathrm{KA} \text { mit Sauerstoff nicht } \\
\text { lange genug abgewartet. } \\
\text { Wiederbelebung unter } \\
\text { Zuhilfenahme von } \mathrm{NaCl} \text {. }\end{array}$ \\
\hline 107 & 6 & $\dagger$ & $63 / 4$ & wiederholt & $\begin{array}{l}\text { vorüber- } \\
\text { gehend }\end{array}$ & $\begin{array}{l}\text { K A mit Sauerstoff nach } \\
21 / 2 \text { nach Beginn der } \\
\text { Kompression, Punktion } \\
\text { des Ventrikels. Adre- } \\
\text { nalin. }\end{array}$ \\
\hline 49 & $4 \frac{1 / 2}{2}$ & $\dagger$ & $1 / 2$ & " & $\begin{array}{l}\text { vorüber- } \\
\text { gehend } \\
\text { guter } \\
\text { Erfolg }\end{array}$ & K A bei Lösung beginnend. \\
\hline $5 \mathrm{I}$ & 5 & lebt & $1 / 4$ & einigemale & $\begin{array}{l}\text { kräftige } \\
\text { Wirkung }\end{array}$ & K A bei Lösung ( $3^{\prime}$ lang). \\
\hline 59 & 5 & $\dagger$ & $1 / 2$ & wiederholt & $\begin{array}{l}\text { vorüber- } \\
\text { gehend }\end{array}$ & K A bei Lösung ( $3^{\prime}$ lang). \\
\hline
\end{tabular}

I) $\mathrm{KA}=$ künstliche Atmung. 
denen der zweiten Tabelle ein, insofern die Massage hier bei relativ kurzer Abklemmungszeit $\left(4^{1 / 2}-5\right.$ Min.) schon frühzeitig (nach $1 / 4-1 / 2$ Min.) begann.

Die zahlreichen Kreuze in Spalte 3 veranschaulichen drastisch genug die zahlenmäßig geringen Erfolge, die wir mit dieser Versuchsanordnung erzielten. In der Hinsicht bedarf die Tabelle kaum einer näheren Erörterung.

Absolut keinen Einflu $B$ der Massage auf die Herzfunktion sahen wir in den 3 Versuchen 92, 46, 4I. Irgendwelche besonders ungünstige Verhältnisse lagen nicht vor, auch das in den Fällen 92 und 4I beobachtete D e liri u m des Vor hof s bedeutet nicht ein absolutes Hindernis für die Wiederbelebung, denn wir haben solches F i m me r n der Vorhofsmuskulatur in mehreren Versuchen wieder verschwinden sehen. Dieses Flimmern, das sich nicht auf die Ventrikelmuskulatur ausdehnt, hat offenbar nicht die ungünstige Prognose, die den fibrillären Zuckungen besonders auf Grund der Versuche B a te $1 \mathrm{l}$ is nachgesagt werden muß. Wie dieser kommt auch d' $\mathrm{H}$ a $\mathrm{ll}$ u in $\mathrm{zu}$ dem Resultat, daß, sobald ,fibrilläre Zuckungen“" aufgetreten seien, es fast ein Ding der Lnmöglichkeit sei, normale rhythmische Kontraktionen wieder zu erreichen.

Daß das in unseren Versuchen beobachtete Flimmern des Vorhofs (sichtbar natürlich nur das des 1. Herzohrs) überwunden werden kann, beweist z. B. Versuch III (s. Tab. VI), in welchem nach der vierten Herzmassage Vorhofflimmern eintrat, das dann spontan normaler Herzaktion Platz machte, die zur Wiederbelebung führte. In Versuch 90 verschwand ebenfalls das Flimmern wieder. Allerdings traten nurvorübergehend energische rhy thmische Kontraktionen wieder auf, dann erlahmte das Herz. Ähnlich in Versuch ro7, so da 3 wohl gesagt werden kann, daß das Vorhofflimmern im Stadium der Wiederbelebungsversuche ein prognostisch ungünstiges Zeichen ist, nicht aber ein funktionelles Hindernis darstellt.

In mehreren Versuchen der Tabelle VIII wurden v o r ü be r g e h e n d e Erfolge durch die Massage erzielt, die darin bestanden, daß die rhythmischen Reize mit kräftigeren Kontraktionen beantwortet wurden, die aber nach gewisser Zeit wieder aufhörten ${ }^{1}$ );

I) Diese vorübergehende Wirksamkeit der Massage wird sehr gut demonstriert durch die beigefügte Kurve 2 des Versuchs $\mathrm{A}^{\top}$. 79. 
das Herz fühlte sich dann ganz schlaff an, war stark erweitert, es kam zu völlig inkongruenter Tätigkeit von Vorhof und Kammer, zuweilen zu Herzohrflimmern und schließlich zum Herzstillstand.

Diese Resultate entsprechen wieder den obigen Erfahrungen, daß die Massage s o hä ufig keine D a uererfolge z e i tig t.

Sehen wir uns nun die wenigen, scheinbar unter der Wirkung der Massage positiv verlaufenen Versuche an, so halten auch sie einer kritischen Beleuchtung nicht alle stand. Zunächst Versuch Nr. I04. Es gelang hier, nachdem infolge zu frühen Aussetzens der künstlichen Atmung mit Sauerstoff eine sekundäre Herzparalyse eingetreten war, durch einmalige Massage sehr schnell, normale Herzaktion zu erzielen. Der Versuch ist nicht beweisend, weil die künstliche Atmung nach dem zweiten Herzstillstand nur $4 \%$ Min. durchgeführt worden war und ferner die kräftigen Herzkontraktionen sich sehr schnell nach einmaligem Ausdrücken des Herzens einstellten (schon nach I Min. 2o Sek. Wiederkehr normaler rhythmischer Herzaktion). Dem Einwand, daß die Erholung Folge der künstlichen Atmung gewesen sei, kann nicht mit Bestimmtheit widersprochen werden. Derselbe Einwand ist in Versuch 95 zu machen, wo die Abklemmungszeit nur $3 \frac{1}{2}$ Min. gedauert hatte. Versuch rog überschreitet einerseits nicht die für die Wiederbelebungsfähigkeit bei künstlicher Atmung mit Sauerstoff gesetzte Zeit und zweitens erholt sich das Herz nicht eigentlich unter der Massage, sondern durch Befeuchten mit heißer Kochsalzlösung, so daß es auch hier mehr als wahrscheinlich ist, da $B$ bei längerem Abwarten auch ohne Herzmassage die Wiederkehr der Herzfunktion und des Lebens eingetreten wäre.

Interessant ist Versuch 48, der die geringe Dauer der Massagewirkung gut kennzeichnet. Es handelt sich um $4^{1 / 2}$ Min. langen Gefäßschluß, Wiederkehr normaler Herzaktion und spontaner Atemzüge nach $3 \frac{1}{2}$ Min., dem ein Wiedernachlassen binnen kurzem folgt, das auch durch künstliche Atmung nicht bekämpft werden kann.

Rechtpraktischverwertbare Resultate hat die direkte Herzmassage bei unseren Versuchen $\mathrm{nicht}$ g ez e itigt. Die wenigen Dauerresultate können bei der enormen 
Variation der Widerstandskraft der Kaninchen nicht ausschlaggebend sein.

Bei der sehr schweren Herzschädigung, die wir mit der Kompression der großen Gefäße setzen, erreicht die Massage wenig und jedenfalls $n$ ich $\mathrm{t}$ mit Sicherheiteine brauchbare Verlängerung der Kompressionsdauer. Die Erfolge der Massage am Menschen stimmen mit unseren Versuchsresultaten gut überein.

Immerhin ist in manchen Versuchen ein gewisser günstiger Einfluß der Massage auf das Herz nicht zu verkennen. Fragen wir uns, welcher von den erwähnten Faktoren diesen Einfluß ausübt, so haben wir bereits oben eine durch die Massage evtl. in FluB gebrachte, ,künstliche Zirkulation" abgelehnt. Als Beweis für unsere Annahme, daß der Atrioventricularverschluß bei der Massage nicht zustande kommt, müssen wir folgende Beobachtungen ansehen: Führt man die Massage am freigelegten Herzen aus - nach Resektion der vorderen Brustwand und Sichtbarmachung der zuführenden großen Venenstämme, so ist leicht zu erkennen, wie bei jedesmaligem Ausdrücken nicht nur diekarotidensich füllen, sondern a uch eine Blutwelle in die Venen geworfen wird. Der Entleerung des Herzens durch die Massage möchten wir auch keine allzu bedeutende Rolle zumessen, denn nach jedem Ausdrücken füllt sich das Herz sofort wieder prall an, entleert sich erst dann mehr und mehr, wenn selbständige Aktion einsetzt. Handelte es sich nur um das erstmalige Überwinden des Widerstandes der maximalen Füllung durch den durch Dilatation geschädigten Muskel, so müßte eine Punktion des Ventrikels mit Aspiration des Inhalts weniger schädlich und mindestens ebenso wirksam sein. Damit haben wir aber nie einen Erfolg erzielt, wenn wir sie bei noch vorhandener spontaner Herztätigkeit ausführten (vgl. auch unsere frühere Arbeit).

Es bleibt daher wohl im wesentlichen der $m$ e $\mathrm{ch}$ a $\mathrm{n}$ is $\mathrm{ch}$ e Reiz a uf den Muskel als das wirksame Agens übrig. Dieser tritt zunächst $\mathrm{f}$ a s $\mathrm{t}$ i n jedem $\mathrm{F}$ a ll e in Aktion: das Ausdrücken wird durch spontane Kontraktionen des Herzens ,,beantwortet". Bleiben diese für längere Zeit aus, so ist keine Aussicht auf Wiederkehr der Herztätigkeit. 
Bemerken möchten wir noch, daß wir auch einige Versuche mit Abklemmung der Aorta und Art. pulmonalis bei künstlich verkleinertem Kreislauf (Umschnürung der Bauch- und Extremitätengefäße) mit nachfolgender Herzmassage gemacht haben, ohne daß wir einen günstigen Einfluß dieser Maßregel gesehen hätten. Wir können so dem Einwande entgegentreten, daß die Massage deswegen versagt, weil sie nicht imstande ist, das in den unteren Körperabschnitten angesammelte Blut in Zirkulation zu setzen. Einige Autoren haben diesem Ubelstand dadurch $\mathrm{zu}$ begegnen versucht, daß sie das dem Herzen zur Verfügung stehende Blutvolumen durch zugeführte Kocbsalzlösung zu vergrößern suchten.

V. Abklemmung von Aorta und Pulmonalis mit Injektionen von Strophantin und Adrenalin ins Herz.

Naheliegend war der Gedanke, das durch den Zirkulationsabschluß von Aorta und Pulmonalis geschwächte Herz mit Hilfe geeigneter Pharmaca anzuregen und hierdurch den Kreislauf wieder in Gang zu bringen. Als brauchbare Stoffe kamen die Substanzen der Digitalisgruppe (Strophantin, Digalen) und die Nebennierenpräparate in Frage. Die ersten entfalten sicher eine Wirkung auf den Herzmuskel. Aber auch bei der durch Adrenalin bedingten Blutdrucksteigerung spielt, wie aus den Untersuchungen von Oliver und Schäfer ${ }^{1}$ ) and denen Gottliebs ${ }^{2}$ ) zu schließen ist, eine Veränderung der Herztätigkeit mit eine Rolle. Wir zogen zu unseren Versuchen das Strophantin und das A d re $\mathrm{n}$ a $\mathrm{l}$ i n heran. Da eine Wirkung dieser Substanzen in dem Moment, wo die Konstriktion von Aorta und Pulmonalarterie entfernt wurde, wünschenswert war, mußten sie direkt ins Herz und zwar in den bei unserer Versuchsanordnung vorliegenden linken Ventrikel injiziert werden. Gewisse Schwierigkeiten machte bei dieser Anwendungsweise die Dosierung. Für die Stoffe der Digitalisgruppe ist erwiesen, daß, wenn sie in zu hoher Konzentration mit dem Herzmuskel in Berührung kommen, die Folge der zu starken Wirkung ein Stillstand des Ventrikels in Systole ist. Das Ereignis haben wir einigemal eintreten sehen. Aber auch bei kleineren

I) $\mathrm{O} 1 \mathrm{iver}$ und $\mathrm{Sch}$ äfer. Journal of physiology 1895 , Bd. I8.

2) Gottlicb. Arch. f. experim. Pathologie und Pharmakol., Bd. 43 , I 899 , S. 286 . 
Experiment. Untersuchungen üb. d. Wirkung von künstl. Atmung usw. 239

Dosen Strophantin entsprach, wie aus den im folgenden mitgeteilten Versuchen hervorgeht, die Wirkung nicht unseren Erwartungen.

Ein günstiger Einfluß des Strophantins mußte dann zum Ausdruck kommen, wenn es durch Einverleibung des Mittels gelang, den bei künstlicher Atmung mit Luft oder Sauerstoff gefundenen Schwellenwert der ertragbaren Aorten- und Pulmonalisabklemmung ( $3^{1 / 2}-4$ bez. $5^{1 / 2}$ Min.) zu überschreiten. Die von uns sofort nach Lösung der Gefäßumschnürung in den linken Ventrikel injizierte Dosis betrug $0,5 \mathrm{mg}$ Strophantin (Boehringer). In zwei Versuchen, wo diese Strophantininjektion stattgefunden hatte (Versuch Nr. 132 und I33), wurde zur künstlichen Respiration Luft verwendet. Ein Tier überstand die Abklemmung von 5 Min. Dauer. Ein zweites ging nach einer Konstriktion von 4 Min. zugrunde. Bei I2 Kaninchen (Versuch Nr. I32-I45) wurden Aorta und Pulmonalis bei künstlicher Sauerstoffatmung 61/2-71/2 Min. abgeklemmt, dann erfolgte die Strophantininjektion. Von diesen Tieren gingen Io zugrunde. Ein Kaninchen (Versuch Nr. I37) vertrug die Abklemmung von $6 \frac{1}{2}$ Min., ein zweites eine solche von 7 Min. (Versuch Nr. I40). In letzterem Versuche sistierte die Spontanatmung ro Min. 6 Sek.; die Kornealreflexe kehrten nach 23 Min. wieder. In den 3 positiven Versuchen (I32, I37 und I40) hatten wir den bestimmten Eindruck, als ob sich das Herz auf die Strophantininjektion hin bessere. Diesem Resultat steht aber das negative von II anderen Versuchen entgegen, in denen kein Nutzen zu verzeichnen war. Wir können also unser Urteil über die Wirkung des Strophantins auf die Herzbelebung bei unserer Versuchsanordnung so formulieren, daß eine günstige Beeinflussung des Herzmuskels eintreten $\mathrm{k}$ a $\mathrm{n} n$, daß sie aber $\mathrm{seh} r$ in $\mathrm{k}$ on $\mathrm{s} t$ a $\mathrm{n} t$ ist.

Am Menschen würden wir Bedenken tragen, das Strophantin direkt ins Herz zu injizieren, weil wir über die zulässige Dosierung hier gar keinen Anhalt haben und weil die Gefahr des systolischen Herzstillstandes bei zu hoher Giftapplikation im Auge behalten werden muß. Anders steht es natürlich mit der Frage der intravenösen Zuführung von Strophantin zu einer Zeit, wo die Zirkulation schon einigermaßen im Gange ist. Es ist sehr wohl denkbar, daß dann, wenn das Strophantin einmal von einer Vene aus ins Herz gelangen kann, eine raschere Wiederherstellung der normalen 
Herzfunktion und damit eine schnellere Wiederkehr der Spontanatmung und der übrigen Gehirnfunktionen erfolgt.

Bessere Resultate ergaben die Adrenalininjektionen. Das Wesen der Wirkung der Nebennierenpräparate auf das Herz besteht darin, daß die Muskelzellen der inneren Schichten der Herzwand zur Kontraktion gebracht und dadurch die systolischen $\mathrm{Zu}$ sammenziehungen des Herzens verstärkt werden. Auf diese Weise kommt es zu einer Steigerung des Blutdruckes, auch wenn man nach dem Verfahren von B o c k den großen Kreislauf durch starre Röhren ersetzt ${ }^{1}$ ). Diese direkteHerzwirkung derNebennierensubstanz benutzten wir für unsere Versuche. Sie zerfallen in zwei Gruppen, In der ersten injizierten wir das Adrenalin in den linken Ventrikel unmittelbar nach Lösung der Arterienumschnürung, in der zweiten erst einige Zeit später, als wir sahen, daß das Herz unter künstlicher Sauerstoffatmung oder Herzmassage sich nicht erholte. Das Resultat der ersten Versuchsreihe war sehr günstig, das der zweiten schlechter. Bei den Versuchen der ersten Gruppe wurde in den linken Ventrikel eine Adrenalindosis von $0,025 \mathrm{mg}$ in der Konzentration I : 4000 injiziert. Zur Charakterisierung der Wirkung dieser Dosis auf den normal arbeitenden Kreislauf wurde in einem Vorversuch die angegebene Adrenalinmenge in den freigelegten linken Ventrikel eines gesunden Kaninchens gebracht. 5 Min. später begann in diesem Versuch der Blutdruck von $\mathrm{I} 20 \mathrm{~mm} \mathrm{Hg}$ binnen 8 Sek. auf $200 \mathrm{~mm}$ zu steigen; in dieser Höhe hielt er sich I5 Sek., fiel dann ziemlich rasch wieder $a b$ und erreichte I Min. 3 Sek. nach der Adrenalininjektion wieder die Norm. Die angegebene Dosis bewirkt also, in den linken Ventrikel eines gesunden Kaninchens injiziert, sehr rasch eine starke, aber flüchtige Blutdrucksteigerung. Da das Adrenalin sofort in den Kreislauf geworfen wird, beruht diese Blutdrucksteigerung natürlich im wesentlichen auf einer Kontraktion der kleinsten Arterien. Bringt man aber diese Dosis nach Lösung einer genügend lange wirksam gewesenen Aorten- und Pulmonaliskonstriktion ins linke Herz, so bleibt sie bei der ganz fehlenden oder nur angedeuteten Tätigkeit desselben

I) Vgl. Schmiedeberg. "Grundriß der Pharmakologie". Leipzig 1909, S. I44f. und Hans Mayer und Gottiieb, „Die experim. Pharmakologie". Urban und Schwarzenberg I9IO, S. $220 \mathrm{f}$. 
Experiment. Untersuchungen üb. d. Wirkung von künstl. Atmung usw. 241

in ihrer Wirkung allein auf den Herzmuskel beschränkt. Hierüber gibt am besten nachfolgende Tabelle IX Auskunft.

$$
\text { Tabelle IX. }
$$

Abklemmung von Aorta und Pulmonalis mit sofort anschließender Adrenalininjektion ins Herz.

\begin{tabular}{|c|c|c|c|c|c|c|c|}
\hline 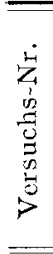 & $\begin{array}{l}\text { Kanin- } \\
\text { chen- } \\
\text { Ge- } \\
\text { wicht }\end{array}$ & 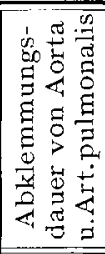 & $\begin{array}{l}\text { Injizierte } \\
\text { Adrenalin- } \\
\text { menge u } \\
\text { Konzen- } \\
\text { tration }\end{array}$ & $\begin{array}{l}\text { Wir- } \\
\text { kung }\end{array}$ & $\begin{array}{c}\text { Wielange } \\
\text { fehlt die } \\
\text { At- } \\
\text { mung? }\end{array}$ & $\begin{array}{c}\text { Wielange } \\
\text { fehlen } \\
\text { die } \\
\text { Korneal- } \\
\text { reflexe? }\end{array}$ & Bemerkungen \\
\hline $19 \mathrm{I}$ & I $700 \mathrm{~g}$ & 7 Min. & $\begin{array}{c}0,025 \mathrm{mg} \\
\mathrm{I}: 4000\end{array}$ & lebt & $\begin{array}{ll}\text { I I } & \text { Min. } \\
37 & \text { Sek. }\end{array}$ & $\begin{array}{ll}\text { I } 7 & \text { Min. } \\
35 & \text { Sek. }\end{array}$ & Nach 3 Tagen $†$ \\
\hline 92 & $2300 \mathrm{~g}$ & 7 Min. & desgl. & $\dagger$ & 一 & 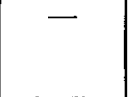 & $\begin{array}{l}\text { Systol. Stillstand des } \\
\text { linken Ventrikels, } \\
\text { H. M. vergeblich. }\end{array}$ \\
\hline 3 & $1600 \mathrm{~g}$ & 7 Min. & desgl. & lebt & $\begin{array}{ll}7 & \text { Min. } \\
3 & \text { Sek. }\end{array}$ & $\begin{array}{ll}26 & \text { Min. } \\
30 & \text { Sek. }\end{array}$ & $\begin{array}{l}\text { Tier bleibt bewußtlos } \\
\text { auf der Seite liegen } \\
\text { und stirbt am näch- } \\
\text { sten Tag. }\end{array}$ \\
\hline & I $450 \mathrm{~g}$ & 7 Min. & desgl. & lebt & $\begin{array}{rr}7 & \text { Min. } \\
50 & \text { Sek. }\end{array}$ & $\begin{array}{ll}\text { I9 } & \text { Min. } \\
25 & \text { Sek. }\end{array}$ & \\
\hline & $1950 \mathrm{~g}$ & 8 Min. & desgl. & erholt & $\begin{array}{r}\text { Io } \text { Min. } \\
9 \text { Sek. }\end{array}$ & $32 \mathrm{Min}$. & $\begin{array}{l}\text { I mal H. M. Herz } \\
\text { schon vor Versuchs- } \\
\text { beginn stark erwei- } \\
\text { tert u. unregelmäB. } \\
\text { Tier zeitweilig re- } \\
\text { flexlos. Tod 35' } \\
\text { nach Lösung d. Ab- } \\
\text { klemmung. }\end{array}$ \\
\hline 5 & I $500 \mathrm{~g}$ & 7 Min. & desgl. & erholt & yo Min. & $\begin{array}{ll}2 \text { I } & \text { Min. } \\
\text { I } 5 & \text { Sek. }\end{array}$ & $\begin{array}{l}\text { Tier I Std. nach Ab- } \\
\text { bruch d. Versuchs } \dagger .\end{array}$ \\
\hline 97 & $1950 \mathrm{~g}$ & 7 Min. & $\begin{array}{l}0,017 \mathrm{mg} \\
\mathrm{I}: 7000\end{array}$ & $\dagger$ & - & - & $\begin{array}{l}\text { Systol. Ventrikelstill- } \\
\text { stand. }\end{array}$ \\
\hline 198 & $1950 \mathrm{~g}$ & 7 Min. & $\begin{array}{l}\text { doppeltc } \\
\text { Dosis } \\
\text { innerhalb } \\
3 \text { Min. }\end{array}$ & $\dagger$ & - & - & H. M. ohne Erfolg. \\
\hline I99 & & 8 Min. & $\begin{array}{l}0,025 \mathrm{mg} \\
\mathrm{I}: 4000\end{array}$ & lebt & $\begin{array}{l}\text { 1o Min. } \\
\text { Io Sek. }\end{array}$ & $\begin{array}{l}\text { I9 } \\
55\end{array}$ & bleibt leben. \\
\hline 200 & $1750 \mathrm{~g}$ & 8 Min. & $\left|\begin{array}{c}0,025 \mathrm{mg} \\
\mathrm{I}: 4000 \\
\text { nach } 7 \text {. Min. } \\
\text { wiederholt }\end{array}\right|$ & $\dagger$ & - & -- & H. M ohne Erfolg. \\
\hline
\end{tabular}

Aus dieser Tabelle geht hervor, daß von 7 Tieren, bei denen nach dem letzten terminalen Atemzug künstliche Sauerstoffatmung eingeleitet und nach Lösung der Gefäßkonstriktion sofort das 
Adrenalin in den linken Ventrikel injiziert wurde, sich 4 von einer 7 Min. währenden Arterienabklemmung erholten; Atmung und Cornealreflexe kehrten wieder. Freilich sind 3 dieser Kaninchen nach Abbruch des Versuchs oder in den nächsten Tagen gestorben. Von 3 Kaninchen, bei denen Aorta und Pulmonalarterie 8 Min. lang abgeklemmt war, hat sich das eine vorübergehend erholt, ein anderes ist dauernd am Leben geblieben. Es ist das die iängst vertragene Konstriktion der beiden Arterien, die wir beobachtet haben. In diesem Versuch wird die $\mathrm{N}$ or mals $\mathrm{ch}$ w ell e v o n $2^{1} / 2$ M i n. durch die geleistete Kunsthilfe (künstliche Sauerstoffatmung und Adrenalininjektion) um $5^{1 / 2}$ Minuten überschritten. Das Protokoll dieses Versuchs ist kurz folgendes:

Versuch Nr. I99. Kaninchen I60o g. I9. II. IgIo.

6h I $8^{\prime}$ Abschnürung von Aorta und Art. pulmonalis.

6h $18^{\prime} 15^{\prime \prime}$ Zuckungen, dann allgemeine Krämpfe.

6h $18^{\prime} 55^{\prime \prime}$ Kornealreflexe verschwunden, Exophthalmus, Maul krampfhaft geöffnet. Herz stark erweitert. Atmung fehlt.

$6 \mathrm{~h}$ Ig' $^{\prime}$ IO $^{\prime \prime}$ I. terminaler Atemzug.

$6 \mathrm{~h} \mathrm{I9^{ \prime }} 5 \mathrm{O}^{\prime \prime}$ 4. terminaler Atemzug.

$6 \mathrm{~h} 20^{\prime} 3^{\prime \prime}$ I2. (und letzter) terminaler Atemzug.

$6 \mathrm{~h} 20^{\prime} 45^{\prime \prime}$ 'Beginn der künstlichen Sauerstoffatmung.

6h 22' $30^{\prime \prime}$ Herztätigkeit schlechter.

$6 \mathrm{~h} 23^{\prime} \quad$ Vorhof schlägt viel frequenter als Ventrikel.

$6 \mathrm{~h} 26^{\prime} \quad$ Lösung der Konstriktion.

$6 \mathrm{~h} 26^{\prime} 20^{\prime \prime}$ Injektion von 0 , I ccm Adrenalin I : 4000 in den linken Ventrikel.

$6 \mathrm{~h} 26^{\prime} 50^{\prime \prime}$ Herz fängt an kräftiger zu schlagen, Tätigkeit sehr unregelmäßig.

6h $29^{\prime}$ I $5^{\prime \prime}$ Delirium des Vorhofs.

$6 \mathrm{~h} 29^{\prime} 50^{\prime \prime}$ Herz sehr verkleinert; stürmische Kontraktionen des Vorhofs.

$6 \mathrm{~h} 3 \mathrm{O}^{\prime} 40^{\prime \prime}$ I. spontaner Atemzug.

$6 \mathrm{~h} \mathrm{30^{ \prime } 4 5 ^ { \prime \prime }}$ 2. spontaner Atemzug; Herztätigkeit noch sehr erregt.

$6 \mathrm{~h} 45^{\prime} 45^{\prime \prime}$ Kornealreflexe wiedergekehrt.

6 h $46^{\prime} 35^{\prime \prime}$ Auf 3 normale Atemzüge kommt I terminaler.

$6 \mathrm{~h} 5 \mathrm{I}^{\prime} 4 \mathrm{O}^{\prime \prime}$ Auf 5 normale Atemzüge kommt I terminaler.

6h $52^{\prime} \quad$ Künstliche Atmung fällt weg; nur noch Ventilation der Trachea mit Sauerstoff.

6h 55' Exophthalmus stark zurückgegangen.

6h $55^{\prime} 30^{\prime \prime}$ Auf 7 normale Atemzüge kommt ein terminaler.

$6 \mathrm{~h} 56^{\prime} 4^{\prime \prime}$ In I Minute 70 Atemzüge.

$6 \mathrm{~h} 5^{8^{\prime}} 3 \mathrm{o}^{\prime \prime}$ Ventilaton der Trachea fällt weg.

$7^{\text {h }}$ Das Tier wird abgebunden. Es bleibt leben. 
Die Wirkung des Adrenalins aufs Herz erhellt aus der Tatsache, daß über die Hälfte der Tiere die auffallend lange Abklemmung der Aorta und Pulmonalarterie von 7 Min. überwunden hat, dann aber auch aus der direkten Beobachtung des frei vorliegenden Herzens. Vor der Adrenalininjektion war das Herz schlaff, stark erweitert; nur die Vorhöfe (sichtbar das linke Herzohr) waren noch etwas in Tätigkeit; zuweilen fand sich Herzflimmern. Die Ventrikel zeigten ganz oberflächliche, wirkungslose Muskelzusammenziehungen. Nach der Einverleibung des Adrenalins wurden dagegen die Ventrikelkontraktionen bald energischer und ergiebiger. Das ganze Herz, zuerst der linke Ventrikel, fühlen sich fester an. Das Adrenalin gelangte auf dem Wege des Koronarkreislaufes bald auch in die übrigen Herzteile; namentlich deutlich war das am Verhalten des linken Vorhofes zu erkennen. Hier traten unter dem Einfluß des Adrenalins außerordentlich intensive, stürmische Kontraktionen auf, dann verkleinerte sich das ganze Herz und auch die Ventrikel gerieten in eine abnorm erregte Tätigkeit, bis sich allmählich die normale Herzaktion wieder herstellte. Hand in Hand mit der Besserung der Herztätigkeit ging eine an der Hellrotfärbung des ganzen linken Herzens kenntliche Arterialisierung des Blutes.

Eine sehr plastische Vorstellung von der Wirkung der Adrenalininjektion gibt Versuch 74, bei dem wir Aorta und Pulmonalis 4 Min. lang umschnürten und die Veränderungen des Blutdruckes am Kymographion registrierten. Dieser Versuch illustriert zugleich sehr deutlich die Wirkung der künstlichen Atmung aufs Herz. Die Injektion von $0,2 \mathrm{mg}$ Adrenalin in den linken Ventrikel brachte bei dem $2300 \mathrm{~g}$ schweren Tiere das $\mathrm{I}^{1 / 2}$ Min. lang nach Lösung der Gefäßumschnürung fast stillstehende Herz wieder zu lebhafter Kontraktion, so daß der Blutdruck binnen $3 / 4$ Min. von I2 $\mathrm{mm}$ auf $\mathrm{I}_{72} \mathrm{~mm}$ anstieg. Die Blutdrucksteigerung war nur kurzdauernd und genügte nicht, um die Spontanatmung wieder in Gang zu bringen. Erst künstliche Luftatmung brachte den wieder gesunkenen Blutdruck auf normale Höhe und führte zur Wiederherstellung der selbständigen Atmung (s. Protokoll S. 244).

Weniger günstig war der Einfluß der Adrenalineinspritzung dann, wenn die Injektion erst einige Zeit nach Lösung der Gefäßumschnürung vorgenommen wurde. Wie die hierher gehörigen, in Tabelle X zusammengestellten Versuche zeigten, waren die Adrena- 
Versuchs-Nr. 74. Vgl. Kurve Nr. 3.

\begin{tabular}{|c|c|c|}
\hline Zeit & $\begin{array}{l}\text { Mitteldruck } \\
\text { in } \mathrm{mm} \mathrm{Hg}\end{array}$ & Bemerkungen \\
\hline $6^{\mathrm{h}} 30^{\prime}$ & II 6 & \\
\hline $6^{\mathrm{h}} 34^{\prime}$ & 120 & \\
\hline $6^{\mathrm{h}} 39^{\prime}$ & IIO & Umschnürung von Aorta und Pulmonalarterie. \\
\hline $6^{\mathrm{h}} 39^{\prime} 9^{\prime \prime}$ & I 8 & \\
\hline $6^{\mathrm{h}} 39^{\prime} 20^{\prime \prime}$ & 48 & \\
\hline $6^{\text {h }} 39^{\prime} 30^{\prime \prime}$ & 40 & \\
\hline $6^{\mathrm{h}} 40^{\prime}$ & 26 & \\
\hline $6^{\mathrm{h}} 4 \mathrm{I}^{\prime}$ & Io & \\
\hline $6^{\mathrm{h}} 43^{\prime}$ & 6 & Lösung der Umschnürung. \\
\hline $6^{\mathrm{h}} 44^{\prime}$ & 8 & $\begin{array}{l}\text { Oberflächliche Herztätigkeit an der Kurve an- } \\
\text { gedeutet. }\end{array}$ \\
\hline $6^{\mathrm{h}} 44^{\prime} 34^{\prime \prime}$ & 12 & $\begin{array}{l}\text { Injektion von } 0,2 \mathrm{mg} \text { Adrenalin ( } \mathrm{r} \text { : I000) in } \\
\text { den linken Ventrikel. }\end{array}$ \\
\hline $6^{\mathrm{h}} 44^{\prime} 53^{\prime \prime}$ & 32 & \\
\hline $6^{\mathrm{h}} 45^{\prime}$ & 94 & \\
\hline $6^{\mathrm{h}} 45^{\prime} \times 8^{\prime \prime}$ & 172 & Geringe Druckschwankungen. \\
\hline $6^{\mathrm{h}} 45^{\prime} 30^{\prime \prime}$ & IIO & Herz verkleinert, kräftige Kontraktionen. \\
\hline $6^{\text {h }} 46^{\prime} 30^{\prime \prime}$ & 80 & \\
\hline $6^{\mathrm{h}} 47^{\prime}$ & 46 & Herz unregelmäßig und oberflächlich. \\
\hline $6^{\text {h }} 47^{\prime} 46^{\prime \prime}$ & 20 & Beginn der künstlichen Luftatmung. \\
\hline $6^{\text {h }} 48^{\prime}$ & 30 & \\
\hline $6^{\text {h }} 48^{\prime} 15^{\prime \prime}$ & I 24 & Herztätigkeit kräftig und regelmäßig. \\
\hline $6^{\text {h }} 48^{\prime} 45^{\prime \prime}$ & 66 & \\
\hline $6^{\mathrm{h}} 5 \mathrm{O}^{\prime}$ & $5^{6}$ & \\
\hline $6^{\mathrm{h}} 50^{\prime} 46^{\prime \prime}$ & 90 & Normale Pulse. \\
\hline $6^{\mathrm{h}} 5 \mathrm{I}^{\prime} 46^{\prime \prime}$ & I38 & I. spontaner Atemzug. \\
\hline $6^{\mathrm{h}} 52^{\prime}$ & r30 & Statt künstlicher Atmung Lunger \\
\hline $6^{\mathrm{h}} 54^{\prime} 30^{\prime \prime}$ & I32 & Versuch abgebrochen. Tier lebt. \\
\hline
\end{tabular}

lininjektionen um so weniger wirksam, je später sie nach Wegnahme der Arterienkompression vorgenommen wurden. Die durch die Überdehnung und die Berührung mit dem venösen Blut geschädigten Herzmuskelzellen sind offenbar nicht mehr imstande, auf den Kontakt mit Adrenalin sich zu kontrahieren. Immerhin war auch in diesen Versuchen, wenn die Zeit zwischen Lösung der Umschnürung und der Adrenalininjektion nicht zu ausgedehnt war. (Versuch Nr. 70, 73, 74, 75), eine günstige Wirkung des Adrenalins auf das Herz mit Sicherheit zu konstatieren.

Auffallend war bei den Adrenalinversuchen, daß mehrere Tiere, die langdauernde Abklemmungen überstanden hatten, nach Ab- 
Experiment. Untersuchungen üb. d. Wirkung von künstl. Atmung usw. 245

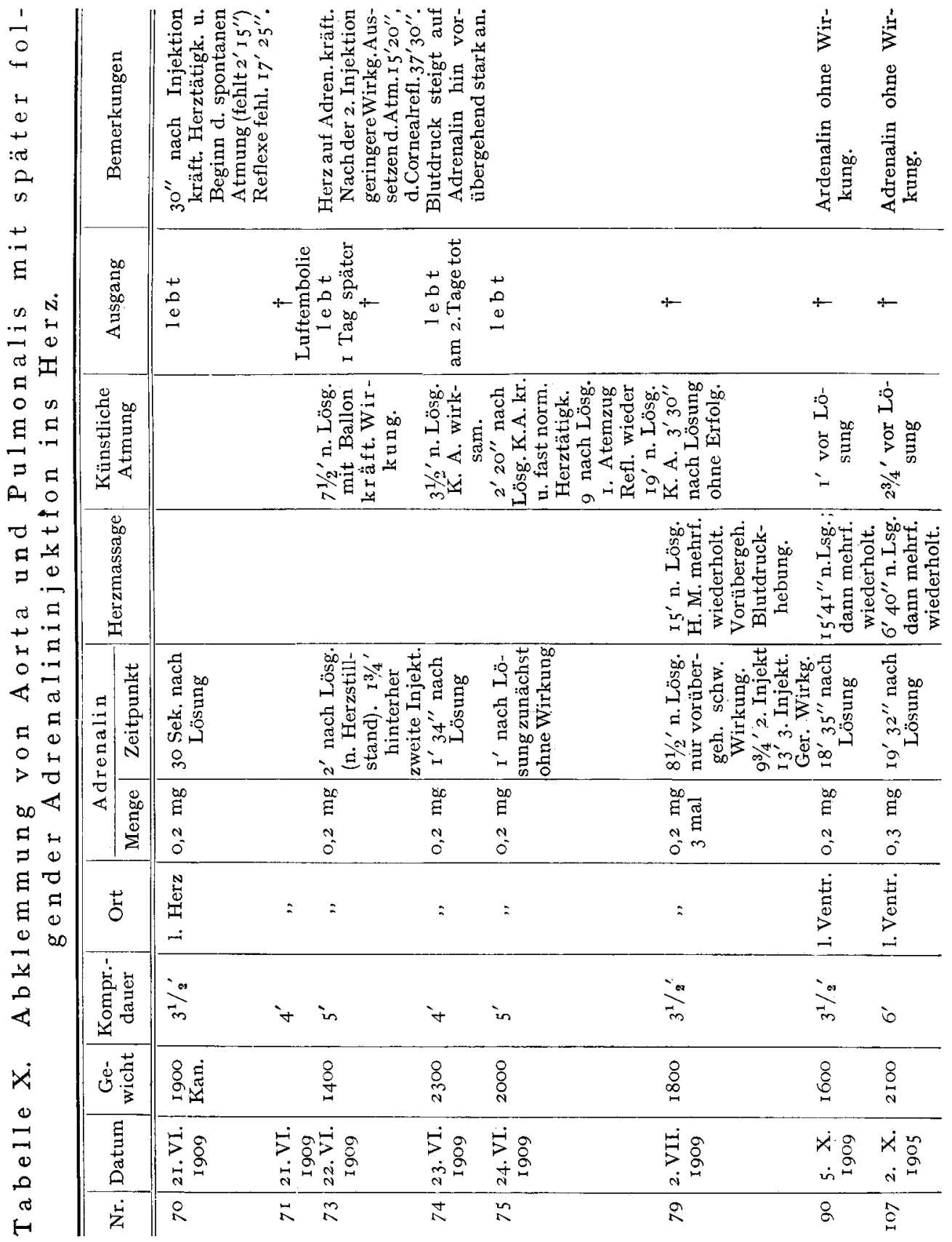


bruch des Versuches oder mehrere Tage später zugrunde gingen. Die Todesursache ist nicht immer aufgeklärt worden. In sinigen Fällen war der Tod auf eine Vereiterung der Operationsstelle zurückzuführen. In anderen fand sich frische Perikarditis und Pleuritis, in einigen lag aber auch der Gedanke nahe, daß das Adrenalin an dem tödlichen Ausgange schuld war. Die verwendeten Giftmengen blieben zumeist weit hinter der Dosis minima letalis (O,I--0,2 $\mathrm{mg}$ pro $\mathrm{kg}$ Kaninchen) zurück. Es kann aber vermutet werden, daß das durch die Gefäßabschnürung schon geschädigte Herz unter der Adrenalinlösung zu einer Kraftleistung erregt wird, der es schließlich später erliegt. Gegen diese Auffassung spricht allerdings der Umstand, daß der Tod erst nach einem oder mehreren Tagen und nicht schon früher eintritt. Am wahrscheinlichsten ist es daher, auch für diese Todesfälle eine infektiöse Ursache anzunehmen.

Am Menschen liegen Bedenken gegen eine direkte Einverleibung des Adrenalins in die linke Herzkammer (etwa $0,2 \mathrm{ccm}$ der Lösung I : I000) nicht vor. Bei schwacher Zirkulation käme auch hier die intravenöse Injektion von $1 / 2-I$ ccm Adrenalin ( $\mathrm{I}$ : IOOO) oder einer größeren Menge physiologischer Kochsalzlösung mit Adrenalinzusatz zur rascheren Wiederherstellung der Herzfunktion in Frage.

\section{Abklem mung der Hohlvenen.}

In unserer früheren Arbeit haben wir bereits darauf hingewiesen, daß die Abklemmung der Hohlvenen an das Herz geringere Anforderungen stellt als die Konstriktion der Aorta und Pulmonalarterie. Der Grund liegt, wie wir nachweisen konnten, darin, daß die Überdehnung des Herzens durch die stagnierende Blutmasse wegfällt und der Lungen- und der Koronarkreislauf eine Zeitlang erhalten bleiben. $\mathrm{H}$ a e $\mathrm{ker}^{\mathbf{1}}$ ) hat während der Hohlvenenabklemmung am Herzen des Hundes sogar Wandresektionen mit Erfolg vornehmen können. Am Kaninchen ergibt sich für die Cavaabklemmungen eine Schwierigkeit insofern, als die Vena cava superior noch paarig vorhanden ist und zu ihrer Umschnürung ein doppelseitiger Pneumothorax gesetzt werden muß. Uns lag aber daran, die Grenzen der ertragbaren Cavaabklemmungen auch beim Kaninchen kennen zu lernen, um mög-

I) $\mathrm{Haecker}$, Experiment. Studien zur Pathologie und Chirurgie des Herzens, Arch. f. klin. Chir. I907, Bd. 84, S. I035. 
Expcriment. Untersuchungen üb. d. Wirkung von künstl. Atmung usw. 247

lichst Vergleiche gegen die Wirkung der Aorten- und Pulmonalarterienkonstriktion zu erhalten. Wir versuchten der genannten Schwierigkeit in der Weise aus dem Wege zu gehen, daß wir erst die linke Vena cava superior unterbanden, die Thoraxwand zur Beseitigung des Pneumothorax unter künstlicher Atmung verschlossen und den Abklemmungsversuch an den übrigen Hohlvenen erst eine oder zwei Wochen später vornahmen. Doch blieb zuweilen der bei der ersten Operation gesetzte Pneumothorax bestehen. Wenn wir dann einige Tage später die andere Pleura ohne künstliche Atmung eröffneten, traten sofort schwere Herz- und 
Tabelle XI. Abklemmung der Hohlvenen.

\begin{tabular}{|c|c|c|c|c|c|c|c|}
\hline $\begin{array}{l}5 \\
2 \\
0 \\
0 \\
0 \\
0 \\
0 \\
0 \\
0 \\
2\end{array}$ & $\begin{array}{c}\text { Ver- } \\
\text { suchstier } \\
\text { und } \\
\text { Gewicht }\end{array}$ & Datum & $\begin{array}{l}\text { Abklem- } \\
\text { mungs- } \\
\text { dauer }\end{array}$ & Ausgang & 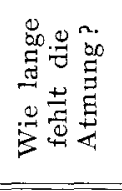 & 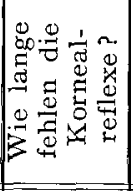 & Bemer kungen \\
\hline 60 & $\begin{array}{l}\text { Kanin- } \\
\text { chen } \\
\text { I } 800 \mathrm{~g}\end{array}$ & $\begin{array}{l}5 . \text { V. og } \\
\text { Ligatur d. } \\
\text { Ik. V. cava } \\
\text { super. } \\
\text { Vers. } 19 . \mathrm{V} .\end{array}$ & Io Min. & $\begin{array}{c}\text { erholt sich } \\
\text { zunächst } \\
\dagger 3 / 4 \text { Stde. } \\
\text { n. Abbruch } \\
\text { d. Versuchs }\end{array}$ & $\begin{array}{l}\text { etwa } \\
\text { Io Min. }\end{array}$ & I I Min. & $\begin{array}{l}\text { Während des } \\
\text { ganzen Ver- } \\
\text { suchs, schon vor } \\
\text { der Abklem- } \\
\text { mung K. A. }\end{array}$ \\
\hline $6 \mathrm{r}$ & $\begin{array}{l}\text { Kanin- } \\
\text { chen }\end{array}$ & $\begin{array}{l}\text { I 5. V. o9 } \\
\text { Lig.d.1. V. } \\
\text { cava sup. } \\
\text { Versuch } \\
\text { 25. V. O9 }\end{array}$ & I 5 Min. & $\dagger$ & - & - & $\begin{array}{l}\text { Keine Erholg. } \\
\text { trotz K.A. u.H. } \\
\text { M Pneumotho- } \\
\text { raxwarn. I.Op. } \\
\text { nicht behoben. }\end{array}$ \\
\hline 62 & $\begin{array}{l}\text { Kanin- } \\
\text { chen }\end{array}$ & $\begin{array}{l}\text { I8. V. o9 } \\
\text { Ligatur d. } \\
\text { 1. V. cava } \\
\text { super. } \\
\text { Versuch } \\
25 . \text { V. } 09\end{array}$ & 12 Min. & $\dagger$ & $\begin{array}{l}\text { etwa } \\
\text { I2 Min. }\end{array}$ & - & $\begin{array}{l}\text { Atmung kommt } \\
\text { wied. in Gang; } \\
\text { das Tier stirbt } \\
\text { inf. Versuchs- } \\
\text { fehlers durch } \\
\text { Abknickung d. } \\
\text { Atmungs- } \\
\text { schlauches. }\end{array}$ \\
\hline 63 & $\begin{array}{l}\text { Hund } \\
\text { (großer } \\
\text { Fox) }\end{array}$ & 28. V. 09 & I6 Min. & $\mid \begin{array}{c}\text { lebt } \\
\dagger 21 / 2 \text { Tage } \\
\text { nach d. } \\
\text { Versuch }\end{array}$ & $\begin{array}{l}381 / 2 \\
\text { Min. }\end{array}$ & $\begin{array}{l}263 / 4 \\
\text { Min. }\end{array}$ & $\begin{array}{l}\text { Der Tod ist an } \\
\text { allgem.Haut-u. } \\
\text { Mediastinalem- } \\
\text { phys, erfolgt. }\end{array}$ \\
\hline 64 & Hund & I. VI. 09 & I 5 Min. & $\dagger$ & - & - & \\
\hline 65 & $\begin{array}{l}\text { Kanin- } \\
\text { chen }\end{array}$ & $\begin{array}{l}\text { I9. V. og } \\
\text { Ligatur d. } \\
\text { 1. V. cava } \\
\text { super. } \\
\text { Versuch } \\
\text { 2. VI. o9 }\end{array}$ & I 5 Min. & $\dagger$ & - & 一 & $\begin{array}{l}\text { K.A. und H.M. } \\
\text { ohne Erfolg. }\end{array}$ \\
\hline 66 & $\begin{array}{l}\text { Kanin- } \\
\text { chen } \\
1950 \mathrm{~g}\end{array}$ & 3. VI. 09 & $20 \mathrm{Min}$. & $\dagger$ & 一 & - & $\begin{array}{l}\text { K. A. und H.M. } \\
\text { nur m. vorüber- } \\
\text { gehend. Erfolg. } \\
\text { Einzeitige Ope- } \\
\text { ration beidopp. } \\
\text { Pneumothorax. }\end{array}$ \\
\hline 67 & $\begin{array}{l}\text { Kanin- } \\
\text { chen } \\
\text { 2 IoOg }\end{array}$ & I0. VI. O9 & I 5 Min. & $\dagger$ & - & - & $\begin{array}{l}\text { K. A. u. H. M. } \\
\text { ohne Erfolg. }\end{array}$ \\
\hline 68 & $\begin{array}{l}\text { Kanin- } \\
\text { chen } \\
2000 \mathrm{~g}\end{array}$ & II. VI. O9 & Io Min. & $\dagger$ & - & 一 & Desgl. \\
\hline 69 & $\begin{array}{l}\text { Kanin- } \\
\text { chen } \\
2200 \mathrm{~g}\end{array}$ & 19. VI.09. & Io Min. & $\dagger$ & $\begin{array}{l}\text { I } 53 / 4 \\
\text { Min. }\end{array}$ & $\begin{array}{l}3^{r^{3 / 4}} \\
\text { Min. }\end{array}$ & $\begin{array}{l}\text { Tier hat sich } \\
\text { zunächst völlig } \\
\text { erholt, stirbt } \\
\text { aber } 1 / 4 \text { Std. n. } \\
\text { Abbruch des } \\
\text { Versuches. }\end{array}$ \\
\hline
\end{tabular}


jedenfalls, daß die Cava a bklemmung länger vertragen wird als die Abschnürung von Aorta und Pulmonalis. Der Grund liegt, wie erwähnt, in der geringeren Schädigung, die bei der Hohlvenenkompression das Herz trifft. Für die Embolieoperation muß jedenfalls diese Tatsache im Auge behalten werden.

VIII. Abklemmung von Aorta und Pulmonalis nach vorheriger Schädigung des Herzens durch partielle Pulmonaliskompression.

Zwischen unseren Abklemmungsversuchen und der bei der Trendelenburgschen Lungenembolieoperation vorgenommenen Konstriktion von Aorta und Art. pulmonalis besteht insofern ein Unterschied, als bei der embolischen Verstopfung der Lungenschlagader schon eine Zeitlang eine Schädlichkeit auf das Herz eingewirkt hat, während unsere Gefäßabklemmungen immer an herzgesunden Tieren vorgenommen wurden. Um nun eine Vorstellung zu bekommen, welchen Einfluß eine durch Widerstandserhöhung im kleinen Kreislauf bedingte Herzschädigung auf die ertragbaren Abklemmungszeiten ausübt, wurde in einer Versuchsreihe vor der totalen Abklemmung von Aorta und Pulmonalarterie erst eine länger dauernde partielle Konstriktion der Lungenschlagader (einmal zugleich auch der Aorta) hergestellt. Die Versuche wurden so angeordnet, daß um die Art. pulmonalis ein Wollfaden gelegt, dieser gekreuzt und angehoben wurde, bis deutliche Zirkulationsstörungen auftraten. Dann wurde die Umschnürung wieder etwas lockerer gelassen. Die an Intensität wechselnde Schnürung blieb an der Pulmonalis Io Min. lang liegen. Auf diese Weise sollte die Wirkung eines im Verlaufe einer gewissen Zeit stoßweise vom Herzen in die Pulmonalarterie eintretenden Embolus nachgeahmt werden. Die Zirkulationsstörungen, die wir so hervorriefen, waren Vergrößerung, Schwarzfärbung, des Herzens, Venenpuls, der an einer freigelegten Vena jugularis sichtbar war, vorübergehendes Fehlen der Kornealreflexe, Zuckungen und Krämpfe sowie Störungen der Atmung bis zum Auftreten der terminalen Atemzüge. Diese schweren Erscheinungen gingen bei Lockerung der Pulmonaliskonstriktion immer sehr rasch wieder zurück. In Tabelle XII 
Tabelle XII. Abklemmung von Aorta und Pulmonalis nach vorübergehender Pulmonaliskompression.

\begin{tabular}{|c|c|c|c|c|c|c|}
\hline 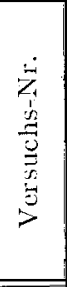 & Datum & Gewicht & $\begin{array}{c}\text { Dauer u. Form } \\
\text { der partiellen } \\
\text { Gefäß- } \\
\text { abklemmung }\end{array}$ & 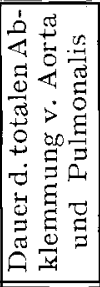 & $\begin{array}{c}\text { Verhalten nach } \\
\text { d. Abklemmung, } \\
\text { Form der Kunst- } \\
\text { hilfe }\end{array}$ & Ausgang \\
\hline I I 5 & $\begin{array}{c}\text { II. XI. } \\
\text { I } 909\end{array}$ & $2000 \mathrm{~g}$ & $\begin{array}{l}\text { Art. pulmonalis } \\
\text { Io Min. teilw. } \\
\text { abgeklemmt. } \\
\text { Atmung un- } \\
\text { regelmäßig. } \\
\text { Herz dunkel ge- } \\
\text { färbt. Ein } \\
\text { Krampfanfall. }\end{array}$ & $\begin{array}{l}21 / 2 \\
\text { Min. }\end{array}$ & $\begin{array}{l}\text { Herz wird sehr } \\
\text { schlecht, bis zum } \\
\text { Stillstand. Nach } \\
31 / 2 \text { Min. K. A. } \\
\text { Herz besser, dann } \\
\text { schlechter. Nach } \\
8 \text { Min. Herzmas- } \\
\text { sage, dann wieder- } \\
\text { holt. Atmung be- } \\
\text { ginnt I } 4 \text { Min. } 35 \\
\text { Sek. n. Lösung. }\end{array}$ & $\begin{array}{l}\text { Tier erholt } \\
\text { sich völlig, } \\
\text { stirbt aber } \\
\text { am i3. XI. } \\
\text { an eitriger } \\
\text { Perikarditis. }\end{array}$ \\
\hline I 6 & $\begin{array}{l}15 . \mathrm{XI} . \\
\text { 1 } 909\end{array}$ & I600 $\mathrm{g}$ & $\begin{array}{c}\text { Aorta u. Pul- } \\
\text { monalis Io Min. } \\
\text { teilweise abge- } \\
\text { klemmt. Atm. } \\
\text { unregelmäßig. } \\
\text { Zuckungen. } \\
\text { Cyan.d. Nasen- } \\
\text { schleimhaut. }\end{array}$ & $\begin{array}{l}21 / 2 \\
\text { Min. }\end{array}$ & $\begin{array}{l}\text { Keine Kunsthilfe. } \\
\text { I } 3 / 4 \text { Min. n. Lö- } \\
\text { sung Beginn der } \\
\text { Spontanatmung. }\end{array}$ & $\begin{array}{l}\text { Tier erholt } \\
\text { sich. }\end{array}$ \\
\hline IIS & $\begin{array}{c}\text { 19. XI. } \\
\text { I } 909\end{array}$ & $1000 \mathrm{~g}$ & $\begin{array}{l}\text { Pulmonalis Io } \\
\text { Min. partiell u. } \\
\text { dabei 3mal total } \\
\text { abgeklemmt. } \\
\text { Dabei } 3 \text { Krampf- } \\
\text { anfälle mit } \\
\text { Schreien u. Rc- } \\
\text { flexlosigkeit. } \\
\text { An der l. frei- } \\
\text { gelegten Vena } \\
\text { jugularis Venen- } \\
\text { puls zu sehen. }\end{array}$ & $\begin{array}{l}21 / 2 \\
\text { Min. }\end{array}$ & $\begin{array}{l}\text { Keine Kunsthilfe. } \\
1 / 2 \text { Min. nach Lö- } \\
\text { sung I. Atemzug. }\end{array}$ & $\begin{array}{l}\text { Tier erholt } \\
\text { sich. }\end{array}$ \\
\hline 118 & $\begin{array}{c}\text { I8. XI. } \\
1909\end{array}$ & $1600 \mathrm{~g}$ & $\begin{array}{c}\text { Pulmonalis Io } \\
\text { Min. partiell ab- } \\
\text { geschnürt. Stau- } \\
\text { ung i. d. freigel. } \\
\text { 1.Vena jugularis } \\
\text { sichtbar. Zeit- } \\
\text { weilige festere } \\
\text { Umschnürung } \\
\text { mit Reflexlosig- } \\
\text { keit, Krämpfen } \\
\text { v. agonaler } \\
\text { Atmung. }\end{array}$ & $3 \mathrm{Min}$. & $\begin{array}{l}\text { Künstl. Atmung } \\
\text { m. I.uft } 2 \text { Min. } \\
53 \text { Sek. n. Lösung } \\
\text { Herztätigkeit sehr } \\
\text { schlecht, crholt } \\
\text { sich n. Herzmas- } \\
\text { sage. Spontan- } \\
\text { atmung beginnt } \\
5 \text { Min. 50 Sek. } \\
\text { nach. Lösung. }\end{array}$ & $\begin{array}{l}\text { Tier erholt } \\
\text { sich völlig, } \\
\text { geht aber am } \\
2 \text { I. XI. an } \\
\text { fibrinöser } \\
\text { Perikarditis } \\
\text { zugrunde. }\end{array}$ \\
\hline
\end{tabular}


Experiment. Untersuchungen üb. d. Wirkung von künstl. Atmung usw. $25 \mathrm{I}$

Tabelle XII. Abklemmung von Aorta und Pulmonalis nach vorübergehender Pulmonaliskompression.

\begin{tabular}{|c|c|c|c|c|c|c|}
\hline 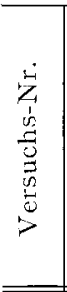 & Datum & Gewicht & $\begin{array}{c}\text { Dauer u. Form } \\
\text { der partiellen } \\
\text { Gefäß- } \\
\text { abklemmung }\end{array}$ & 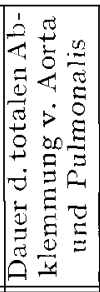 & $\begin{array}{c}\text { Verhalten nach } \\
\text { d. Abklemmung, } \\
\text { Form der Kunst- } \\
\text { hilfe }\end{array}$ & Ausgang \\
\hline 120 & $\begin{array}{c}\text { 20. XI. } \\
\text { I } 909\end{array}$ & I $350 \mathrm{~g}$ & $\begin{array}{l}\text { Pulmonalis par- } \\
\text { tiell Io Min. } \\
\text { abgeschnürt. } \\
\text { Zeitweise Ab- } \\
\text { schnürung bis } \\
\text { z. Reflexlosig- } \\
\text { keit u. Exoph- } \\
\text { thalmus. Herz } \\
\text { stark vergröB., } \\
\text { steht vorüber- } \\
\text { gehend still. In } \\
\text { der Vena jugu- } \\
\text { laris Venenpuls } \\
\text { sichtbar. }\end{array}$ & Min. & $\begin{array}{l}\text { Erholung ohne } \\
\text { Kunsthilfe. } \\
\text { Spontanatmung } \\
\text { beginnt I Min. } \\
53 \text { Sek. nach } \\
\text { Lösung. }\end{array}$ & $\begin{array}{c}\text { Tier bleibt } \\
\text { leben. }\end{array}$ \\
\hline I 2 I & $\begin{array}{c}\text { I5. XI. } \\
\text { I } 909\end{array}$ & $1650 \mathrm{~g}$ & $\begin{array}{l}\text { Pulmonalis Io } \\
\text { Min. part. abge } \\
\text { klemmt. Venes } \\
\text { puls i. d. jugula- } \\
\text { ris. I Min. lang } \\
\text { auch dic Aorta } \\
\text { komprimiert. } \\
\text { Krämpfe. }\end{array}$ & $\begin{array}{c}3 \\
\text { Min. }\end{array}$ & $\begin{array}{l}\text { Erholung ohne } \\
\text { Kunsthilfe. Spon- } \\
\text { tanatmung be- } \\
\text { ginnt etwa I Min. } \\
\text { nach Lösung. }\end{array}$ & $\begin{array}{l}\text { Bleibt leben. } \\
\text { Schwäche d. } \\
\text { r. Hinter- } \\
\text { beins. }\end{array}$ \\
\hline I I 7 & $\begin{array}{l}\text { I6. XI. } \\
\text { I909 }\end{array}$ & $1950 \mathrm{~g}$ & $\begin{array}{l}\text { Pulmonalis par- } \\
\text { ticll abgeschn., } \\
\text { Zuckungen. } \\
\text { Tier schreit. } \\
\text { Atmungs- } \\
\text { lirampf. }\end{array}$ & $\stackrel{4}{4}$ & $\begin{array}{c}\text { Keine Erholung } \\
\text { des Hcrzens } \\
\text { trotz Massage. }\end{array}$ & $\uparrow$ \\
\hline
\end{tabular}

finden sich einige Versuche zusammengestellt, die die Wirkung dieser Kreislaufschädigung auf die Abklemmungszeiten darstellen.

Die Versuche zeigen, daß in der Regel die vorhergegangene, Io Min. lang mit wechselnder Intensität unterhaltene Pulmonalisumschnürung auf die ertragbare totale Abklemmung von Aorta und Lungenschlagader keine sehr weitgehende Wirkung ausübt, oder mit anderen Worten, daß sie die Leistungsfähigkeit des Herzens nur wenig schädigt. Nur in einem Versuche ( I $_{5}$ ) war bei der, sonst gut vertragenen Abklemmungszeit von $2 \frac{1}{2}$ Min. erheb- 
liche Kunsthilfe (künstliche Atmung, Herzmassage) zur Erholung des Herzens nötig. In zwei anderen Versuchen (II6. II9) bedurfte es dessen nicht. Ja, von zwei Tieren wurden sogar ohne künstliche Maßnahmen 4 Abklemmungswerte überwunden, die die Normalschwelle von $2 \frac{1}{2}$ Min. noch um $1 / 2$ Min. übertrafen (Versuch 120 und I2I). Diese Resultate sind einigermaßen überraschend, sie stimmen aber gut mit früheren Angaben ( $\mathrm{L} \mathrm{i} \mathrm{c} \mathrm{h} \mathrm{t} \mathrm{h} \mathrm{e} \mathrm{i} \mathrm{m}{ }^{1}$ ) überein, nach denen lange fortgesetzte, teilweise Einengungen der Pulmonalarterie das Herz merkwürdig wenig schädigen. Ferner passen hierzu auch klinische Beobachtungen. Tre $\mathrm{n} \mathrm{d} \mathrm{e} \mathrm{le} \mathrm{n} \mathrm{burg}$ hat ganz besonders auf die Fälle von Lungenembolie aufmerksam gemacht, die protrahiert verlaufen. Hier handelt es sich um partiellen Verschlu $\beta$ des Lungenkreislaufs durch einen Embolus, der am Conus pulmonalis hängen bleibt oder die Lungenarterie oder einen Ast nur teilweise verstopft. Diese Widerstandserhöhung im kleinen Kreislauf wird vom Herzen ziemlich lange ertragen oder auch ganz überwunden. Die schweren, zum Tode führenden Herz- und Lungenerscheinungen treten erst beim völligen Verschluß der Lungenarterie auf. Unsere Versuche ergeben jedenfalls, daß nach vorheriger, Io Min. fortgesetzter partieller Abklemmung der Art. pulmonalis das Herz sich einer totalen Umschnürung von Aorta und Lungenschlagader gegenüber nahezu wie ein gesundes verhält.

$$
\text { IX. Folgerungen. }
$$

Die Indikation zur Ausführung der Trendelenburgschen Lungenembolicoperation ist dann gegeben, wenn ein vollkommener oder doch nahezu vollkommener Verschluß der Lungenarterie erfolgt ist. Besonders geeignet für die Operation sind natürlich die Fälle, bei denen der vollkommenen Verlegung des Lungenkreislaufs eine bemerkbare, partielle Einengung vorangegangen war und daher genug Zeit zur Vorbereitung und Ausführung der Operation gegeben ist. Der Erfolg der Operation ist dann im wesentlichen davon abhängig, wie lange Zeit zwischen dem völligen Verschluß und der Extraktion der Emboli verstrichen ist, da die Schwere der Herzschädigung allein davon abhängt.

I) Lichtheim.; Die Störungen des Lungenkreislaufs. Berlin I 876 . 
In der Leipziger Klinik werden Kranke mit den Symptomen einer Lungenembolie sofort in den Operationssaal gebracht und hier beobachtet. Das Instrumentarium ist stets gebrauchsfertig. In einigen wenigen Fällen traten keine schweren Erscheinungen auf, so daß die Kranken nach mehrstündiger Beobachtung auf die Abteilung zurückgebracht werden konnten. Wenn die Erscheinungen aber allmählich an Schwere zunehmen oder, wie es häufig der Fall ist, sich plötzlich verschlimmern, wird zur Operation geschritten. Die Verschlimmerung ist zu erkennen an Zunahme der mit leich ter Cyanose verbundenen Blässe des Gesichts und raschem Nachlaß der Pulsspannung bis zum völligen Verschwinden. Bald setzt dann noch die bis dahin tiefe und angestrengte Atmung aus, das Bewußtsein erlischt, die Kornealreflexe verschwinden; die Pupillen werden weit und starr und der Kranke unterscheidet sich nicht mehr von einem Toten. Wenn irgend möglich muß die Operation begonnen werden, ehe diese letzten Symptome eingetreten sind; die Resultate unserer Versuche lassen es aber nicht als unmöglich erscheinen, daß selbst eine erst im Moment des Todes oder kurz vorher begonnene Operation noch von Erfolg sein könnte. Denn vorausgesetzt, daß das menschliche Herz sich dem Verschluß der Pulmonalis gegenüber nicht anders verhält wie das Kaninchenherz, stehen von dem Momente des totalen Verschlusses der Pulmonalis bis zu dem, wo nach Extraktion der Emboli die Zirkulation durch die Pulmonalis wieder freigegeben wird, nahezu $6 \mathrm{Min}$. zur Verfügung. In 5-6 Min. läßt sich aber die ganze Operation bis zur Lösung der Pulmonalisumschnürung sehr wohl ausführen. Bei Verschluß der Lungenarterie geht dem definitiven Tode ein Stadium des Scheintodes voraus, währenddessen nach Lösung des Verschlusses cine Wiederbelebung noch möglich ist. Der Tod tritt durch Herzlähmung ein und die Wiederbelebung erfolgt, sobald es gelingt, das Herz wieder zu regelmäßiger Tätigkeit zu bringen. Für die Brauchbarkeit der Operation wird es daher von großer Bedeutung sein, hierzu geeignete Mittel an der Hand zu haben.

Die vorliegende Arbeit hat sich die Aufgabe gestellt, solche Mittcl ausfindig zu machen und suchte sie in der Weise experimentell zu lösen, daß der Wert der Wiederbelebungsmethoden für verschiedene Abklemmungszeiten durch genügend lange 
Versuchsreihen zahlenmäßig berechnet wurde. Diejenige Methode, die die längste Abklemmungszeit am Versuchstier ermöglichte, muß auch, auf die Embolieoperation übertragen, die beste Maßregel zur Wiederbelebung des versagenden Herzens sein.

Der Wert der von uns geprüften Wiederbelebungsmethoden erhellt am besten aus nachfolgender tabellarischer Übersicht:

\begin{tabular}{|c|c|}
\hline Wicderbelebungsmethode & $\begin{array}{c}\text { Maximale Abklemmnngs- } \\
\text { zeit (Mittelwert) }\end{array}$ \\
\hline $\begin{array}{l}\text { Keine } \\
\text { Künstliche Atmung mit atmoshpärischer Luft } \\
\text { Künstliche Atmung mit Sanerstoff } \\
\text { Künstliche Sauerstoffatmung und Herzmassage } \\
\text { Natr. percarbonic. (Sauerstoff) Injektion ins Grehirn } \\
\text { Strophantin ins Herz.. } \\
\text { Künstl. Sauerstoffatmung mit Adrenalininjektion } \\
\text { ins Herz . . . . . . . . . . . . . . . }\end{array}$ & 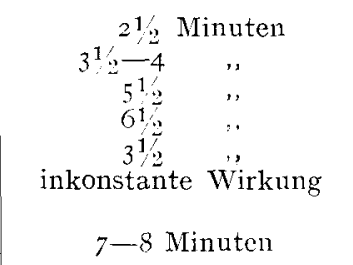 \\
\hline
\end{tabular}

Aus der Tabelle geht ohne weiteres die große Überlegenheit der künstlichen Respiration mit Sauerstoff hervor, vielleicht unterstützt durch eine sofort nach Lösung der Gefäßumschnürung vorgenommene $\mathrm{Adrenalin} \mathrm{injek-}$ tion in die linke Herzkammer. Als bei der Embolieoperation bequem verwendbares Adjuvans kommt noch die direkte Herzmassage in Frage, obwohl, wie wir gezeigt haben, man ihren Wert nicht zu hoch einschätzen darf.

Auf Grund des Ergebnisses unserer Versuche, daß die künstliche Atmung einen sa wirksamen Faktor bei der Wiederbelebung nach der Trendelenburgschen Operation darstellt, hat Herr Geheimrat Trendelenburg den für Tiere von der Firma Petzold ${ }^{1}$ ) bereits angegebenen Apparat zur künstlichen Atmung in vergrößerter Form und eingerichtet für die Sauerstoffatmung herstellen lassen. Der Apparat steht fortwährend gebrauchsfertig zur Verfügung und ist leicht von einer Person zu bedienen. Der Gebrauch des Apparates ist so gedacht: während der Beobachtung des Emboliekranken wird, evtl. unter Lokalanästhesie, die Trachea freig e legt. Tritt die erwartete Verschlimmerung

I) Wilhelm Petzold, Kleinzschocher-Leipzig. 
Experiment. Untersuchungen üb. đ. Wirkung von künstl. Atmung usw. 255

cin, so wird die Embolieoperation begonnen und, solange dic Atmung im Gange bleibt, fortgesetzt. Wenn die Atmung aber aufhört, wird sofort die Trachea inzidiert, eine Tamponkanüle in die Trachea geschoben, künstliche Sauerstoffatmung eingeleitet und die Embolieoperation fortgesetzt. Die künstliche Respiration mit Siuerstoff darf erst unterlassen werden, wenn der terminale Atmungstyp völlig dem normalen gewichen ist.

Leider ist die Erprobung des Respirationsapparates bei einer Ėmbolicoperation noch nicht möglich gewesen, da längere Zeit kein gceigneter Fall zur Beobachtung gekommen ist.

Ausdrücklich möchten wir darauf hinweisen, daß bei der

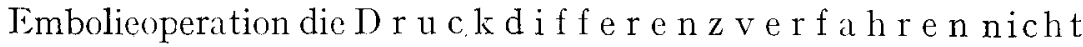
i n Betrach t kom men, weil es sich stets um Bekämpfung des völlig en Atmungsstillstandes handelt. Die von S a u e r $\mathrm{bruch}{ }^{\mathbf{1}}$ ) der künstlichen Atmung vorgeworfenen Ubelstände sind zum Teil (Schwanken des Lungenvolums, interstitielles Emphysem, schädliche Rückwirkung auf die Zirkulation, Infektion von der Trachealwunde aus) durch geeignete Konstruktion des Instrumentariums, namentlich richtige Abmessung des Respirationsvolums zu umgehen, zum Teil (Wärmeverlust) von so untergeordneter Bcdeutung, daß sie keinen Ausschlag geben können, wo die künstliche Atmung als einzige Respirationsmöglichkeit in Frage kommt. Auch die Frage der Narkose spielt keine Rolle, da zu dem Zeitpunkt, wo die künstliche Respiration angewendet werden soll, der Kranke infolge des Herzstillstandes bewußtlos ist. Endlich läßt sich durch Erhöhung des Inspirationsvolums im Momente des Thoraxverschlusses der Pneumothorax leicht beseitigen.

Wir konnten uns von der Richtigkeit dieser Tatsachen und von dem guten Funktionicren unseres Respirationsapparates in einem Versuche überzcugen, wo wir bei cinem Hammel nach Herstcllung eines doppclseitigen Pneumothorax in Narkose gegen die natürliche Atmung cine Stunde lang die künstliche Respiration mittelst des Apparates ohne Schaden für das Tier durchführten.

I) S a u crbruch, Über die physiologischen und physikalischen Grundlagen bei intrathoracalen Eingriffen in meiner pneumatischen Operationskammer. Verhandl. der Deutschen Gesellscl. f. Chir. 33. Kongr. I904. 


\section{Kurvenerklärung.}

Kurve I. Vgl. Text S. I76. Versuchs-Nr. I8I. Kaninchen 2 I50 g.

Aufzeichnung von Blutdruck und Atmung. Abklemmungszeit 21/2 Min. Wiedererholung des Versuchstieres ohne Kunsthilfe.

An der Atmungskurve sind die terminale Atmung, sowie der Wiederbeginn der spontanen Atmung gut erkennbar. Die Blutdruckkurve zeigt die ausgeprägte Vagusreizwirkung (im Gegensatz zu Kurve 2).

I 5 Min. nach Lösung der Konstriktion normaler Atmungstypus und normale Blutdruckkurve.

Kurve 2. Vgl. Text S. I 84 und 235. Versuchs-Nr. 79. Kaninchen 1800 g.

Blutdruck zu Beginn des Versuchs $90 \mathrm{~mm} \mathrm{Hg.} 3 \frac{1 / 2}{1 / 2}$ Min. währende Konstriktion von Aorta und Arteria pulmonalis mit vorübergehendem Wiederanstieg des Blutdrucks auf $4 \mathrm{I} \mathrm{mm} \mathrm{Hg}$ ohne Vaguspulse. (Während der Abklemmung ausnahmsweise nur I terminaler Atemzug.) Versuch der Wiederbelebung mit künstlicher Atmung und Injektion von Adrenalin ins Herz ohne Erfolg. Beginn der Herzmassage, nachdem der Druck wieder den Nullwert nahezu erreicht hat (1 3 Min. 42 Sek. nach Lösung der Kompression). Vorübergehender Anstieg der Blutdruckkurve auf jedes Ausdrücken des Herzens hin ohne nachhaltige Wirkung.

Kurve 3. Vgl. Text S. 243 f. Versuchs-Nr. 74. Kaninchen $2300 \mathrm{~g}$.

Demonstration der vorübergehenden sehr kräftigen Adrenalinwirkung und der vorhaltenden der künstlichen Atmung. 

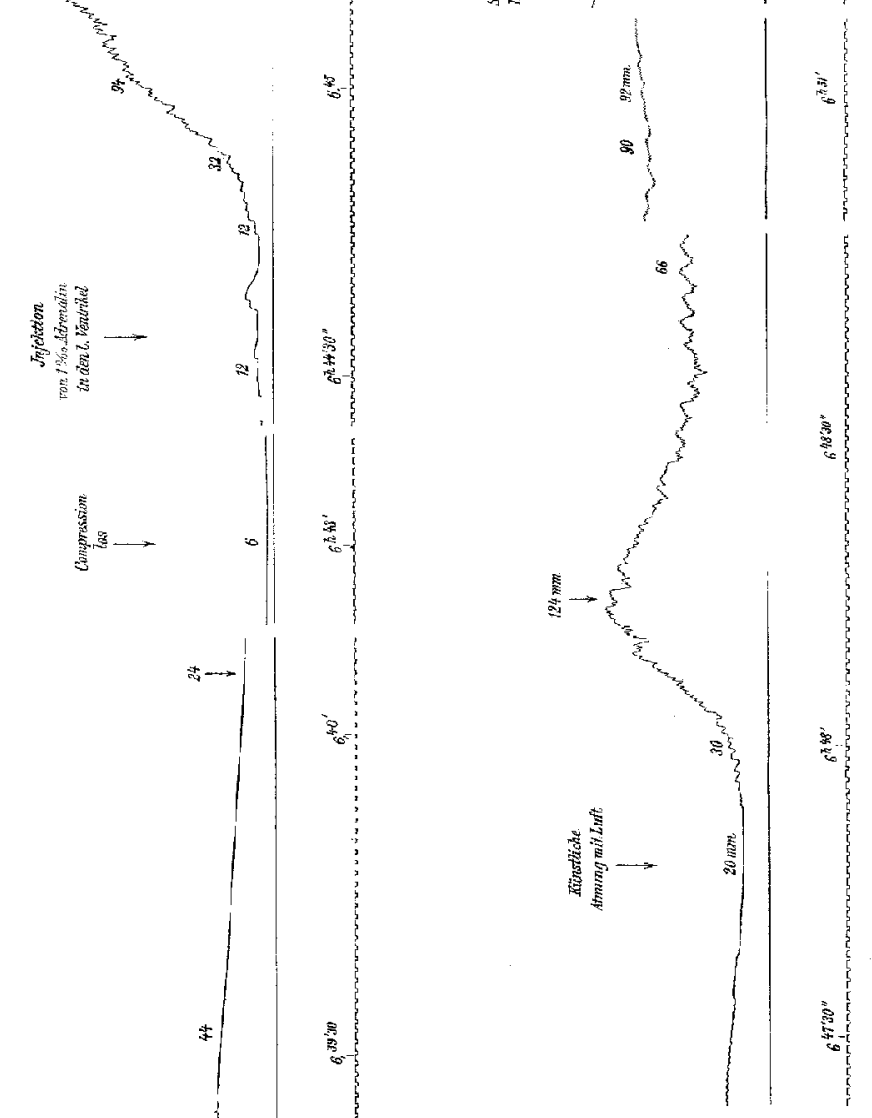

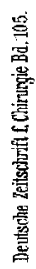

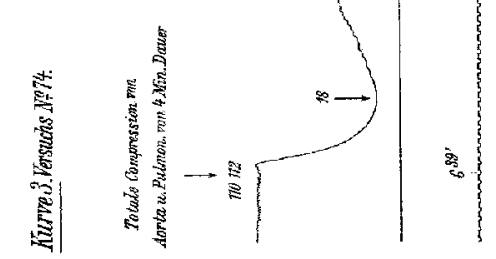


产
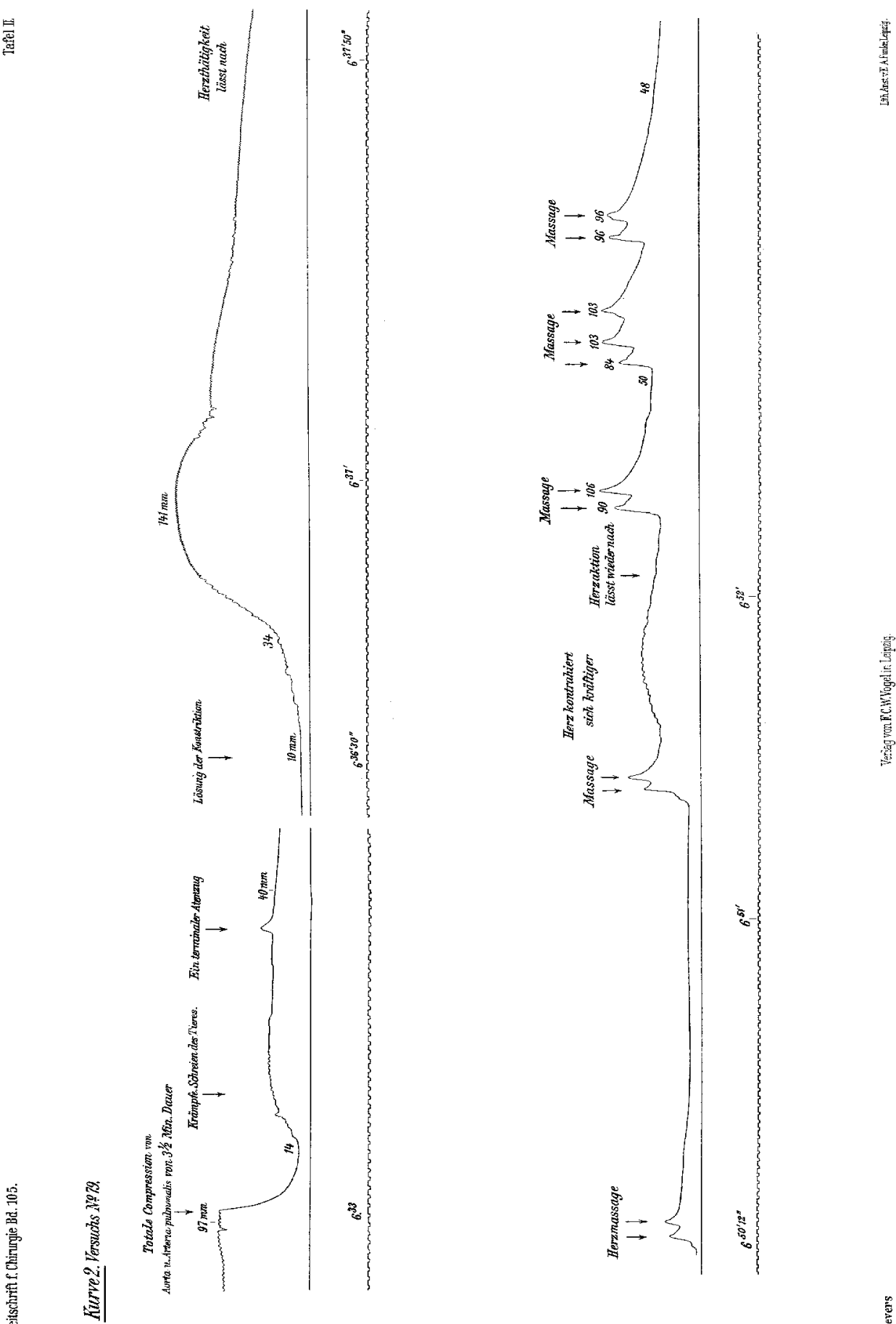

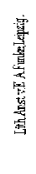

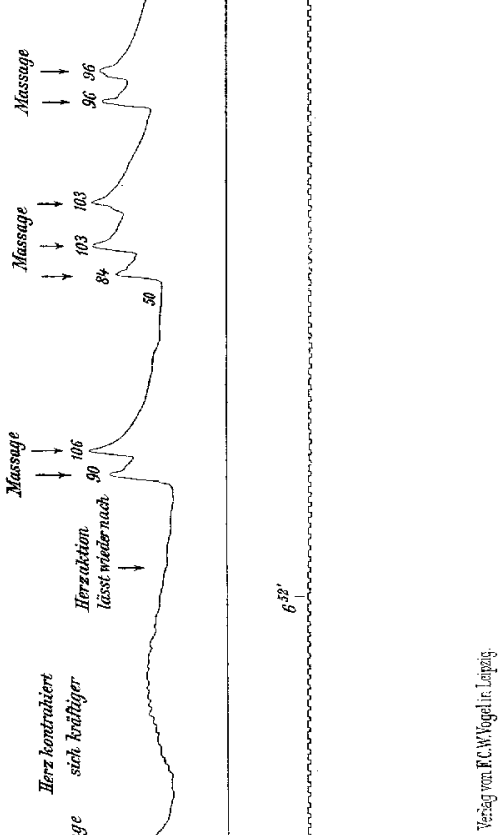

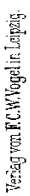

竞 
裉

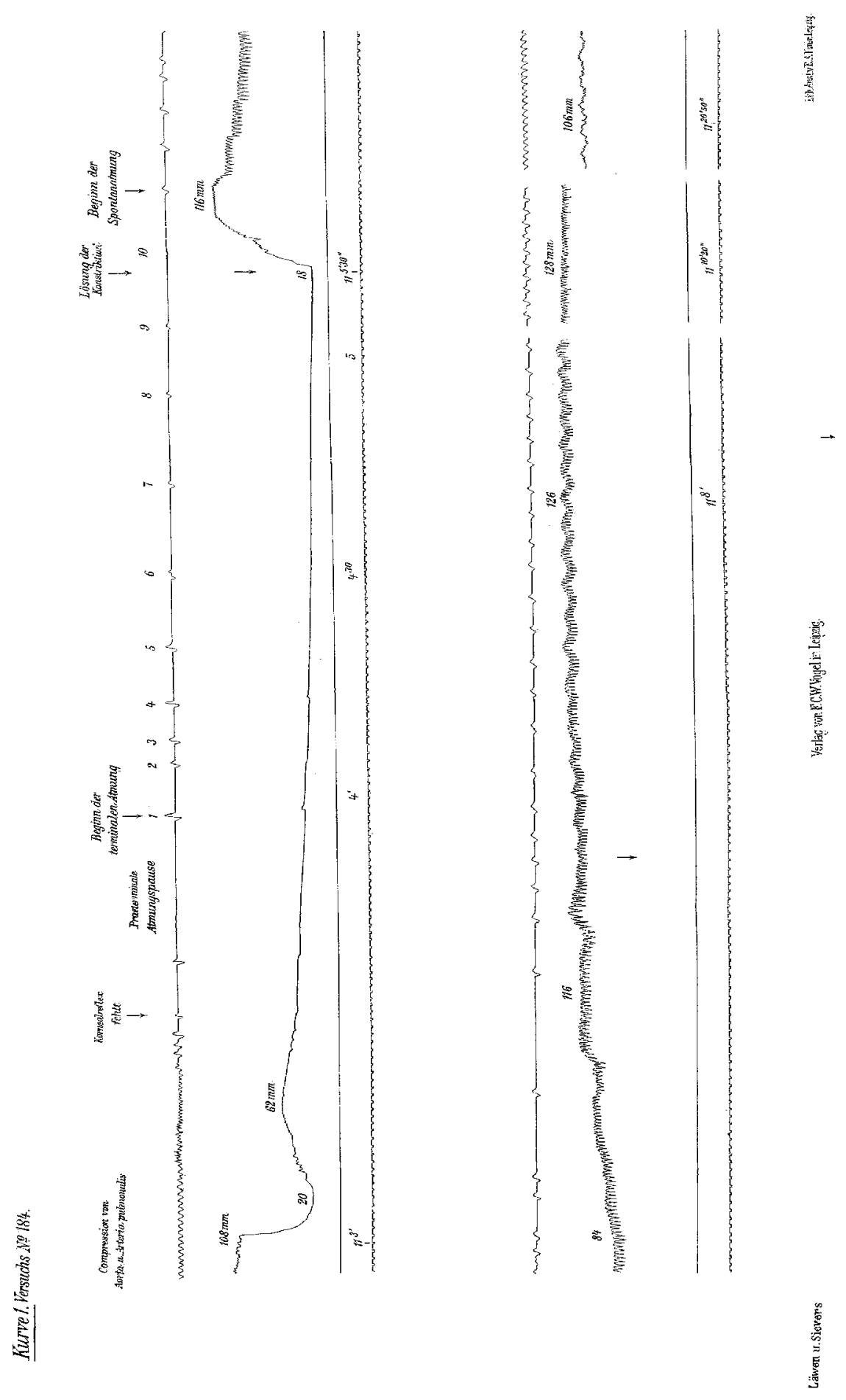

